Portland State University

PDXScholar

Winter 3-19-2019

\title{
The Impact of Infrastructure on Habitat Connectivity for Wildlife
}

Leslie Lynne Bliss-Ketchum

Portland State University

Follow this and additional works at: https://pdxscholar.library.pdx.edu/open_access_etds

Part of the Natural Resources and Conservation Commons Let us know how access to this document benefits you.

\section{Recommended Citation}

Bliss-Ketchum, Leslie Lynne, "The Impact of Infrastructure on Habitat Connectivity for Wildlife" (2019). Dissertations and Theses. Paper 4832.

https://doi.org/10.15760/etd.6708

This Dissertation is brought to you for free and open access. It has been accepted for inclusion in Dissertations and Theses by an authorized administrator of PDXScholar. Please contact us if we can make this document more accessible: pdxscholar@pdx.edu. 
The Impact of Infrastructure on Habitat Connectivity for Wildlife

by

Leslie Lynne Bliss-Ketchum

A dissertation submitted in partial fulfillment of the requirements for the degree of

Doctor of Philosophy

in

Environmental Sciences and Resources

Dissertation Committee:

Catherine E. de Rivera, Chair

Martin Lafrenz

Daniel Taylor-Rodriguez

Sarah Eppley

Portland State University

2019 


\begin{abstract}
Wildlife need connected habitats to move across the landscape to meet foraging needs, reproduce and establish new territories. Increasingly, habitat areas are lost due to conversion to alternative uses such as agriculture or urban development and being carved into pieces by roads and other transportation infrastructure. Roads are considered a major contributor to habitat fragmentation particularly as they are long, linear features prevalent throughout the landscape. The potential barriers species encounter and interact with on the landscape, such as roads or fences, could be permeable to some species and a near complete barrier to others. This creates a challenge when conservation professionals work on methods to plan for enhancing and preserving connectivity across the landscape.
\end{abstract}

While roads can present weak to complete barriers to wildlife, depending on the animal and traffic volume, mitigations such as under-crossings and green bridges on highways at least partially increase the permeability of the landscape to some of these species. The few studies evaluating the effectiveness of these structures for at least three years typically focused on a single species. Here, we monitored the crossing structure under Boeckman Road, in Wilsonville Oregon, for wildlife activity across summer seasons for ten years, since construction of the road and subsequent opening to traffic. This long-term multi-species dataset, which includes monitoring when the road was closed to traffic has provided a unique opportunity. Wildlife activity was collected using sand track pads monitored during summer seasons from 2009 to 2018. Wildlife activity showed a significant community level response from year to year and species-specific responses to 
year, vegetation change, disturbance, detection area, and previous experimental additions of artificial light. Black-tailed deer showed a significant negative association with disturbance, i.e. the presence of traffic and construction activity. Average annual detections of coyote, bullfrog, cottontail rabbit, and eastern gray squirrel demonstrate a dramatic but not significant response to the road closure period. In addition, it appears that the transition between species with preferences for lower canopy cover, and those preferring greater canopy cover, co-occurs with the road closure period, particularly in 2013. This is also the year that invasive plant management activities (mowing and spraying) stopped. Long-term studies such as this one can help researchers and managers design monitoring programs to best account for variable responses over time by documenting changes in use and working to identify covariates and interactive effects that may be driving those changes. Managers working on projects where vegetation disturbance or restoration is being conducted next to crossing structures may decide to delay monitoring until vegetation communities and/or habituation responses have had time to stabilize, avoiding erroneous conclusions about structure use.

Roads create barriers to animal movement through collisions and habitat fragmentation. Investigators have attempted to use traffic volume, the number of vehicles passing a point on a road segment, to predict effects to wildlife populations approximately linearly and along taxonomic lines; however, taxonomic groupings cannot provide sound predictions because closely related species often respond differently. We assess the role of wildlife behavioral responses to traffic volume as a tool to predict barrier effects from vehiclecaused mortality and avoidance, to provide an early warning system that recognizes 
traffic volume as a trigger for mitigation, and to better interpret roadkill data. We propose four categories of behavioral response based on the perceived danger to traffic:

Nonresponders, Pausers, Speeders, and Avoiders. Nonresponders attempt to cross highways regardless of traffic volume. Pausers stop in the face of danger so have a low probability of successful crossing when traffic volume increases. Hence, highway barrier effects are primarily due to mortality for Nonresponders and Pausers at high traffic volumes. Speeders run away from danger but are unable to do so successfully as traffic volume increases. At moderate to high volume, Speeders are repelled by traffic danger. Avoiders face lower mortality than other categories because they begin to avoid traffic at relatively low traffic volumes. Hence, avoidance causes barrier effects more than mortality for Speeders and Avoiders even at relatively moderate traffic volumes. By considering a species' risk-avoidance response to traffic, managers can make more appropriate and timely decisions to mitigate effects before populations decline or become locally extinct.

Barriers to animal movement can isolate populations, impacting their genetic diversity, susceptibility to disease, and access to resources. Barriers to movement may be caused by artificial light, but few studies have experimentally investigated the effects of artificial light on movement for a suite of terrestrial vertebrates. Therefore, we studied the effect of ecological light pollution on animal usage of a bridge under-road passage structure. On a weekly basis, sections of the structure were subjected to different light treatments including no light added, followed by a Reference period when lights were off in all the structure sections. Sand track data revealed use by 23 mammals, birds, reptiles and 
amphibians, nine of which had N30 tracks for species-level analysis. Columbia blacktailed deer (Odocoileus hemionus columbianus) traversed under unlit bridge sections much less when neighboring sections were lit compared to when none were, suggesting avoidance due to any nearby presence of artificial light. Similarly, deer mouse (Peromyscus maniculatus) and opossum (Didelphis virginiana) track paths were less frequent in the lit sections than the ambient. Crossing was correlated with temporal or spatial factors but not light for three of the other species. These findings suggest that artificial light may be reducing habitat connectivity for some species though not providing a strong barrier for others. Such information is needed to inform mitigation of habitat fragmentation in the face of expanding urbanization.

The effectiveness of a landscape for habitat connectivity is relative to individual species, particularly those of differing taxa and mobility types. Given limited resources, conservation planning efforts are restricted to a subset of representatives, or surrogate species. The goal of a surrogate species approach is to use a few species to best represent the needs of the larger community. It has been common practice in connectivity planning and mapping to utilize habitat generalists or umbrella species as surrogates. Recent research suggests that these species typically function as poor representatives and may not encompass the connectivity needs of a diversity of species. Rather, surrogate species selected based on diverse habitat needs are thought to better represent actual connectivity needs on the landscape for an array of species. We propose a process to guide the selection of species for connectivity planning and assessment purposes and provide an example application of the process. Steps include: 1) clarification and articulation of 
project goals; 2) acquisition of data to prepare for analysis; 3) hierarchical cluster analysis to group species based on habitat associations; 4) refinement of species clusters; 5) feedback from species experts and/or literature to support selections; and 6) final species selections. Several of these steps permit stakeholder participation and local expert input into the selection process, enhancing engagement in and broadening awareness of the project. This process, which uses project goals to select surrogate species in an inclusive and tractable way, can be applied to connectivity mapping across a range of geographic scales.

Through the work conducted herein we provide contributions to the understanding of how elements of the built environment impact wildlife communities ability to move across the landscape. Additionally, we provide new tools to support resource managers in barrier mitigation and connectivity planning. Habitat fragmentation effects are a complex set of issues that require resources and collaboration to reach meaningful solutions. The work presented here can also support decision-making, communication, and collaborative efforts that will ultimately result in on-the-ground impacts to reduce fragmentation effects and mitigate existing barriers effectively to promote the long-term viability of wildlife and the systems they depend on. 


\section{Acknowledgments}

A special acknowledgement to Catherine de Rivera. She is an incredible human being whose dedication to her students and all that she does is obvious to anyone who knows her. She is thoughtful and insightful and an amazing ecologist. I have so much respect for her and am so grateful to have been a part of her lab. Without her support this would not have been possible. She is a mentor, inspiration, and friend. Special thanks to my committee members, Sarah Eppley, Martin Lafrenz, and Daniel Taylor-Rodriguez for their guidance and support through the completion of this degree. I look forward to our continued work together!

I would also like to include deep and heartfelt thanks to all those in my Portland State University sphere throughout the years that have provided support in so many different ways. I've listed you in semi-chronological, but otherwise no particular order. Forgive me if I have neglected to mention you by name as I thank you all the same for being part of my journey. Amy Larson, Val Brennis, Vanessa Howard-Morgan, Robyn Draheim, and Laura Johnson, thank you all for being an amazing group of inspiring women who supported my entry to graduate school and continue to be fabulous in so many ways. Ian Davidson and Christina Davidson, thank you for always encouraging me in my graduate work and being all around sweet people. Toni Pennington for your encouragement and for teaching the class that introduced me to the science of road ecology. Tim Davidson for being hilarious and fun, a friend, and an amazing model of an awesome and dedicated scientist. Trever Sheffels for his kindness and for bringing me along in the field to assist with nutria telemetry. Brian Turner for being an excellent and kind human being and 
friend, you are like family to me! Brian Steves for being an all-around cool guy and always willing to lend his expertise. Erin Kincaid for being an awesome travel buddy, whose company I could still enjoy after an eleven-hour drive. Inez Lawson, Whitney McClees, Corrine Heath, Sydney Gonsalves, Natalie Rogers, Kerrissa Battle, Jalene Littlejohn, Amy Truitt, Carolina Olivares Varas, Sarah Zielin, Aileen Smith, for being great lab mates and supporting me through so many lab meetings and feedback sessions. Amanda Temple for being a frog tracking rockstar and jumping right in to all the connectivity assessment and modeling craziness. Crista Von Behren for being a great and supportive person who I could commiserate with about our graduate timelines. Deanna Hutchinson \& Trisha Mott for making undergraduate projects and coursework the best pirate-themed silliness. A special Yo Yo to Mr. B, aka John Borowski, for inspiring me as an angsty teen to re-engage with learning and through that pursue my love of all thing's nature. Thank you to all the students I have been fortunate to have the opportunity to teach through courses at Portland State. You remind me to stay connected to the fundamentals and inspire my excitement for learning. A special thank you to professors Alan Yeakley, Yangdong Pan, Michael Murphy, Olyssa Starry whose coursework, collaboration, or other guidance has been and continues to be so valuable to me.

Special thank you to all the student and community volunteers including Annaliese Sytsma, Sarah Henderson, Tyler Nelson, Chris Pate, Harmony VanEaton, Janel Hull, Marie Hepner, Jon David Nelson, Lily Bright, and Erica Patterson, that have assisted me in the field with work at Boeckman Road, Lava Butte, and other projects. So many fun moments, neat critters, and beautiful places we were able to experience together! 
I have been inspired and so fortunate to work with an incredible array of colleagues and professionals such as Kerry Rappold, Lori Hennings, Sandra Jacobson, Andrea Hanson, Dolores Wiesbaum, Cris Hein, David Kennedy, Audrey Hatch, Mindy Trask, Don Whittaker, Betsey Glenn, Dana Sanchez, Kendel Emmerson, Danielle Jarkowsky, Simon Wray, Cidney Bowman, Holly Michaels, Racheal Wheat, Tim Greseth, Jennifer Ringo, Arty Rodriguez, Sarah Sand, John Goodell, Johnathan Soll, Curt Zonick, Katy Weil, Quinn Read, Ted Labbe, Han Li, Bob Sallinger, Joe Liebezeit, Elaine Stewart, Roberta Swift, Shawna Bautista, to name a few. You all have been incredible project partners, collaborators, and mentors. I look forward to continuing the efforts we've started, and working on new adventures to come!

A very special thank you to my Samara Group team for supporting project work while I turned my attention to completing this degree. Jalene Littlejohn you are an incredible business wife and we make an awesome team. I am so thankful for where we are today, even with the inevitable bumps along the way, we have done and are doing amazing things. Marie Hepner you are my rock, thank you so much for all your support!

The love, support, and inspiration from my parents Patti, Terry, and Vivien brought me to the place where I could reach out and accomplish these goals, providing the structure to make it feasible. Last, but certainly not least, no one has supported me more through this journey than my husband Joe. His support, in so many different forms, has given me this opportunity to pursue my educational, research, and career goals. We have built an amazing life together, have been through so much, and remain strong through it all. I look forward to what the future brings. 
Table of Contents

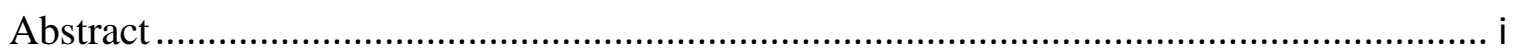

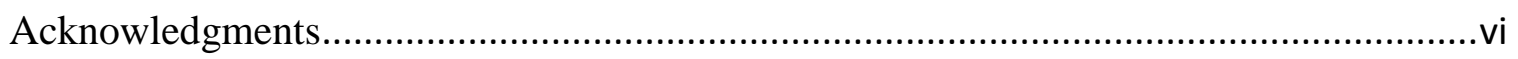

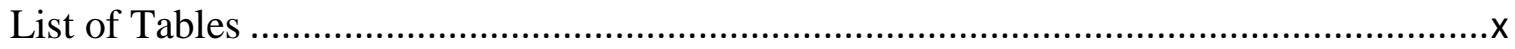

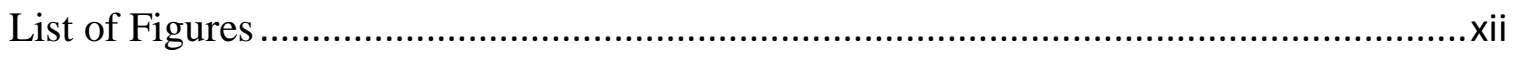

Chapter 1 - Introduction to the dissertation ............................................................ 1

Chapter 2 - The Influence of Traffic, Habitat Change, \& Time: Long Term Monitoring of

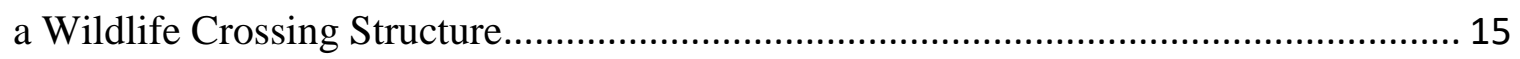

Chapter 3 - A Behavior-Based Framework for Assessing Barrier Effects to Wildlife from

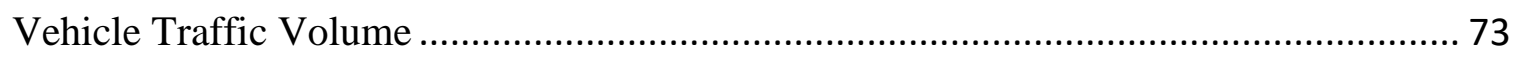

Chapter 4 - The Effect of Artificial Light on Wildlife Use of a Passage Structure ........ 113

Chapter 5 - Goals-Based Species Selection Process for Connectivity Modeling and

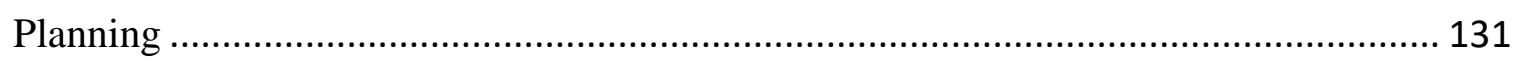

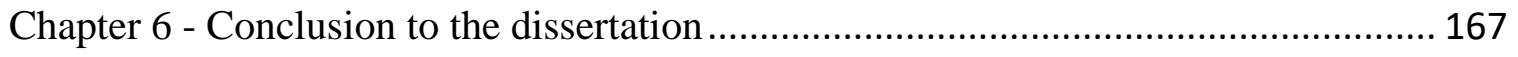

Appendix A - Species use of a passage structure before and after the addition of a dry

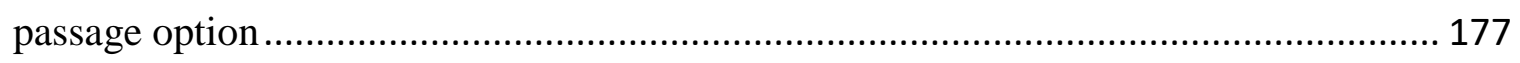

Appendix B Community response to artificial light ............................................... 178

Appendix C Drinking water inquiry curriculum................................................ 180 
List of Tables

Table 2.1 A sample of published wildlife crossing monitoring projects and the duration of

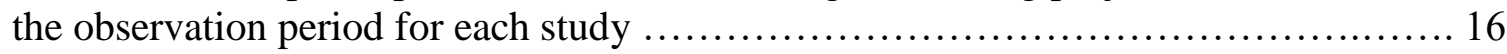

Table 2.2 Timeline of Activity: Timeline showing the initiation and conclusion (when applicable) of various activities in and around the bridged undercrossing structure of the Boeckman Road Extension Project ......................................... 23

Table 2.3: Total wildlife track detections by year: Species in red are those used in NMDS and Bayesian modeling analysis........................................... 42

Table 2.4: Average Daily Traffic at Boeckman Road by Year: Data with asterisks (*) indicate the value given is an estimation of average daily traffic values.

Table 2.5: Vegetation Cover in Mitigation Area 1 of the Boeckman Road Extension Project: Percent cover of canopy, shrubs and combined low vegetation, bare ground and/or open water of mitigation area 1 (north of the Boeckman Extension Project)..... 45

Table 3.1: Summary of population-level impacts from traffic based on species' risk response characteristics 92

Table 3.2: Interpretation of carcass evidence and priority mitigation approaches across traffic volume levels and risk response categories

Table 5.1: Example Candidate Species Scoring Worksheet: Following initial species filtering, a group of biologists, species experts, and other practitioners from the region can score candidate surrogate species with a shared worksheet, evaluating the project-

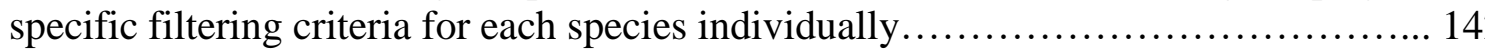

Table 5.2: Metro Connectivity Toolkit Project Final Species Selections \& Associated Habitats: Species selected as surrogates to represent the habitat connectivity needs of most species in the Metro region. American beaver, red-legged frog and southern alligator lizard require or are closely associated with multiple habitat types and are 
therefore listed under more than one habitat type. Forested habitats are more variable and in order to best represent them, each vertebrate group was represented............... 149

Table 5.3: Species Information Worksheet: This table shows questions and associated species for one habitat grouping in the coast range ecoregion, (open water, riparian, wetlands). Color coding quickly communicates the taxa grouping of the species in

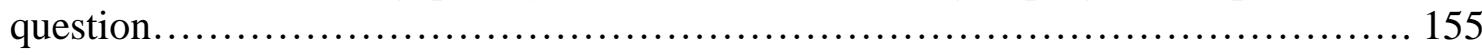




\section{List of Figures}

Figure 2.1: Boeckman Road Extension project Area Development Over Time Aerial photos showing changes over time to the immediate area of the Boeckman Road Project. 2004 photo shows pre-construction condition, with consecutive photos (2008 and 2018) showing the development of Villebois, beginning to the south and as construction continued, progressing over time to the north. Also pictured is the eventual construction of Boeckman Road, Kinsman Road, and Villebois Drive North. Mitigation areas implemented because of the construction of Boeckman road are also indicated......... 25

Figure 2.2: Boeckman Road Mitigation Areas \& Crossing Structures: 2007 and 2018 images show the mitigation activities under construction and present day. The bridge structure is viewed here looking south from mitigation area 1 in 2010 . . .

Figure 2.3: Sand Tracking of Wildlife Activity: Sand tracking pads showing evidence of wildlife activity

Figure 2.4: Two scales connecting through censoring: Illustration of how two scales connect through censoring with the variable w on the horizontal axis, representing the latent continuous scale, and the variable y on the vertical axis, representing observed responses

Figure 2.5: Boeckman Road Wildlife Monitoring Ordination Plot 2009-2018: The ordination plot of wildlife activity at the Boeckman Road wildlife undercrossing structure. Ellipses show the standard error around the centroid for each year. Colors illustrate time of the detection in relationship to the road closure period (2012-2013). Stress value $=0.2088637$ and $A N O S I M$ results of $\mathrm{R}=0.551, \mathrm{P}=0.001$

Figure 2.6: Species with increasing frequency of detection over time: Average annual frequency of detection for garter snake, red-legged frog, raccoon, salamander/newt, and the pacific jumping mouse show trends of generally increasing over time from 2009 to

2018 
Figure 2.7: Species with decreasing frequency of detection over time: Average annual frequency of detection for pacific chorus frog, deer mouse, mink, skunk, pheasant, and shrew show trends of generally decreasing over time from 2009 to 2018.

Figure 2.8: Species with the greatest frequency of detection during road closure: Average annual frequency of detection for coyote, bullfrog, eastern cottontail rabbit, and eastern gray squirrel show the greatest values during the road closure period, particularly the

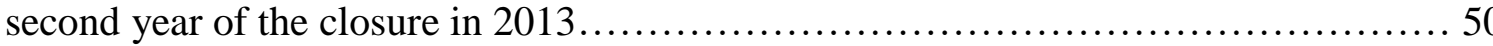

Figure 2.9: Species with no obvious trends in frequency of detection relative to time or road closure: Average annual frequency of detection for Columbia black-tailed deer, Townsend's vole, and opossum show variability in detections independent of any obvious linear trends or strong relationship with the road closure period.

Figure 2.10: Significant Beta Values: Canopy cover, disturbance from traffic and construction activities, the experimental application of artificial light, and the location within the undercrossing structure resulted in significant beta values for some species. Canopy cover $(\mathrm{C} 2=5-25 \%, \mathrm{C} 3=25-50 \%)$ was compared to $\mathrm{C} 1=$ less than $5 \%$ canopy cover. The presence of traffic and construction activities (Disturbanceyes) were compared to detections during 2012 and 2013 when the road was closed and there was also no active construction present. The experimental application of artificial light included times when all lights were off (LightBreak), one section of the bridge lights were off (LightZero), or the artificial light experiment was not active (LightNoTrt). Each of these applications were compared to when artificial light was on and actively being applied to a given bridge section (see also Bliss-Ketchum et al. 2016). Locations within the bridge crossing structure (LocationB2, LocationB3) were compared to Location B1

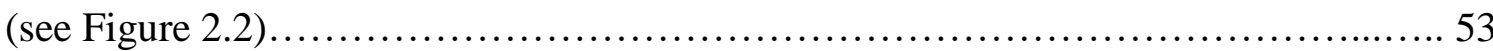

Figure 2.11: Temporal dependence between pairs of species and the residual covariance from the estimated effect of the model predictors: The matrix on the left shows how different species respond to the yearly effect, illustrating the temporal dependence between any pair of species. To the right species average response to year is shown by the residual covariance from the estimated effect of the model predictors for each of the frequently observed species in the community. Similar responses are shown in warm colors with deep red showing the strongest positive association. Opposing responses are shown in cooler colors with dark blue showing the strongest negative associations..... 55 
Figure 2.12: Sensitivity Plot of Predictor Variables: Plot illustrating the relative sensitivity of the predictor variables not captured by the year effect across all species. Results show that the location within the structure where the detection was collected is the least important (B2, B3) and canopy cover of 5-25\% (C2) being the most

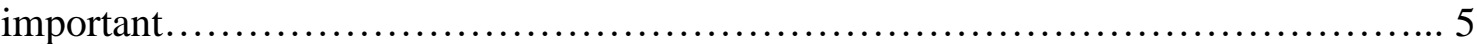

Figure 3.1: The total barrier effect (solid line) from mortality (dashed line) and avoidance (dotted line) for the four response categories. (a) Nonresponders do not recognize moving vehicles as threats or are unable to detect a moving vehicle in time to avoid mortality regardless of traffic volume. (b) Pausers respond to threats with adaptations that slow or stop them. Defenses include crypsis, armoring, or malodorous sprays. (c) Speeders recognize moving vehicles as threats and react with a rapid flight response. (d) Avoiders recognize moving vehicles as threats and respond by avoiding the road at much lower traffic volume than Speeders. The shape of the curves depends on species characteristics, such as animal speed, home range size, seasonality, and motivation to cross. These graphs do not include actual traffic volume values because the response varies across species, but it is not likely that individuals of any species will successfully cross when

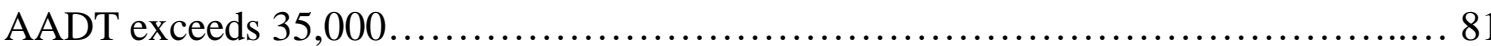

Figure 3.2: Conformity of response conceptual model. Individual species vary in how tightly they conform to a given categorical response. While behavior between these categories is not continuous, a species can exhibit multiple categories of these behaviors. California tortoiseshell butterfly, turtles, pronghorn antelope, and grizzly bears all tightly conform to one category. The eastern gray squirrel, for example, spans a wider range of responses centered in the Pauser category. The species examples given here illustrate the potential variability within a species' range of response to a given traffic volume response category. Saturation of bars approximate the span of response categories for the labeled species 88

Figure 3.3: Diverse behavioral response to traffic by closely related taxa. Species response to traffic is driven behaviorally rather than taxonomically, and closely related species can fall into different behavioral response categories. 97 
Figure 4.1: Average detections during Reference and Zero periods for the nine most common species. Error bars represent $95 \%$ confidence intervals....

Figure 4.2: The mean number of tracks detected per week for each of the three light-level treatments, High, Low and Zero, for each species with N30 tracks and no strong difference between the Reference period and the Zero treatment. Bars with the same letter are not significantly different from one another and species were not compared with each other and are shown with different letters. Error bars represent $95 \%$ confidence intervals................................................................... 121 
Chapter 1 - Introduction to the Dissertation

Wildlife need connected habitats to move across the landscape to meet foraging needs, reproduce and establish new territories. These movements can occur on a range of timescales including daily movements, seasonal or annual migrations, and multigenerational range shifts. Increasingly, habitat areas are lost due to conversion to alternative uses such as agriculture or urban development, and are carved into pieces by roads and other transportation infrastructure. As fragmentation continues, the remaining habitat patches become increasingly important for species long-term survival, isolated as additional infrastructure is built, and vulnerable to disturbance from edge effects and stochastic events. These impacts can ultimately contribute to local extirpation of species, thereby reducing the genetic diversity of populations and impacting the long-term survival of those that remain.

Urbanization is occurring at a rapid rate, with more people living in cities than ever before and the human population growing exponentially. As cities grow, more resources from outside the city are required to support concentrations of people and more land area is required to house and otherwise support them. Transportation networks are also increasingly important in facilitating the connectivity of goods and people to support growing cities. As infrastructure development and resource use increase, the impacts to wildlife movement and long-term viability of natural systems become more severe. With greater understanding of how wildlife interacts with and responds to the built 
environment it is possible to consider ways to design and mitigate these systems in a way that will reduce our impact.

The built environment, in part, describes physical structures on the landscape, such as buildings and roads. The presence of these structures can result in direct impact to the ability of species to move across the landscape. For example, strictly arboreal animals, like the western ringtail possum (Pseudocheirus occidentalis), become isolated as a result of the lack of canopy cover over roads built through forested habitats (Yokochi \& Bencini 2015). While the physical presence of a road itself creates a barrier for some species, the human activity that accompanies the road amplifies the barrier effect. The primary human activity occurring on roads is the presence of moving vehicles, which is described as traffic volume and typically measured by average annual daily traffic (AADT). The presence of traffic creates additional impacts to wildlife through direct mortality from roadkill and/or limiting movements by eliciting avoidance behavior. Roads are considered a major contributor to habitat fragmentation particularly as they are long, linear features that are prevalent on the landscape in remote and through urban and urbanizing areas. In addition to the ubiquitous presence of roads, the resulting ecological impacts can extend far beyond the physical footprint of a given road. Forman and coauthors (2003) estimated that over one-fifth of the land area of the United States is ecologically impacted by roads. The prevalence of road infrastructure makes understanding species response and interactions increasingly important. 
The potential barriers species encounter and interact with on the landscape, such as roads or fences, could be permeable to some species but a near complete barrier to others. In addition, anthropogenically managed habitats, such as agricultural environments, city parks, or managed forests also can present barriers to some and available habitat to others. This creates a challenge when conservation professionals work on methods to plan for enhancing and preserving connectivity across the landscape. We do not fully understand how species interact with potential barriers on the landscape and navigate surrounding habitats. We can use what we know about species behavior, natural history, and habitat associations to develop and test theory and to determine best fit for conservation planning objectives. Some overarching theory has been developed, such as island biogeography and then its application to habitat islands and metapopulation theory, but less theory has been developed that guides decision-making about individual species or barriers such as roads. Similarly, effective approaches are lacking that help link theory to its application on an actionable scale. The application of island biogeography theory to terrestrial systems presents a challenge as the matrix, or surrounding non-habitat area, is not consistent as it would be for an island surrounded by an ocean for terrestrial organisms. Rather, in terrestrial systems areas described as matrix include a diverse array of landscape features.

Landscape ecology theory acknowledges that spatial patterns across large geographic scales affect ecological process and vice versa. Human modified landscapes limit the ability for species to move across the landscape with largely negative impacts. 
Development of various models in the field of landscape ecology has become more inclusive of inherent complexities of the interaction between organisms and the landscape. While these models continue to improve, practitioners and land managers are challenged in efforts to put models and theory into practice and develop effective mitigation strategies.

Efforts to effectively enhance connectivity for the array of regional wildlife are inherently complex because the response to landscape fragmentation is species specific. Impacts of fragmentation are reflected at various levels of organization including individuals, populations, and communities. Avoidance of the built environment can result in fragmentation of populations of some species but not others, inhibiting movements of species and altering the community of species able to access resources and conspecifics. The evidence of community level impacts is most obvious in urban environments where alternative land uses and fragmentation are most intense. The community of species commonly detected in urban settings differs from those in less developed areas. Urban areas have effectively filtered out species that are unable to utilize the habitat structure and/or adapt to the human activity in urban environments. The mechanisms and component parts of the built environment that create a gradient of fragmentation effects across species are not well understood.

Structural differences created by infrastructure and land use change, as well as the presence and intensity of human activity contribute to fragmentation. We can make 
reasonable inference as to how structural elements might impact a given species. For example, can an individual animal physically move through a fenced backyard habitat? We can assume, based on morphology and basic knowledge of the natural history of a given species whether or not the fenced backyard creates a barrier. It is less obvious, however, how the presence of a dog or cat in said backyard changes not only the ability of an individual animal to successfully move through a backyard, but also the willingness of that individual to do so. Species have preferences and make choices about how they move through the environment. The nuance of that decision-making process, and the perception of threat in combination with physical barriers impact our ability to conserve species in the face of increased urbanization.

Yet even with incomplete knowledge we must find ways to use best available information to move conservation efforts forward and protect available spaces. Practitioners and land managers will be most effective in addressing large landscape scale connectivity issues through collaborative efforts. Clear communication is a central component of collaboration. Processes that are transparent, repeatable, and can support engagement will provide the framework for collaboration to address the complexities of connectivity planning.

\section{The Influence of Traffic, Habitat Change, \& Time: Long Term Monitoring of a Wildlife Crossing Structure: Chapter 2 addresses how animal use of monitoring} structures may change over time and the variables that influence that change. Few studies 
on road under- or over-crossing structures have monitored more than a couple of years or for multiple species use. Therefore, their conclusions about the effectiveness of structures may not extend longer term or for different species beyond the one or two species typically studied. In addition, most studies to date are on passages that are installed as retrofits to existing highways with relatively high traffic volumes. One of the main limitations of monitoring wildlife use for only one to two years is that factors known to be influential in species use of crossings are not static over time (Bissonette \& Adair 2008, Bond \& Jones 2008, Foster \& Humphrey 1995, Cain et al. 2003, Dickson et al 2005). Some of these factors may vary across the lifetime of the structure, particularly vegetation structure. When the creation of crossing structures is accompanied by vegetation changes, such as additions or alterations from mitigation, or a reduction of vegetation cover due to construction activities, the subsequent growth or regrowth of that vegetation will likely impact species use of that particular area, thereby influencing use of the crossing structure. In addition to vegetative habitat structure, the presence and intensity of traffic volume impacts species movements (Jacobson et al. 2016), but there has been little opportunity to observe how wildlife may interact with existing road infrastructure in the absence of the vehicle and pedestrian activity that co-occurs there.

We addressed these gaps by conducting 10 years of monitoring of tracks of the assemblage of animals at a new road, complete with a large under-bridge crossing as well as culverts, in an urbanizing area. This long-term dataset, the history of the road use, and surrounding habitat, have provided unique opportunities for study, including two 
monitoring periods when the road was closed to traffic. The long-term monitoring conducted at Boeckman Road provides valuable information on activity and presence for diverse species of a community of wildlife utilizing wetland and forested habitats at a road type not well represented in the crossing structure literature (arterial), where purpose-built wildlife crossing structures were installed concurrently with the initial construction of the road, and in an area with diverse and urbanizing land use.

\section{A Behavior-Based Framework for Assessing Barrier Effects to Wildlife from}

Vehicle Traffic Volume: Chapter 3 identifies how we can use animals' behavioral responses to risk to predict the barrier effect of traffic volume on roads. Investigators have attempted to use traffic volume, the number of vehicles passing a point on a road segment, to predict effects to wildlife populations approximately linearly and along taxonomic lines; however, taxonomic groupings cannot provide sound predictions because closely related species often respond differently. We expect that vehicle traffic is likely to trigger antipredator responses because of the risk of mortality from vehicles (Andrews et al. 2005). Moreover, the main predictions of the risk-disturbance hypothesis seem likely to be met with traffic and roads: risk response increases with a direct and fast approach, larger individual or group size, and distance to refuge (Frid and Dill 2002). Risk response increases with direct and rapid approach because such an approach can convey intent to kill (Stankowich and Blumstein 2005). Second, Frid and Dill (2002) predicted risk responses would increase when the approaching object was bigger or part of a larger group. When traffic volume is higher, vehicles likely appear as part of a larger 
group and increase perceived risk. Consistent with this hypothesis, Tibetan antelope (Pantholops hodgsoni) exhibit more risk-avoidance behavior during times of high traffic than low (Lian et al. 2011). The risk-disturbance hypothesis therefore incorporates ecological and evolutionary implications for animal behavior toward traffic.

We address the limitations of previous models suggesting responses are taxonomic, with the hypothesis that individuals perceive increased traffic as increased threat based on risk response (Alexander et al. 2005, Andrews et al. 2005, Lee et al. 2010, Clevenger and Huijser 2011). Furthermore, we hypothesize that species responses to traffic are reasonably predictable — individuals avoid roads, speed across roads, pause on roads, or fail to respond - based on their behavioral adaptations in response to perceived risk. We assess the role of wildlife behavioral responses to traffic volume as a tool to predict barrier effects from vehicle-caused mortality and avoidance, to provide an early warning system that recognizes traffic volume as a trigger for mitigation, and to better interpret roadkill data.

\section{The Effect of Artificial Light on Wildlife Use of a Passage Structure: Chapter 4}

describes avoidance behavior exhibited by terrestrial wildlife when experimental applications of artificial light were introduced to a wildlife crossing structure. Little is known about how artificial light impacts terrestrial wildlife. Artificial light is a common and increasingly frequent feature on the landscape, typically accompanying the presence of roads and other human activity. This research brings together two fields of study, 
impacts of artificial light and the effectiveness of wildlife crossing structures designed to mitigate the barrier effects of roads. Given the cost associated with constructing crossing structures, it is important that we ensure they are as effective as possible. Increasingly, crossing structures are proposed for use by foot or bike traffic as well as for wildlife, particularly in urban and urbanizing areas where most remaining habitat areas also accommodate human recreation. Structures built for human use typically include artificial light for safety. However, studies have yet to examine the effect of artificial light on wildlife passage use. Examining wildlife response to artificial light in the context of an under-road passage allows for efficient sampling and separates out the effect of illumination from traffic volume and many other barrier effects of roads. Hence, examining artificial light in passages informs the larger question about the role of artificial light on connectivity as well as the specifics about passage structures. This study aims to determine the effect of artificial light on wildlife use of passage structures by investigating if the presence of light influences use of a crossing structure by species in the local community of terrestrial vertebrates. We hypothesized that the presence of artificial light would decrease use of an under-road crossing structure, especially for mammals, and that higher intensity light would decrease it further.

\section{Goals-Based Species Selection Process for Connectivity Modeling and Planning: In}

Chapter 5 we propose a goals-based process for selecting surrogate species for conservation planning, particularly for modeling and mapping of connectivity zones on the landscape. Modeling and mapping connectivity are an essential first step in 
identifying locations on the landscape where conservation action and barrier mitigation can be implemented. We propose this goals-based selection perspective in order to identify surrogate species in a project-specific way by defining the criteria used for selection, such as specific habitat types and species closely tied to those habitats, then building a set of surrogates that represent diverse mobility (taxa) and an array of speciesspecific needs and functions across the area of interest. In addition, the proposed process can serve as a communication tool that enables a defensible process for selecting surrogates and end product maps used for informed decision making that has stakeholder buy in. The focus of surrogate species selection for connectivity and other conservation planning to this point has been on identifying the best surrogate type to use, such as umbrella or focal species. While umbrella species have been shown to perform unreliably as good surrogates for other species and under various type of habitat fragmentation, in some applications they have appeared to be successful. Focal species were originally described as being the individuals most severely impacted by a given threat; however, the use of "focal" species in connectivity exercises has not adhered to that definition.

With the Goals-Based Species Selection approach we can best select species to address two key issues in connectivity planning and management: habitat permeability (barriers) and habitat quality. The process includes recommendations for selecting species on a regional basis, using input from a variety of biologists, conservation planners, species experts, and potential end-users of the products. Input from diverse participants supports a more robust process scientifically as well as stakeholder engagement that can serve to 
promote and support connectivity projects and their products. In order to provide clear tracking of the process to select these species, we propose a method that uses project goals to drive species selection in a transparent and tractable way that is also able to engage stakeholders throughout the process.

This body of work aims to provide a contribution to the understanding of community and individual responses of wildlife to physical and behavioral barriers on the landscape and, by utilizing this information and providing goal-oriented processes, practitioners will be able to better apply mitigation and planning resources to address habitat fragmentation on the landscape. 
Chapter 1 - References

Alexander, S. M., N. M. Waters, and P. C. Paquet. 2005. Traffic volume and highway permeability for a mammalian community in the Canadian Rocky Mountains. Canadian Geographer/Le Géographe Canadien. Vol. 49. Pages 321-331.

Andrews, K. M., J. W. Gibbons, and T. Reeder. 2005. How do highways influence snake movement? Behavioral responses to roads and vehicles. Copeia. Vol. 2005. Pages 772-782.

Bissonette, J. A., and W. Adair. 2008. Restoring habitat permeability to roaded landscapes with isometrically-scaled wildlife crossings. Biological Conservation. Vol. 141. Pages 482-488.

Bond, A.R., Jones, D.N. 2008. Temporal trends in use of fauna-friendly underpasses and overpasses. Wildlife Research. Vol 35. Pages 103-112

Cain, A.T., Tuovila, V.R., Hewitt, D.G., Tewes, M.E. 2003. Effects of a highway and mitigation projects on bobcats in Southern Texas. Biological Conservation. Vol 114. Pages 189-197. 
Clevenger, A. P., and M. P. Huijser. 2011. Wildlife crossing structure handbook: design and evaluation in North America. FHWA-CFL/TD-11-003. US DOT, Federal Highway Administration, Lakewood, Colorado, USA.

Dickson, B. G., J. S. Jenness, and P. Beier. 2005. Influence of vegetation, topography, and roads on cougar movement in southern California. Journal of Wildlife Management

Forman, R. T., et al. 2003. Road ecology: science and solutions. Island Press, Washington, D.C., USA. 69:264-276.

Foster, M.L., Humphrey, S.R. 1995. Use of Highway Underpasses by Florida Panthers and Other Wildlife. Wildlife Society Bulletin (1973-2006), Vol. 23, No. 1 (Spring, 1995), pp. 95-100. https://www.jstor.org/stable/3783202

Frid, A., and L. M. Dill. 2002. Human-caused disturbance stimuli as a form of predation risk. Conservation Ecology 6:11.

Jacobson, S. L., L. L. Bliss-Ketchum, C. E. de Rivera, and W. P. Smith. 2016. A behavior-based framework for assessing barrier effects to wildlife from vehicle traffic volume. Ecosphere 7(4):e01345. 10.1002/ecs2.1345 
Lee, E., D. Croft, and D. Ramp. 2010. 26 Flight response as a causative factor in kangaroo-vehicle collisions. Macropods: the Biology of Kangaroos, Wallabies, and Rat-kangaroos. CSIRO, Collingwood, Australia

Lian, X., T. Zhang, Y. Cao, J. Su, and S. Thirgood. 2011. Road proximity and traffic flow perceived as potential predation risks: evidence from the Tibetan antelope in the Kekexili National Nature Reserve, China. Wildlife Research 38:141-146.

Stankowich, T., and D. T. Blumstein. 2005. Fear in animals: a meta-analysis and review of risk assessment. Proceedings of the Royal Society Biological Sciences Series B 272:2627-2634.

Yokochi, K., Chamber, B.K., Bencini, R. 2015. An artificial waterway and road restrict movements and alter home ranges of endangered arboreal marsupial. Journal of Mammalogy. Vol. 96. Issue 6. Pages 1284-1294. 
Chapter 2 - The Influence of Traffic, Habitat Change, \& Time: Long Term Monitoring of a Wildlife Crossing Structure

\section{Chapter 2 - Introduction}

While roads can present weak to complete barriers to wildlife, depending on the animal and traffic volume, mitigations such as under-crossings and green bridges on highways at least partially increase the permeability of the landscape to some of these species (Jacobson et al. 2016, Taylor \& Goldengay 2010, Colley et al. 2017, Ford et al. 2017). Of the datasets used in 28 published studies evaluating use of crossing structures, approximately $60 \%$ were collected over a 1-2-year timescale $(n=16), 35 \%$ on a $3-5$-year timescale $(\mathrm{n}=10)$ and only one with information spanning greater than 5 years (Table 2.1). Studies on the effectiveness of crossing mitigations to date have shown changes in use over time but have typically been only monitored for a relatively short term, spanning 1-2 years (but see Ford et al. 2017). In addition, they have been conducted on large highways where structures were retrofitted rather than included in the original road design. Monitoring studies show immediate use by several but not all species and large reductions in collisions between large animals and vehicles after these crossing structures have been installed (McCollister \& Van Manen 2010, Bliss-Ketchum et al. 2015, Bond \& Jones 2008). Many studies, and particularly ones with datasets spanning greater than three years, show variability in wildlife use annually, illustrating the challenge in relying on 1-2-year studies to provide a reliable indication of stable wildlife use of passage 
structures (Gagnon et al 2011, Gloyne \& Clevenger 2001, Clevenger \& Waltho 2003,

Soanes et al 2013).

Table 2.1 A sample of published wildlife crossing monitoring projects and the duration of the observation period for each study

\begin{tabular}{|c|c|c|c|}
\hline Paper Title & Citation & Years & Months \\
\hline Road Mitigation Is a Demographic Filter for Grizzly Bears & Ford et al. 2017 & 17 & \\
\hline $\begin{array}{l}\text { Camera Traps on Wildlife Crossing Structures as a Tool in } \\
\text { Gray Wolf (Canis lupus) Management - Five-Years } \\
\text { Monitoring of Wolf Abundance Trends in Croatia }\end{array}$ & Sver et al. 2016 & 5 & \\
\hline $\begin{array}{l}\text { Anthropogenic effects on activity patterns of wildlife at } \\
\text { crossing structures }\end{array}$ & $\begin{array}{l}\text { Barrueto, Ford, \& } \\
\text { Clevenger } 2014\end{array}$ & 5 & \\
\hline $\begin{array}{l}\text { Effectiveness of a highway overpass to promote landscape } \\
\text { connectivity and movement of moose and roe deer in } \\
\text { Sweden }\end{array}$ & $\begin{array}{l}\text { Olsson, Widen \& } \\
\text { Larkin } 2008\end{array}$ & 4.5 & \\
\hline $\begin{array}{l}\text { Movement re-established but not restored: Inferring the } \\
\text { effectiveness of road-crossing mitigation for a gliding } \\
\text { mammal by monitoring use }\end{array}$ & $\begin{array}{l}\text { Soanes et al. } \\
2013\end{array}$ & 4 & \\
\hline $\begin{array}{l}\text { LONG-TERM, YEAR-ROUND MONITORING OF WILDLIFE } \\
\text { CROSSING STRUCTURES AND THE IMPORTANCE OF } \\
\text { TEMPORAL AND SPATIAL VARIABILITY IN PERFORMANCE } \\
\text { STUDIES }\end{array}$ & $\begin{array}{l}\text { Clevenger \& } \\
\text { Waltho } 2003\end{array}$ & 4 & \\
\hline $\begin{array}{l}\text { Cougar Puma concolor use of wildlie crossing structures on } \\
\text { the Trans-Canada highway in Banff National Park, Alberta }\end{array}$ & $\begin{array}{l}\text { Gloyne \& } \\
\text { Clevenger } 2001\end{array}$ & 4 & \\
\hline $\begin{array}{l}\text { Factors influencing the discovery and use of wildlife passages } \\
\text { for small fauna }\end{array}$ & $\begin{array}{l}\text { Martinig \& } \\
\text { Belanger-Smith } \\
2016\end{array}$ & 3 & \\
\hline Effects of traffic on elk use of wildlife underpasses in Arizona & $\begin{array}{l}\text { Gagnon et al. } \\
2007\end{array}$ & 3 & \\
\hline $\begin{array}{l}\text { Monitoring wildlife crossing structures along highways in } \\
\text { Changbai Mountain, China }\end{array}$ & Wang et al. 2017 & 3 & \\
\hline $\begin{array}{l}\text { Mitigating Roadway Impacts to Migratory Mule Deer-A Case } \\
\text { Study with Underpasses and Continuous Fencing }\end{array}$ & $\begin{array}{l}\text { Sawyer, Lebeau \& } \\
\text { Hart } 2012\end{array}$ & 3 & \\
\hline $\begin{array}{l}\text { Seasonal and regional animal use of drainage structures to } \\
\text { cross under roadways }\end{array}$ & $\begin{array}{l}\text { Sparks \& Gates } \\
2017\end{array}$ & 2.5 & \\
\hline $\begin{array}{l}\text { Use by small and medium mammals of wildlife crossing } \\
\text { structures on two motorways in southwestern France }\end{array}$ & Fagart et al. 2016 & 2 & \\
\hline $\begin{array}{l}\text { Mitigation reduces road mortality of a threatened } \\
\text { rattlesnake }\end{array}$ & Colley et al. 2017 & 2 & \\
\hline $\begin{array}{l}\text { Mitigating Reptile Road Mortality: Fence Failures } \\
\text { Compromise Ecopassage Effectiveness }\end{array}$ & $\begin{array}{l}\text { Baxter-Gilbert et } \\
\text { al. } 2015\end{array}$ & 2 & \\
\hline
\end{tabular}




\begin{tabular}{|c|c|c|c|}
\hline $\begin{array}{l}\text { WILDLIFE ROADKILLS AND UNDERPASS USE IN NORTHERN } \\
\text { SPAIN }\end{array}$ & Puig et al. 2012 & 2 & \\
\hline $\begin{array}{l}\text { Seasonal changes in wildlife use of motorway crossing } \\
\text { structures and their implication for monitoring programmes }\end{array}$ & Mata et al. 2009 & 2 & \\
\hline $\begin{array}{l}\text { Temporal trends in use of fauna-friendly underpasses and } \\
\text { overpasses }\end{array}$ & $\begin{array}{l}\text { Bond \& Jones } \\
2008\end{array}$ & 2 & \\
\hline $\begin{array}{l}\text { Use of highway underpasses by Florida panthers and other } \\
\text { wildlife }\end{array}$ & $\begin{array}{l}\text { Foster \& } \\
\text { Humphrey } 1995\end{array}$ & 1 & 2 \\
\hline $\begin{array}{l}\text { Factors affecting the use of fauna underpasses by bandicoots } \\
\text { and bobtail lizards }\end{array}$ & $\begin{array}{l}\text { Chambers \& } \\
\text { Bencini } 2015\end{array}$ & 1 & 1 \\
\hline $\begin{array}{l}\text { Utilization of a wide underpass by mammals on an } \\
\text { expressway in the Western Carpathians, S Poland }\end{array}$ & $\begin{array}{l}\text { Myslajek et al. } \\
2016\end{array}$ & 1 & \\
\hline $\begin{array}{l}\text { Use of highway underpasses by large mammals and other } \\
\text { wildlife in Virginia - Factors influencing their effectiveness }\end{array}$ & Donaldson 2007 & 1 & \\
\hline $\begin{array}{l}\text { Towards effective culvert design: monitoring seasonal use } \\
\text { and behavior by Mediterranean mesocarnivores }\end{array}$ & $\begin{array}{l}\text { Serronha et al. } \\
2013\end{array}$ & 1 & \\
\hline $\begin{array}{l}\text { Use of highway undercrossings by wildlife in southern } \\
\text { California }\end{array}$ & Ng et al. 2004 & 1 & \\
\hline $\begin{array}{l}\text { A remarkably quick habituation and high use of a rope bridge } \\
\text { by an endangered marsupial, the western ringtail possum }\end{array}$ & $\begin{array}{l}\text { Yokochi \& Bencini } \\
2015\end{array}$ & 0 & 9 \\
\hline $\begin{array}{l}\text { USING CAMERAS TO MONITOR TUNNEL USE BY LONG-TOED } \\
\text { SALAMANDERS (AMBYSTOMA MACRODACTYLUM): AN } \\
\text { INFORMATIVE, COST-EFFICIENT TECHNIQUE }\end{array}$ & $\begin{array}{l}\text { Pagnucco et al. } \\
2011\end{array}$ & 0 & 4 \\
\hline $\begin{array}{l}\text { Complementary use by vertebrates of crossing structures } \\
\text { along a fenced Spanish motorway }\end{array}$ & Mata et al 2005 & 0 & 4 \\
\hline $\begin{array}{l}\text { General versus specific surveys: Estimating the suitability of } \\
\text { different road-crossing structures for small mammals }\end{array}$ & $\begin{array}{l}\text { D'Amico et al. } \\
2015\end{array}$ & 0 & 2 \\
\hline
\end{tabular}

Of the studies conducted for four or more years, many focus on documenting individual species (Gloyne \& Clevenger 2001, Ford et al 2017, Sver et al. 2016, Soanes et al. 2013). Gloyne and Clevenger (2001) found that cougar (Puma concolor) detections in crossing structures steadily increased over the course of the ten seasons of monitoring (summer, winter, spring, fall, etc.), with over $56 \%$ of total detections occurring during the last three monitoring seasons. A similar trend was described for grizzly bears (Ursus arctos) by Ford and coauthors (2017) who noted that use of structures generally increased over the seventeen-year monitoring period. These examples describe large and relatively longlived predators that are hypothesized to be particularly wary of traffic volume and roads 
(Jacobson et al. 2016). Increased use of crossing structures over time has also been demonstrated by smaller species. Monitoring by Soanes and coauthors (2013) on the squirrel glider (Petaurus norfolcensis), concluded that a minimum of two years was required to document use of structures, and that longer-term studies are needed. Time needed for species to habituate to crossing structures is given as the primary reason why long-term studies are needed; however, several other influencing factors can result in variable wildlife use of crossing structures.

Studies comparing species use in multiple crossings have cited several environmental and/or structural factors as possible explanatory variables predicting crossing use. More specifically, contributing factors such as vegetation cover and surrounding habitat, topography, and crossing structure characteristics have been described as influential (Bissonette \& Adair 2008, Bond \& Jones 2008, Foster \& Humphrey 1995, Cain et al. 2003, Dickson et al 2005). In addition, it is important to consider that some of these factors may vary across the lifetime of the structure, particularly vegetation changes. When the creation of crossing structures are accompanied by vegetation changes, such as additions or alterations from mitigation, or a reduction of vegetation cover due to construction activities, the subsequent growth (or regrowth) of that vegetation will likely impact species use of that particular area, thereby influencing use of the crossing structure. Because individual species react differently to changes in vegetative habitat structure, some may increase use, whereas others may decrease over time with subsequent vegetative changes. While habitat conditions and other physical 
characteristics near and around crossing structures likely play a role in species use of crossing structures, additional factors that may elicit behavioral responses, are also likely to be influential.

It is important to acknowledge that the presence of some species or individuals may also affect use by others (Little 2003); therefore, structure use may not increase for all species over time once use starts. In addition, use can be affected by fluctuation in population size (Sver et al 2016), and changes in traffic volume and human presence (Barrueto et al. 2014). Research by Olsson et al. (2008) pointed to increasing traffic volume as a reason for decreased use of crossing structures by moose (Alces alces) and roe deer (Capreolus capreolus). Traffic volume contributes at minimum, visual and auditory disturbances to wildlife and the intensity of those disturbances increases with increasing traffic volume (Gagnon 2011, DeVault et al. 2013, Shannon et al. 2016). Published studies examining structure use and traffic volume are conducted on major highways, and while these collectively have variable average annual daily traffic (AADT), they share the large-scale infrastructure (and capacity for high traffic volumes) typical of major transportation pathways. Traffic volume has been shown to impact species movements through direct mortality and/or avoidance behavior (Jacobson et al. 2016), but little is known about how wildlife may interact with road infrastructure independent of the vehicle and pedestrian activity that co-occurs there. 
The wildlife undercrossing structure at the Boeckman Road Extension project, in Wilsonville Oregon, has been monitored for wildlife activity across summer seasons for the last ten years, since construction of the road and subsequent opening to traffic in 2009. This long-term dataset, the history of the road use, and surrounding habitat, have provided unique opportunities including two monitoring periods when the road was closed to traffic. The long-term monitoring conducted at Boeckman Road provides valuable information on activity and presence for diverse species of a community of wildlife utilizing wetland and forested habitats at a road type not well represented in the crossing structure literature (arterial), where purpose-built wildlife crossing structures were installed concurrently with the initial construction of the road, and in an area with diverse and urbanizing land use.

Given that responses to vegetative habitat structure, and traffic volume vary across species and influence the community, we expect that species more closely associated with low vegetation (grassland type) and/or agricultural type habitats will be detected more frequently during early years of monitoring when those conditions were more common in the immediate area of the structure. Therefore, for the species expected to be found in the study area, we expect mink, skunk, Townsend's vole, and ring-necked pheasant will be more frequent early in the project (Johnson \& O'Neil 2001). Conversely, we expect, that species more closely associated with wetland riparian type habitat conditions and associated shrub and canopy cover, will show increased presence and activity in the crossing structure over time. Therefore, for the species expected to be 
found in the study area, we expect that red-legged frog, pacific chorus frog, garter snake, pacific jumping mouse, raccoon and eastern cottontail rabbit will be detected more frequently after the canopy has filled in more and less of the area is characterized only by grasses and a few shrubs. Coyote, Columbia black-tailed deer, and deer mouse are general in their habitat associations and so are not expected to respond strongly to vegetation changes (Johnson \& O’Neil 2001). The time when the road was closed to traffic is also expected to illicit a response in frequency of structure use, for species categorized as avoiders of traffic volume (Jacobson et al. 2016) and possibly those needing more time to habituate to structure presence. We expect coyotes and Columbia black-tailed deer to respond negatively to the presence of traffic. Hence, we predict these species will be detected more frequently during the time periods when the road was closed to traffic and may also show increased frequency of use over time. 
Chapter 2 - Methods

\section{$\underline{\text { Site Description and History }}$}

We collected evidence of animal presence and activity in wetland habitat surrounding the Boeckman Road Extension (construction completed in 2008) in Wilsonville, Oregon, USA $(45.316245,-122.783933)$. Maintaining habitat connectivity was considered a goal of this Extension project from inception, due to ecologically sensitive design objectives from the city of Wilsonville as well as the project being located in the path of an important habitat connectivity zone, joining the Willamette River and the Rock Creek Unit of the Tualatin River National Wildlife Refuge. A variety of land uses surround the research area including wetlands, conifer and oak dominated forests, farms, an industrial park, and housing. The Boeckman Road Extension project is located at the edge of the Portland Metro urban growth boundary and therefore in a dynamic location where development is active and ongoing (Table 2.2). 
Table 2.2: Timeline of Activity

Timeline showing the initiation and conclusion (when applicable) of various activities in and around the bridged undercrossing structure of the Boeckman Road Extension Project

\begin{tabular}{|c|c|c|c|c|c|c|c|c|c|c|c|c|c|c|c|}
\hline & ষ্ণ & 응 & ஜ & ○ે & 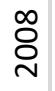 & ஜ & 웅 & $\underset{ }{\stackrel{ }{\circ}}$ & 궁 & $\stackrel{m}{\stackrel{\overbrace{}}{N}}$ & 穴 & 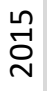 & 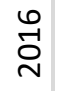 & ન્નું & 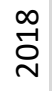 \\
\hline $\begin{array}{l}\text { Villebois } \\
\text { Construction }\end{array}$ & & & & & & & & & & & & & & & \\
\hline $\begin{array}{l}\text { Boeckman Road } \\
\text { Extension Construction } \\
\text { and Active Use }\end{array}$ & & & & & 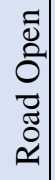 & & & & & & 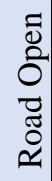 & & & & \\
\hline $\begin{array}{l}\text { Boeckman Extension } \\
\text { Mitigation: Restoration } 8 \\
\text { Invasive Species } \\
\text { Management }\end{array}$ & & & & & & & & & & & & & & & \\
\hline $\begin{array}{l}\text { Wildlife Monitoring } \\
\text { Activities }\end{array}$ & & & & & & & & & & & & & & & \\
\hline $\begin{array}{l}\text { Artificial Light } \\
\text { Experiment }\end{array}$ & & & & & & & & & & & & & & & \\
\hline $\begin{array}{l}\text { Boeckman Road } \\
\text { Temporary Closure }\end{array}$ & & & & & & & & & & & & & & & \\
\hline $\begin{array}{l}\text { Villebois Drive N } \\
\text { Construction } \\
\text { and Active Use }\end{array}$ & & & & & & & & & & & & 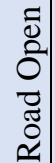 & & & \\
\hline $\begin{array}{l}\text { SW Barber Street } \\
\text { Extension Construction } \\
\text { and Active Use }\end{array}$ & & & & & & & & & & & & & 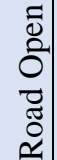 & & \\
\hline $\begin{array}{l}\text { SW Kinsman Road } \\
\text { Construction } \\
\text { and Active Use }\end{array}$ & & & & & & & & & & & & & & 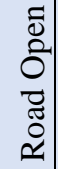 & \\
\hline
\end{tabular}




\section{Housing Development \& Connector Roads}

The Boeckman Road Extension project was initiated to support Villebois, a new mixeduse housing development that, when completed, increases the population of Wilsonville by over $30 \%$ (Figure 2.1). Construction on the housing development broke ground in 2004 and stalled significantly in 2008, likely as a consequence of a precipitous drop in housing prices. Housing construction began to boom again starting in 2014, with the housing development nearly complete as of 2019. In addition to the continued construction of suburban single and multi-family housing, three new connector roads (Villebois Drive N, an extension of SW Barber St, and SW Kinsman Road) were also built in 2014, 2015, and 2016 respectively, to join Boeckman road in a north-south direction to north and south ends of the housing development and provide greater access to the park and ride for the WES commuter rail line. At the time of the construction of the Boeckman Road Extension wetland habitat mitigation activities were also occurring. 


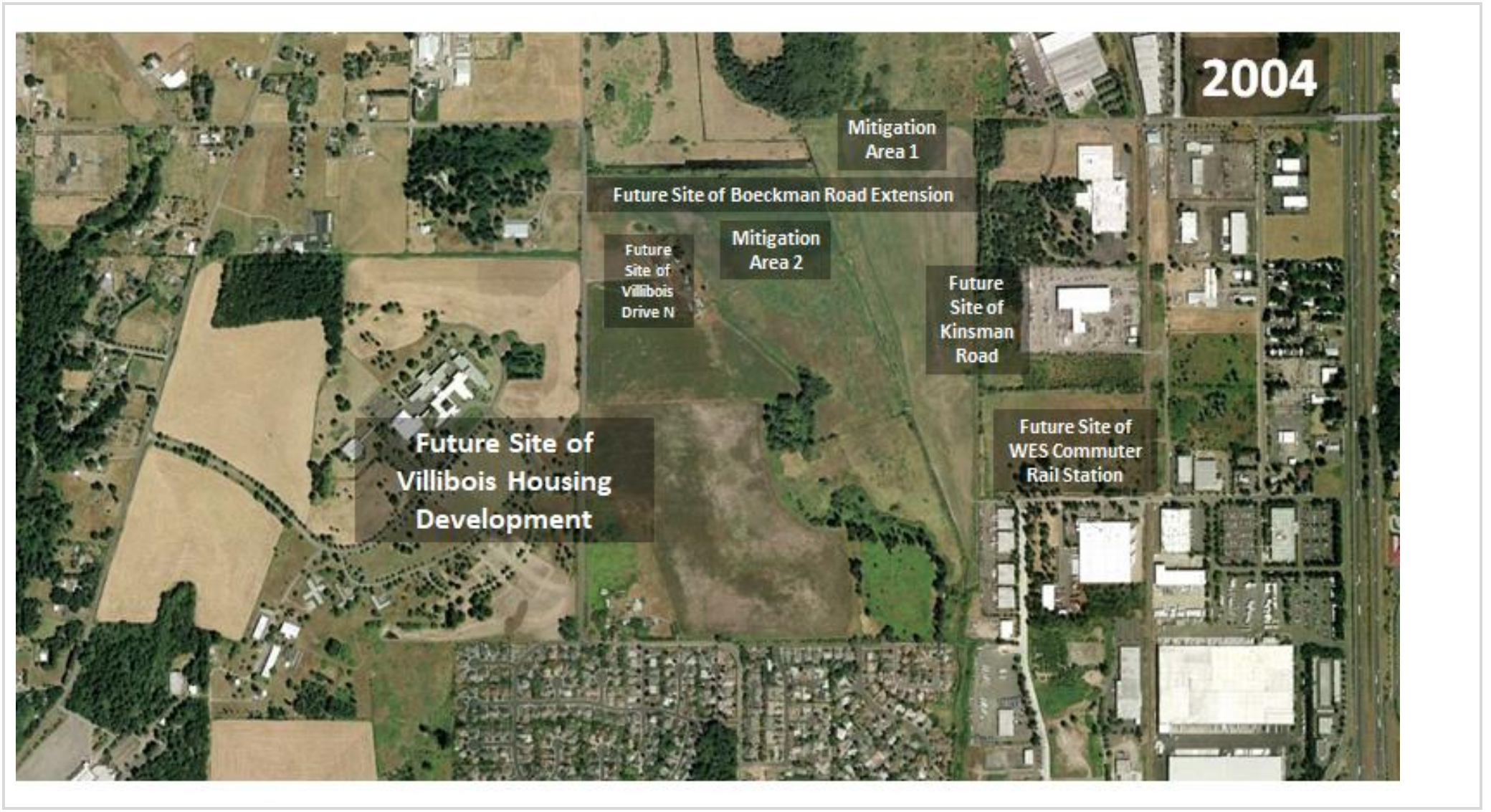

N 


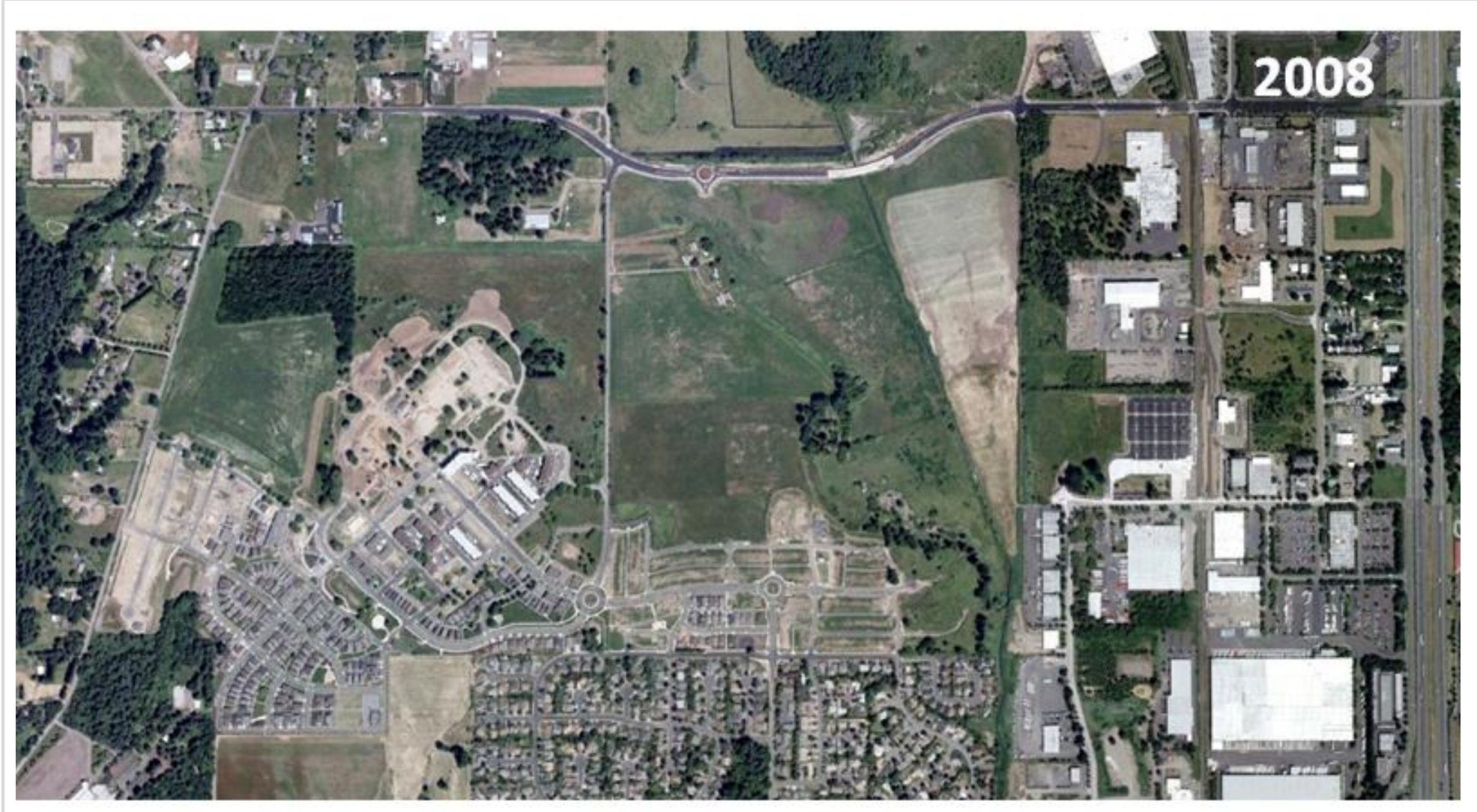

N 


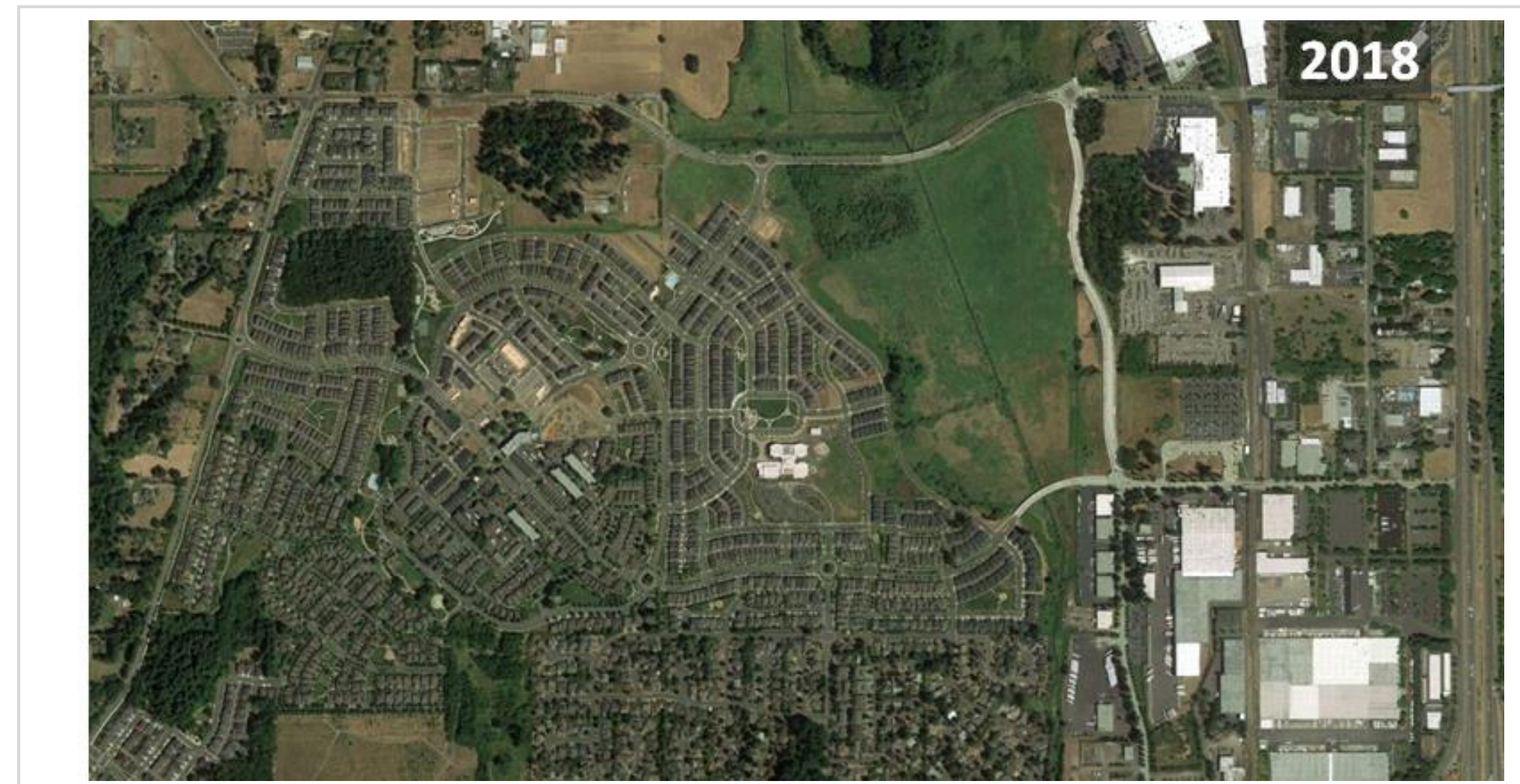

Photos from Google Earth (using historical imagery slider tool)

Figure 2.1: Boeckman Road Extension project Area Development Over Time

Aerial photos showing changes over time to the immediate area of the Boeckman Road Project. 2004 photo shows pre-construction condition, with consecutive photos (2008 and 2018) showing the development of Villebois, beginning to the south and as

construction continued, progressing over time to the north. Also pictured is the eventual construction of Boeckman Road, Kinsman Road, and Villebois Drive North. Mitigation areas implemented because of the construction of Boeckman road are also indicated. 


\section{Habitat Mitigation Activities \& Maintenance}

Mitigation activities for emergent wetlands impacted by the construction of the Boeckman Road Extension were initiated concurrently with Boeckman road construction activities. The city of Wilsonville greatly expanded on the required mitigation, converting agricultural ditches to meandering channels, adding depressional areas for seasonal flooding, removing invasive grasses, and planting a variety of native species in north eastern and south western quadrants of the project area (Figure 2.2). Mitigation activities included a five-year plan for managing invasive plants (mowing and spraying), encouraging growth of restoration plantings, and monitoring hydrology. In addition to habitat mitigation actions, Boeckman road was also constructed to include thirteen different under-crossing structures of various sizes and shapes. The largest of these structures is a bridge, ranging in height from $1.5-2.7 \mathrm{~m}(5-9 \mathrm{ft})$ tall with a $120 \mathrm{~m}(400 \mathrm{ft})$ span. 


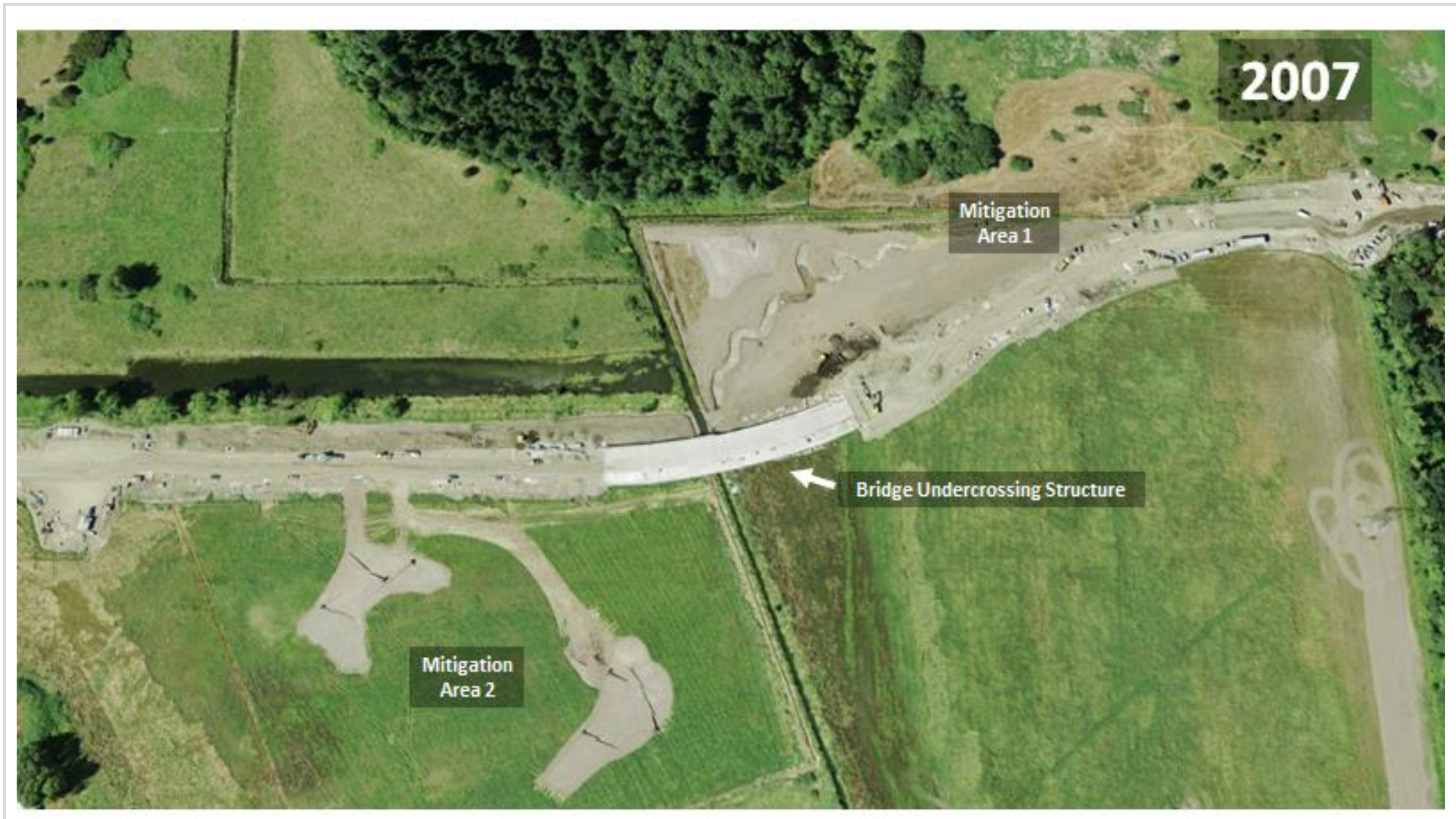

2017 \& 2018 photos from Google Earth (using historical imagery slider tool) 


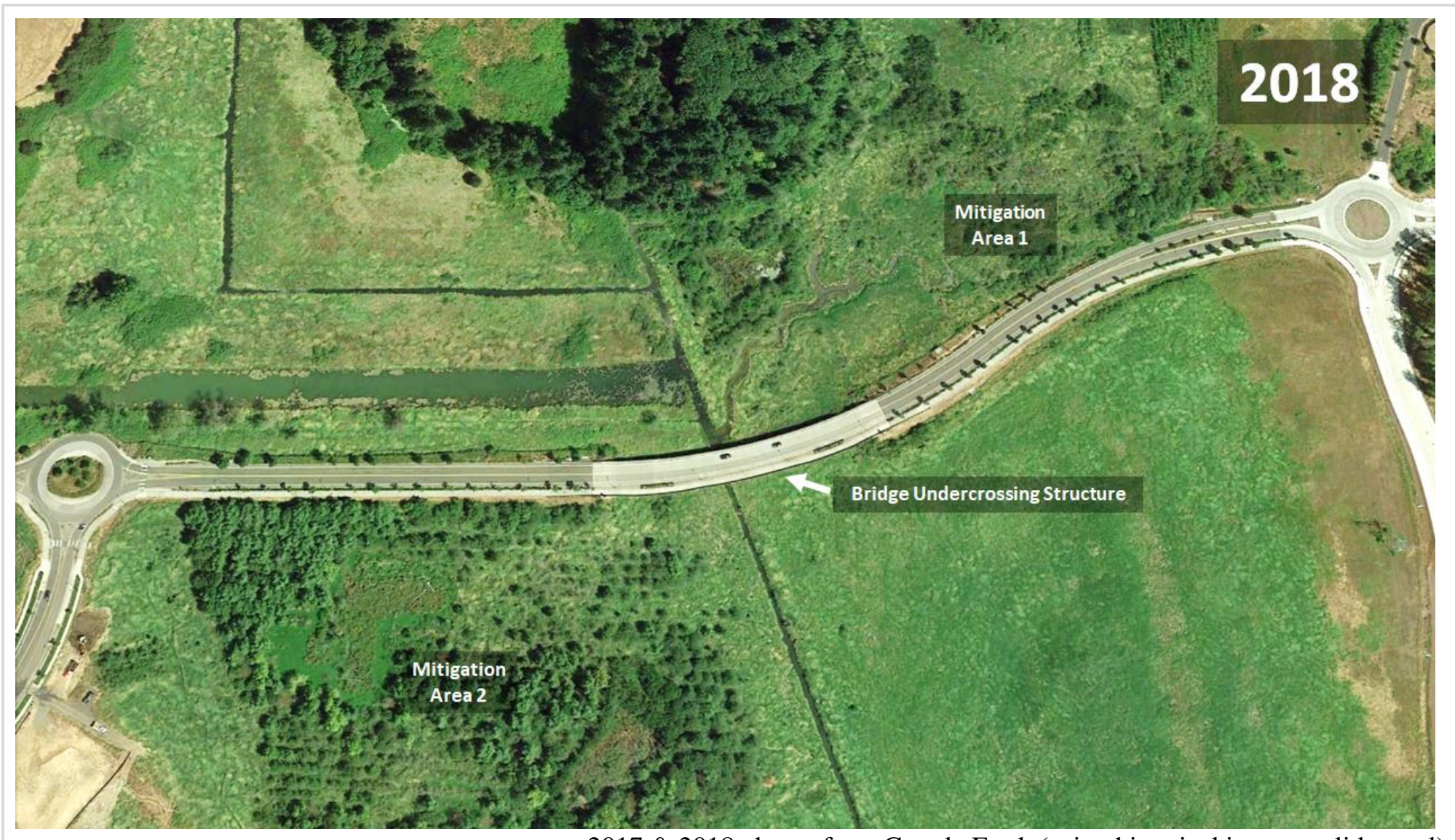

2017 \& 2018 photos from Google Earth (using historical imagery slider tool) 


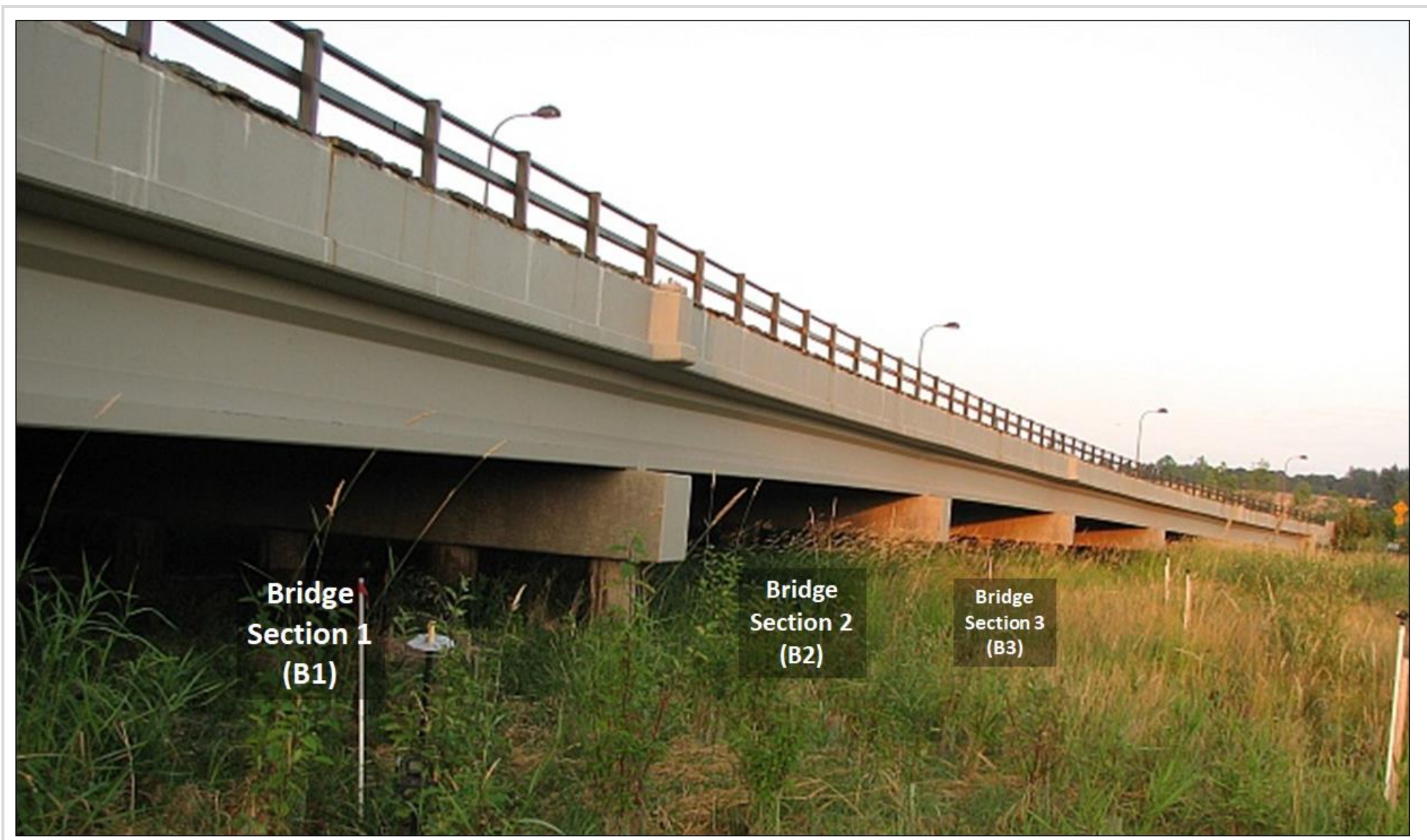

Figure 2.2: Boeckman Road Mitigation Areas \& Crossing Structures

2007 and 2018 images show the mitigation activities under construction and present day. The bridge structure is viewed here looking south from mitigation area 1 in 2010. 


\section{Boeckman Road Closure \& Repair}

Shortly after the Boeckman road extension opened in 2008, structure issues became apparent as a portion of the road fill leading up to the large bridge structure began to sink (Oregonian, 2012). In July of 2012 Boeckman Road was closed to all traffic (vehicle and pedestrian), reopening in September 2013.

\section{Artificial Light Experiment}

Boeckman road has provided an opportunity for student engagement and field monitoring experience as well as exploration and testing of the impacts of additional infrastructure and development on wildlife activity. In 2011 \& 2012 an experiment was conducted in order to test the influence of artificial light on wildlife activity in crossing structures. Three levels of artificial light (high, low, and zero) were temporarily added to different areas of the bridge structure for three weeks, followed by a full week when all light treatments were turned off (break) (Bliss-Ketchum et al 2016). This pattern of applying light was repeated throughout the monitoring seasons of 2011 and 2012.

\section{Wildlife Presence and Activity Monitoring}

Previous to the construction of the Boeckman Road Extension Project in 2004, a mammal survey of the surrounding area was conducted by experienced mammal tracker Terry Kem, in order to document sign of mammal species present (de Rivera \& Bliss-Ketchum 2010). Post construction, the presence of wildlife was recorded through sand track monitoring. Use of passage structures is commonly measured using tracking methods, 
particularly when smaller species detections are desired (Myslajek et al. 2016, D’Amico et al. 2015, Serronha et al. 2013). In addition, Mateus et al. (2011) found that using tracking methods to detect wildlife activity was more cost effective and had higher detection success than video surveillance. Tracks were identified using "Animal Tracks of Washington and Oregon" (Sheldon 1997). Additional verification of track ID was supported through the supplemental use of motion detection cameras from 2009-2011. All species detected through camera monitoring were also detected in the sand bed record during the same period. Further track identification was supported by incidence when a given species crossed sand beds while a researcher was present. An approximately $0.6 \mathrm{~m}$ wide sand tracking strip was distributed across the central span of the east end of the large bridge wildlife crossing structure (Figure 2.3). Data were collected by bridge segment, labeled B1, B2, B3. The sand track was monitored during the summer seasons each year starting in 2009 and is ongoing. Data used for analysis in this report range from 2009 to 2018. Monitoring was only conducted during summer seasons due to frequent flooding of the wetland habitat during the water year (approximately October 1st to May 31 st), resulting in reduced activity and detectability of many species. Because of interannual variability in the date that the site was first and last dry enough to reflect increased use by wildlife and effectively use sand tracks, the actual dates of monitoring vary considerably across years, starting as early as May but as late as August: and ending as early as August but as late as October. Monitoring did occur throughout the dry season in all years, however. 


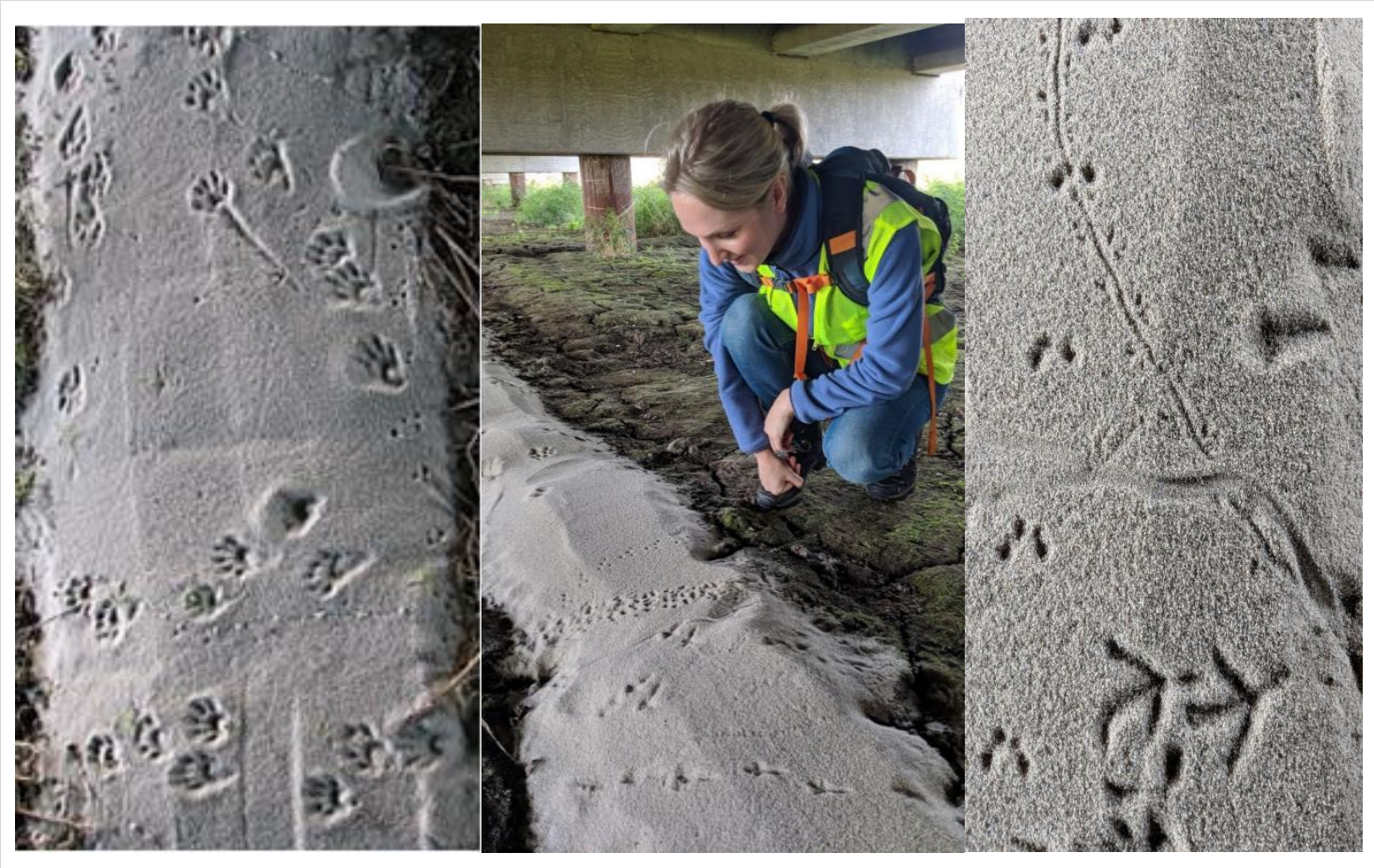

Figure 2.3: Sand Tracking of Wildlife Activity

Sand tracking pads showing evidence of wildlife activity.

Tracks of mammals, reptiles, amphibians, waterfowl and marshland birds were

documented weekly by tallying occurrences of each species then wiping the sand track beds. Track evidence of invertebrates and passerine or columbiform birds were not recorded, although present, due to the difficulty of identification to species. Motion detection cameras were used in 2009 and 2010; however, cameras did not record data not already captured by sand track beds. Cameras aided in early track identification, building confidence in the trackpad system but ultimately were removed because of the improved detection of smaller animals in particular, as well as repeated incidents of vandalism and theft of the cameras. 


\section{$\underline{\text { Additional Data Collection }}$}

Traffic volume was sampled continuously over seven consecutive days in June 2010, March 2012 and June 2016. The 2010 sampling was conducted by HDR engineering, while 2012 and 2016 was provided by the City of Wilsonville Development Engineer. Years between direct traffic measurements were estimated based on the difference between the known average daily traffic values, with the difference divided equally among the years and extrapolated out for 2017 and 2018. Vegetation change was documented through aerial photo review from 2009-2018 (source: Google Earth). Total percent cover of low vegetation, bare ground, open water, shrub, and canopy cover was estimated for the restoration area to the north of the Boeckman Road Extension. Categories of cover for a given vegetation structure were estimated within bins $(<5 \%, 5-$ $25 \%, 25-50 \%, 50-75 \%,>75 \%$ ) that are relatively easy to distinguish visually. Invasive plant management methods and timing of application was documented using annual reports created by HDR for the City of Wilsonville (HDR 2009-2013) with management actions concluding by 2013.

\section{$\underline{\text { Statistical analysis }}$}

\section{Data Exploration}

Community data were analyzed using Nonmetric Multidimensional Scaling (NMDS) ordination plots and Analysis of Similarity (ANOSIM) to explore the relationship between the community of vertebrate wildlife using the passage structure and changes 
over time including the presence of vehicle traffic. Stress was calculated and testing proceeded if values were <0.2. ANOSIM tests were run using 999 permutations.

\section{GJAM Model Building}

Given the high amount of variability, complex timelines, and potential for species interactions, a Bayesian model was required to analyze the data further, taking into account the influences of the various species in the whole community response. Utilizing this approach, we aimed to develop a model to identify the factors that define which species make use of the Boeckman Road Wildlife Crossing Structures in Wilsonville,

Oregon in the period ranging from the beginning of the Summer 2009 sampling period, through the end of Summer 2018 sampling. In the course of this period vegetation composition was transitioning, traffic was interrupted due to a road closure for repairs during two years, and an experiment testing the impact of artificial lighting was conducted (Table 2).

Because this particular problem involves multiple species co-occurring in time and space, the different species can mutually influence how their populations develop and use of the road crossing structures. Evaluating species jointly (e.g., communities of species) has been widely acknowledged by the ecological community as a necessity to correctly assess the behavior of groups of species (Clark et al. 2017). 
The effort to model how species jointly use the crossing structure is particularly challenging for several reasons. First, there are two scales of temporal dependence that need to be accounted for: (i) a year-to-year scale, which, among other things, encapsulates the temporal evolution of the landscape; and (ii) observations collected within the same year are measured in consecutive weeks spanning a few months, as a consequence, these are bound to be strongly correlated. Second, given that not all species considered in the analysis are present at all locations at all sampling instances, the vector of responses collected at a given location and time point are mostly made up of zeros (zero-overrepresentation). Third, while the observations attempt to measure the number of individuals (from each species considered) using the structure at a given time point, these measurements are prone to error due: to track blurring (e.g., as a result of flooding, or tampering by some individual animals), potential track misidentification, avoidance of the sand track-traps by some species, multiple crossings by an individual, etc.

With this in mind, from the challenges mentioned above, in this initial modeling effort, we attempt to adequately handle the two most pressing issues: the large-scale temporal dependence, and the zero-overrepresentation. To do so, we use the Bayesian Joint Species Distribution framework described in Clark et al., 2017, which has been implemented in the R package GJAM (Generalized Joint Attribute Modeling) version 2.2.4. 
The models in GJAM are tailored to deal with multivariate responses that may be of the same type (i.e., binary, counts, continuous, censored-continuous, and categorical), or may correspond to combinations of them. Regardless of the combination of response types, the artifact that enables combinations is interpreting the responses as censored versions from latent continuous variables. This entails using an underlying multivariate model for continuous data, having each response variable associate with one of the latent continuous variables. The latter is then censored to match the original scale of the data, as shown in Figure 2.4 below, where the variable $w$ on the horizontal axis, represents the latent continuous scale, and the variable $y$ on the vertical axis, represents observed responses. This Figure illustrates how the two scales connect through censoring.

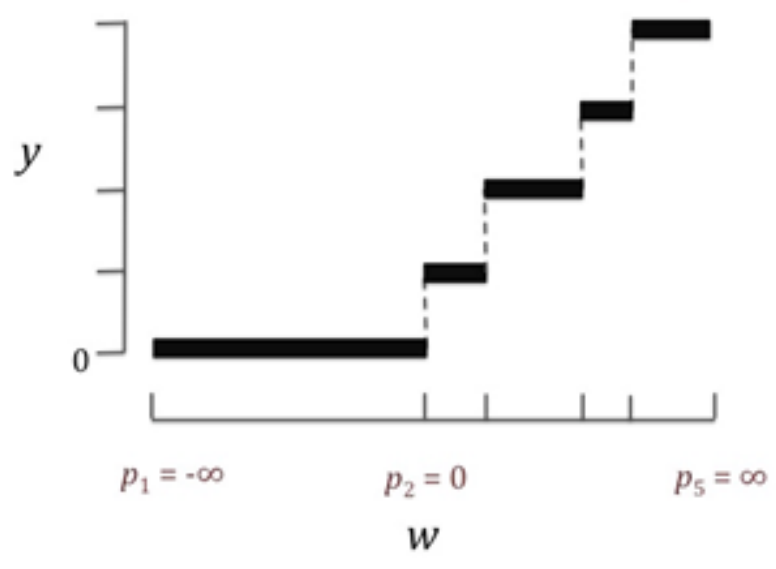

Figure 2.4: Two scales connecting through censoring Illustration of how two scales connect through censoring with the variable $w$ on the horizontal axis, representing the latent continuous scale, and the variable $y$ on the vertical axis, representing observed responses.

In our particular problem, the data consist of the number of tracks for each species observed on a particular section of the crossing structure, during a sampling instance. In 
other words, the data consist of discrete counts of the number of individuals from each species observed.

As mentioned before, the number of zeros in the entire dataset for each of the species ultimately considered ranges between $20 \%$ and $87 \%$, with a median across all species of 66\%. This being the case, even the traditionally used zero-inflated Generalized Linear Models (Poisson, Negative Binomial) would perform poorly. In contrast, GJAM deals with zero inflation letting the model determine what fraction of the distribution of the latent variable is attributed to the zero category of the observed variable. Finally, to account for the large-scale temporal component, we introduce in the mean component for the latent variables in GJAM, a random effect for the years.

While the entire dataset contains track counts for 28 different species, only 13 of these were included in the modeling, since species absent from more of $90 \%$ of the observations were removed. The remaining species, all of which had more than 80 detections, were coyote, deer, deer mouse, mink, opossum, raccoon, skunk, vole, bullfrog, tree frog, red-legged frog, newt, and snake. In addition to the yearly temporal random effect, the mean structure for the fitted model used as fixed effects:

1. Location: a three-level categorical variable that captures the section of the crossing structure to which the observation belongs. 
2. Light: a five-level (no treatment (not during the light level experiment), break between treatment rotations, zero treatment, low light treatment (units), high light (units)) categorical variable that captures the light treatment level in effect when the observation was collected.

3. Canopy: a three-level (C1: $<5 \%, \mathrm{C} 2: 5 \%-25 \%, \mathrm{C} 3:>=25 \%)$ categorical variable that describes the percentage of the area with canopy cover.

4. Disturbance: A two-level (yes, no) categorical variable that indicates if there was any disturbance (road construction, vehicular traffic) at the time when each week's data was collected. 
Chapter 2 - Results

\section{Wildlife Activity Monitoring}

The pre-construction mammal survey conducted in March of 2004 documented sign of black-tailed deer, raccoon, coyote, nutria, beaver, mink, and domestic dog in the area to the north and south of the future location of Boeckman Road. Post construction during summer season monitoring, starting May 4th 2009 and concluding September 24th 2018, 7,975 tracks were observed and recorded (Table 2.3). Twenty-eight distinct species of mammal, amphibian, reptile and bird were identified. The most frequently detected species was the deer mouse (Peromyscus maniculatus) with 2,045 tracks recorded, and the least frequently detected was the American beaver (Castor canadensis) with only 2 tracks recorded. 
Table 2.3: Total wildlife track detections by year

Species in red are those used in NMDS and Bayesian modeling analysis

\begin{tabular}{|c|c|c|c|c|c|c|c|c|c|c|c|}
\hline & 2009 & 2010 & 2011 & 2012 & 2013 & 2014 & 2015 & 2016 & 2017 & 2018 & Total \\
\hline $\begin{array}{r}\text { American Beaver } \\
\text { (Castor } \\
\text { canadensis) }\end{array}$ & 0 & 0 & 0 & 1 & 0 & 0 & 0 & 1 & 0 & 0 & 2 \\
\hline $\begin{array}{r}\text { Coyote } \\
\text { (Canis latrans) } \\
\end{array}$ & 15 & 0 & 0 & 0 & 84 & 3 & 8 & 10 & 4 & 0 & 124 \\
\hline $\begin{array}{r}\text { Columbia Black- } \\
\text { tailed Deer } \\
\text { (Odocoileus } \\
\text { hemionus } \\
\text { columbianus) } \\
\end{array}$ & 267 & 40 & 269 & 233 & 93 & 106 & 64 & 38 & 81 & 122 & 1313 \\
\hline $\begin{array}{l}\text { Deer Mouse } \\
\text { (Peromyscus } \\
\text { maniculatus) }\end{array}$ & 287 & 372 & 160 & 225 & 310 & 274 & 251 & 41 & 40 & 85 & 2045 \\
\hline $\begin{array}{r}\text { Domestic Cat } \\
\text { (Felis catus) } \\
\end{array}$ & 63 & 1 & 0 & 4 & 0 & 0 & 0 & 0 & 0 & 0 & 68 \\
\hline $\begin{array}{r}\text { Short-tailed } \\
\text { weasel } \\
\text { (Mustela erminea) }\end{array}$ & 0 & 0 & 0 & 0 & 0 & 0 & 0 & 11 & 2 & 0 & 13 \\
\hline $\begin{array}{r}\text { Mink } \\
\text { (Neovison vison) }\end{array}$ & 15 & 0 & 51 & 28 & 13 & 6 & 14 & 2 & 3 & 0 & 132 \\
\hline $\begin{array}{r}\text { Nutria } \\
\text { (Myocastor } \\
\text { coypus) }\end{array}$ & 0 & 0 & 2 & 0 & 0 & 2 & 2 & 1 & 0 & 0 & 7 \\
\hline $\begin{array}{r}\text { Opossum } \\
\text { (Didelphis } \\
\text { virginiana) }\end{array}$ & 14 & 25 & 38 & 106 & 1 & 0 & 0 & 4 & 16 & 71 & 275 \\
\hline $\begin{array}{r}\text { Pacific Jumping } \\
\text { Mouse } \\
\text { (Zapus trinotatus) }\end{array}$ & 0 & 0 & 2 & 1 & 4 & 8 & 4 & 4 & 14 & 0 & 37 \\
\hline $\begin{array}{l}\text { Porcupine } \\
\text { (Erethizon } \\
\text { dorsatum) }\end{array}$ & 0 & 0 & 0 & 0 & 3 & 0 & 0 & 0 & 0 & 0 & 3 \\
\hline $\begin{array}{r}\text { Eastern Cottontail } \\
\text { Rabbit } \\
\text { (Sylvilagus } \\
\text { floridanus) } \\
\end{array}$ & 0 & 0 & 0 & 0 & 24 & 8 & 5 & 0 & 0 & 0 & 37 \\
\hline $\begin{array}{r}\text { Raccoon } \\
\text { (Procyon lotor) }\end{array}$ & 36 & 36 & 35 & 14 & 68 & 73 & 38 & 255 & 267 & 47 & 869 \\
\hline $\begin{array}{r}\text { Norway Rat } \\
\text { (Rattus } \\
\text { norvegicus) }\end{array}$ & 0 & 0 & 1 & 2 & 0 & 0 & 0 & 0 & 0 & 0 & 3 \\
\hline $\begin{array}{r}\text { Shrew } \\
\text { (Sorex spp.) }\end{array}$ & 3 & 33 & 3 & 4 & 0 & 0 & 0 & 1 & 3 & 0 & 47 \\
\hline $\begin{array}{r}\text { Striped Skunk } \\
\text { (Mephitis } \\
\text { mephitis) }\end{array}$ & 25 & 21 & 27 & 33 & 2 & 5 & 0 & 0 & 0 & 0 & 113 \\
\hline
\end{tabular}




\begin{tabular}{|c|c|c|c|c|c|c|c|c|c|c|c|}
\hline $\begin{array}{r}\text { Squirrel (Eastern } \\
\text { Gray) } \\
\text { (Sciurus } \\
\text { carolinensis) }\end{array}$ & 0 & 0 & 5 & 6 & 7 & 0 & 0 & 0 & 0 & 0 & 18 \\
\hline $\begin{array}{r}\text { Townsend Vole } \\
\text { (Microtus } \\
\text { townsendii) }\end{array}$ & 136 & 92 & 25 & 22 & 35 & 48 & 115 & 21 & 78 & 30 & 602 \\
\hline $\begin{array}{r}\text { American } \\
\text { BullFrog } \\
\text { (Lithobates } \\
\text { catesbeianus) }\end{array}$ & 20 & 1 & 42 & 0 & 54 & 1 & 7 & 16 & 3 & 0 & 144 \\
\hline $\begin{array}{r}\text { Pacific Chorus } \\
\text { Frog } \\
\text { (Pseudacris } \\
\text { regilla) } \\
\end{array}$ & 25 & 83 & 333 & 259 & 145 & 109 & 26 & 27 & 54 & 46 & 1107 \\
\hline $\begin{array}{r}\text { Northern Red- } \\
\text { legged Frog } \\
\text { (Rana aurora) } \\
\end{array}$ & 0 & 0 & 0 & 22 & 53 & 47 & 69 & 53 & 46 & 24 & 314 \\
\hline Salamander/Newt* & 4 & 0 & 7 & 0 & 8 & 10 & 11 & 0 & 43 & 1 & 84 \\
\hline $\begin{array}{r}\text { Garter Snake } \\
\text { (Thamnophis spp) }\end{array}$ & 19 & 26 & 14 & 12 & 8 & 41 & 113 & 62 & 78 & 40 & 413 \\
\hline $\begin{array}{r}\text { Great Blue Heron } \\
\text { (Ardea herodias) }\end{array}$ & 4 & 1 & 3 & 0 & 0 & 12 & 1 & 0 & 0 & 2 & 23 \\
\hline $\begin{array}{r}\text { Mallard } \\
\text { (Anas } \\
\text { platyrhynchos) }\end{array}$ & 6 & 6 & 3 & 1 & 0 & 35 & 5 & 2 & 0 & 0 & 58 \\
\hline $\begin{array}{r}\text { Ring-necked } \\
\text { Pheasant } \\
\text { (Phasianus } \\
\text { colchicus) } \\
\end{array}$ & 15 & 32 & 8 & 2 & 0 & 0 & 0 & 0 & 0 & 0 & 57 \\
\hline $\begin{array}{r}\text { Common Snipe } \\
\text { (Gallinago } \\
\text { gallinago) }\end{array}$ & 0 & 0 & 1 & 0 & 3 & 24 & 1 & 26 & 0 & 0 & 55 \\
\hline $\begin{array}{r}\text { Virginia Rail } \\
\text { (Rallus limicola) }\end{array}$ & 0 & 0 & 2 & 4 & 0 & 0 & 3 & 3 & 0 & 0 & 12 \\
\hline Total & 954 & 769 & 1031 & 979 & 915 & 812 & 737 & 578 & 732 & 468 & 7975 \\
\hline
\end{tabular}

*Ambystoma gracile, Ambystoma macrodactylum \& Taricha granulosa are known to the area 


\section{$\underline{\text { Traffic Volume }}$}

Traffic volume increased over time with the exception of the two monitoring seasons when the road was closed for repair (Table 2.4).

Table 2.4: Average Daily Traffic at Boeckman Road Data with asterisks $(*)$ indicate the value given is an estimation of average daily traffic values.

\begin{tabular}{c|c|c}
\hline Month & Year & $\begin{array}{c}\text { Vehicles/Day } \\
\text { Average }\end{array}$ \\
\hline & 2008 & 0 \\
\hline & 2009 & $2801^{*}$ \\
\hline June & 2010 & 2952 \\
\hline March & 2011 & $3103^{*}$ \\
\hline July & 2012 & 3253 \\
\hline July & 2012 & 0 \\
\hline & 2013 & 0 \\
\hline & 2014 & $4114^{*}$ \\
\hline June & 2015 & $4976^{*}$ \\
\hline & 2016 & 5838 \\
\hline & 2017 & $6700^{*}$ \\
\hline & 2018 & $7562^{*}$ \\
\hline
\end{tabular}

\section{$\underline{\text { Vegetation cover }}$}

Canopy cover has steadily increased over time as mitigation plantings, particularly willow stakes, have matured (Table 2.5). Shrub cover peaked in 2010-2012 as mitigation plantings grew, but were not yet large enough to be considered canopy. Low vegetation, bare ground and/or open water cover has been slightly more variable as flooding frequency and level vary annually. Low vegetation cover, such as by reed canary grass, Phalaris arundinacea, was at its lowest in 2012 and 2013, at the end of the vegetation management period and has generally been increasing since. 
Table 2.5: Vegetation Cover in Mitigation Area 1 of the Boeckman Road Extension Project

Percent cover of canopy, shrubs and combined low vegetation, bare ground and/or open water of mitigation area 1 (north of the Boeckman Extension Project).

\begin{tabular}{c|c|c|c}
\hline Year & Canopy & Shrub & $\begin{array}{c}\text { Low vegetation, } \\
\text { bare ground, and/or } \\
\text { open water }\end{array}$ \\
\hline 2009 & $<5 \%$ & $5-25 \%$ & $>75 \%$ \\
\hline 2010 & $<5 \%$ & $25-50 \%$ & $50-75 \%$ \\
\hline 2011 & $5-25 \%$ & $25-50 \%$ & $50-75 \%$ \\
\hline 2012 & $5-25 \%$ & $25-50 \%$ & $25-50 \%$ \\
\hline 2013 & $5-25 \%$ & $5-25 \%$ & $25-50 \%$ \\
\hline 2014 & $25-50 \%$ & $5-25 \%$ & $50-75 \%$ \\
\hline 2015 & $25-50 \%$ & $5-25 \%$ & $25-50 \%$ \\
\hline 2016 & $25-50 \%$ & $5-25 \%$ & $50-75 \%$ \\
\hline 2017 & $25-50 \%$ & $5-25 \%$ & $50-75 \%$ \\
\hline 2018 & $25-50 \%$ & $5-25 \%$ & $50-75 \%$ \\
\hline
\end{tabular}

\section{Data Exploration}

NMDS ordination plots illustrated how the community of wildlife differed annually from 2009 detections to 2018 ones (Figure 2.5). The first three years of monitoring (20092011, cobalt ellipses "Before Road Closure") show generally reduced variability compared to other years, particularly in 2011 and 2010, and yet showed inter-annual variability. For example, 2010 was distinct from 2009 and 2011, driven by peaks in pheasant, deer mice, and shrew, and to a lesser extent, skunk, raccoon, and garter snake and an absence of bullfrogs. The years when the road was closed to traffic (2012 and 2013, red ellipses "During Road Closure") show the greatest variability, particularly along the NMDS2 axis. The remaining years (2014-2018, cyan ellipses "After Road Closure") overlap along the NMDS2 axis, but show two distinct groups along the NMDS 
1 axis, with 2014, 2015, and 2018 overlapping, and 2016 and 2017 highly overlapped.

ANOSIM analysis showed significant differences between annual wildlife detections $(\mathrm{R}=0.551, \mathrm{P}=0.001)$.

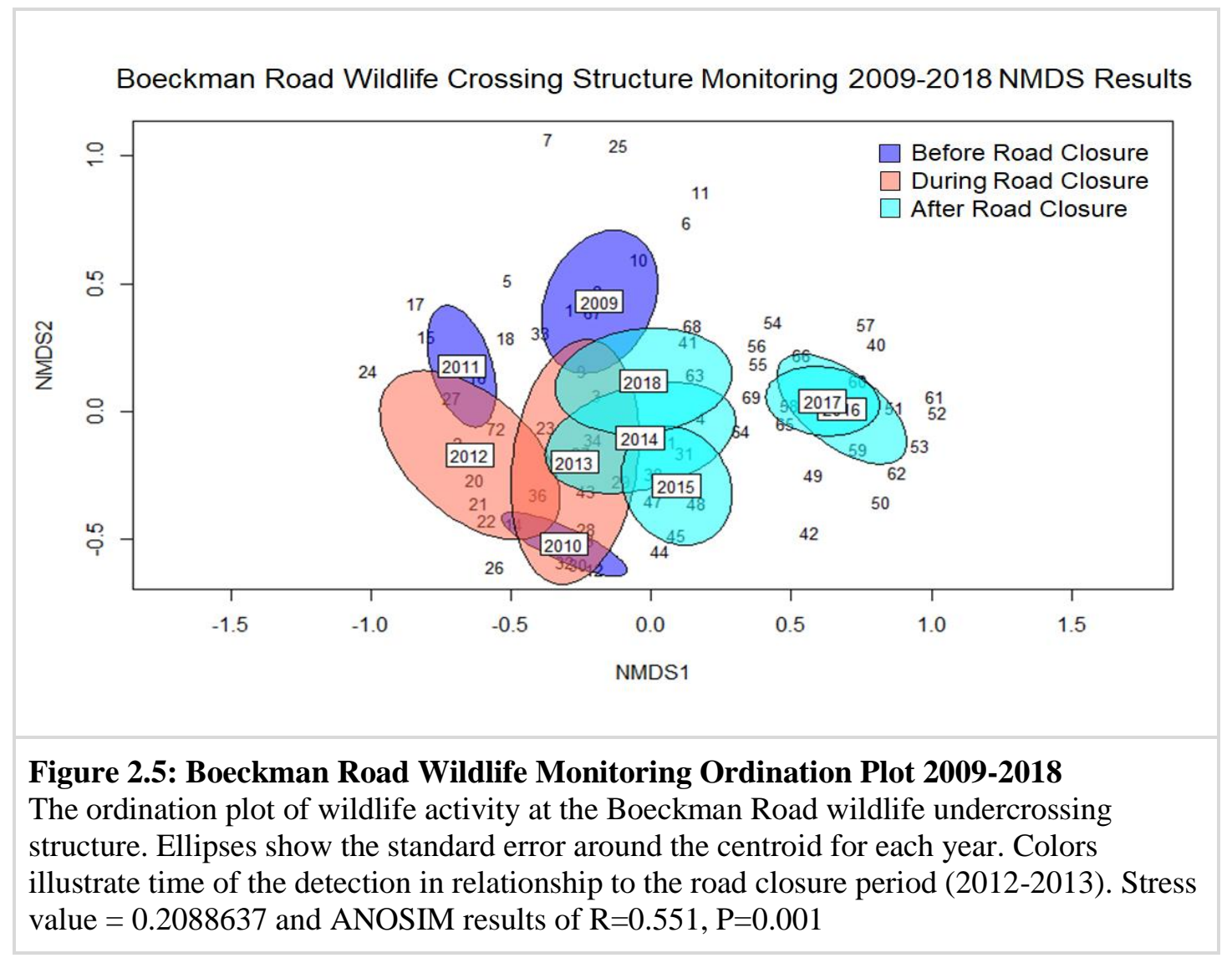

\section{Individual species response}

The average annual frequency of detections of individual species crossing under the road varied across the community. Detections of some of the species generally increased across the years, with a subset of these, Pacific jumping mouse and red-legged frog, not even detected until the third or fourth year after the road opened (Figure 2.6). Another group of species generally decreased over time, with some of these having three to six 
years without detection more recently, such as ring-necked pheasant, skunk, and shrew (Figure 2.7). Some species were most frequently detected during the road closure period, such as coyote, bullfrog, rabbit and squirrel (Figure 2.8). Coyote in particular were known to frequent the nearby area as signs of scat were frequently noted; however, detections within the crossing structure have been very low, or zero with the exception of 2013. Still other species, such as deer, vole, and opossum, showed no obvious trend related to road closure or the progression of time. Fluctuations in detection frequency for these species rose and fell across the ten-year monitoring period (Figure 2.9). Some species with too few detections to be considered in community analysis, the pacific jumping mouse, pheasant, shrew, eastern cottontail rabbit, and eastern gray squirrel, nonetheless showed interesting patterns of response in relationship to the frequency of detection over time and/or lack of traffic. 


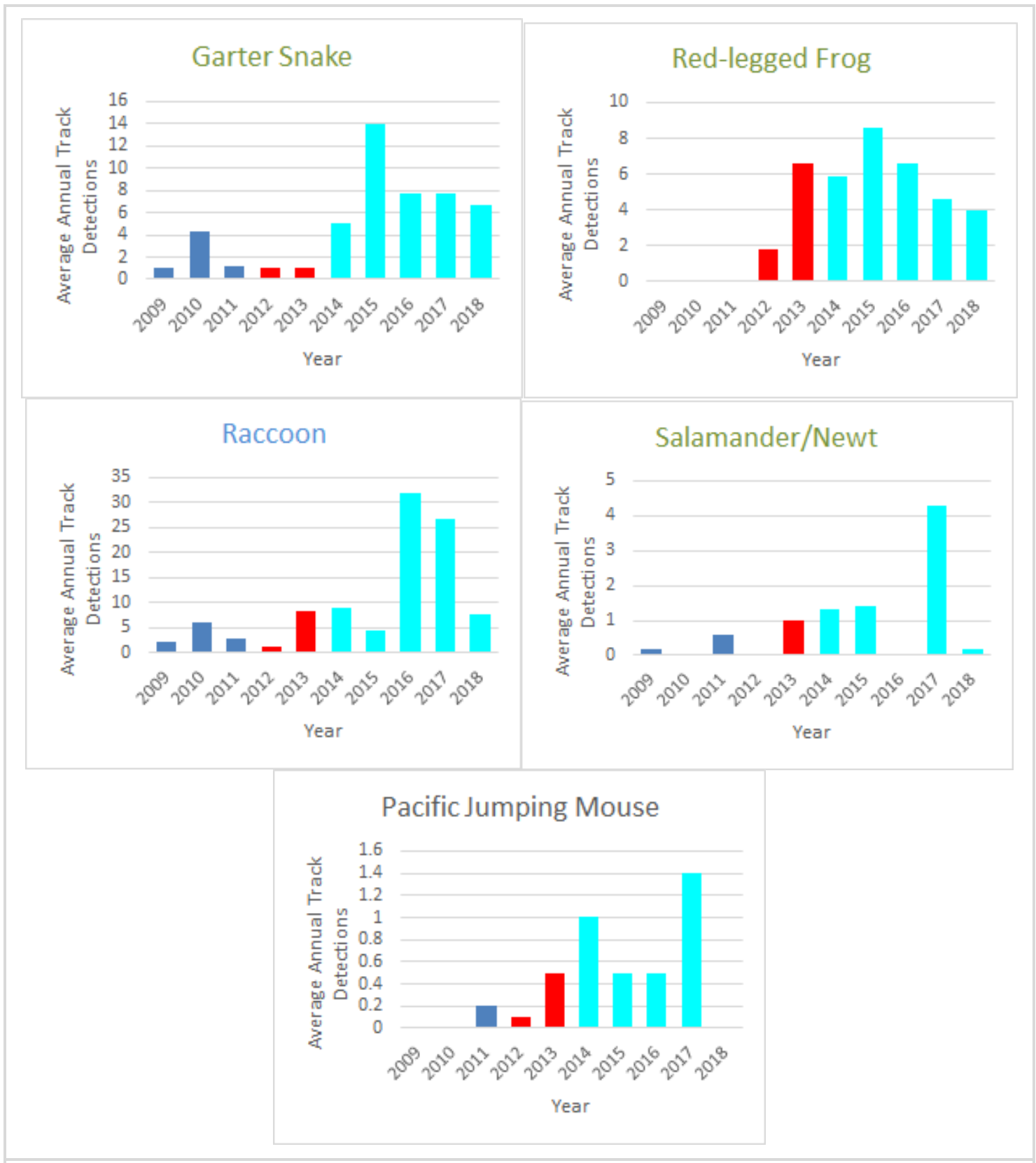

Figure 2.6: Species with increasing frequency of detection over time

Average annual frequency of detection for garter snake, red-legged frog, raccoon, salamander/newt, and the pacific jumping mouse show trends of generally increasing over time from 2009 to 2018. 


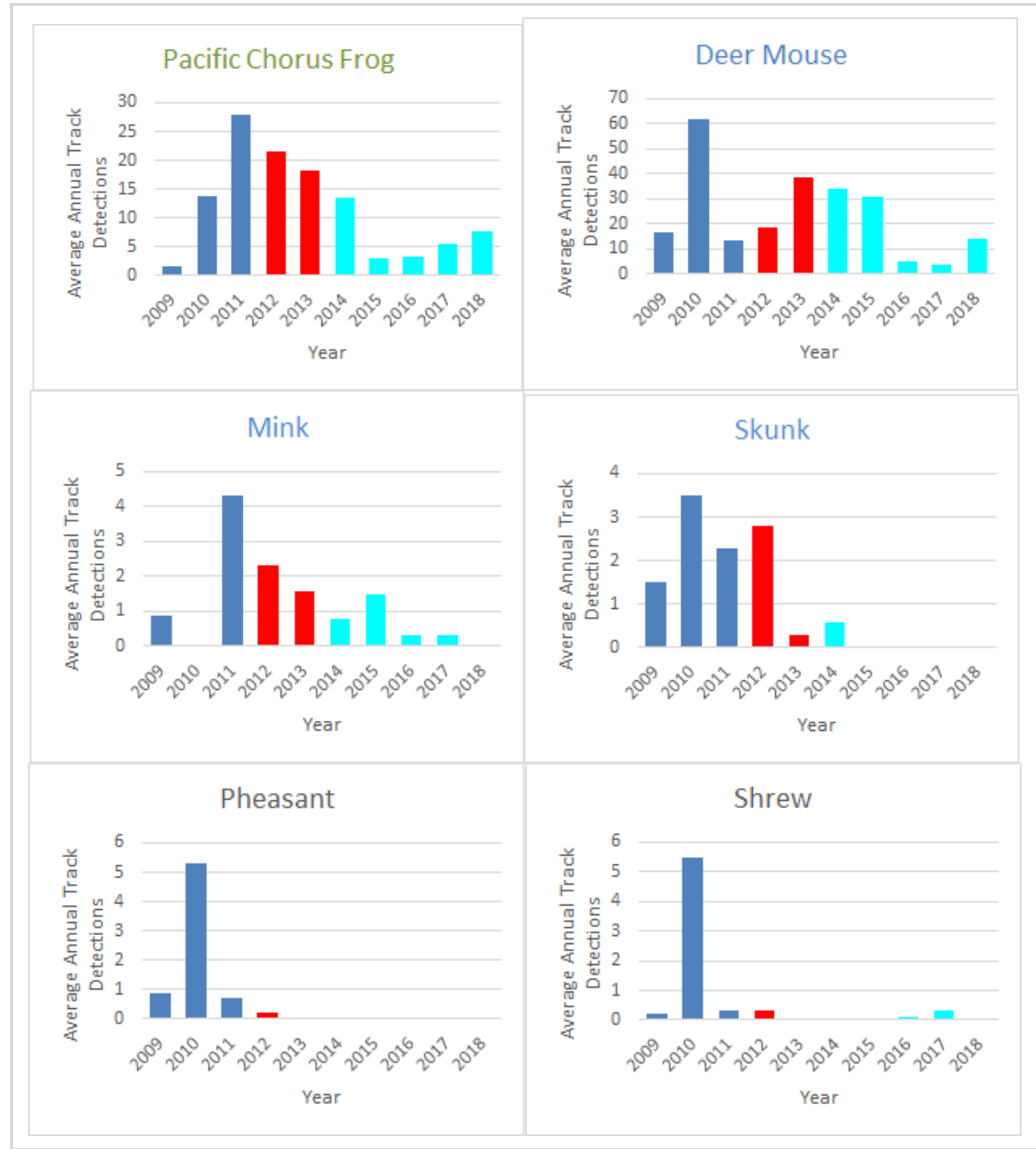

Figure 2.7: Species with decreasing frequency of detection over time Average annual frequency of detection for pacific chorus frog, deer mouse, mink, skunk, pheasant, and shrew show trends of generally decreasing over time from 2009 to 2018. 


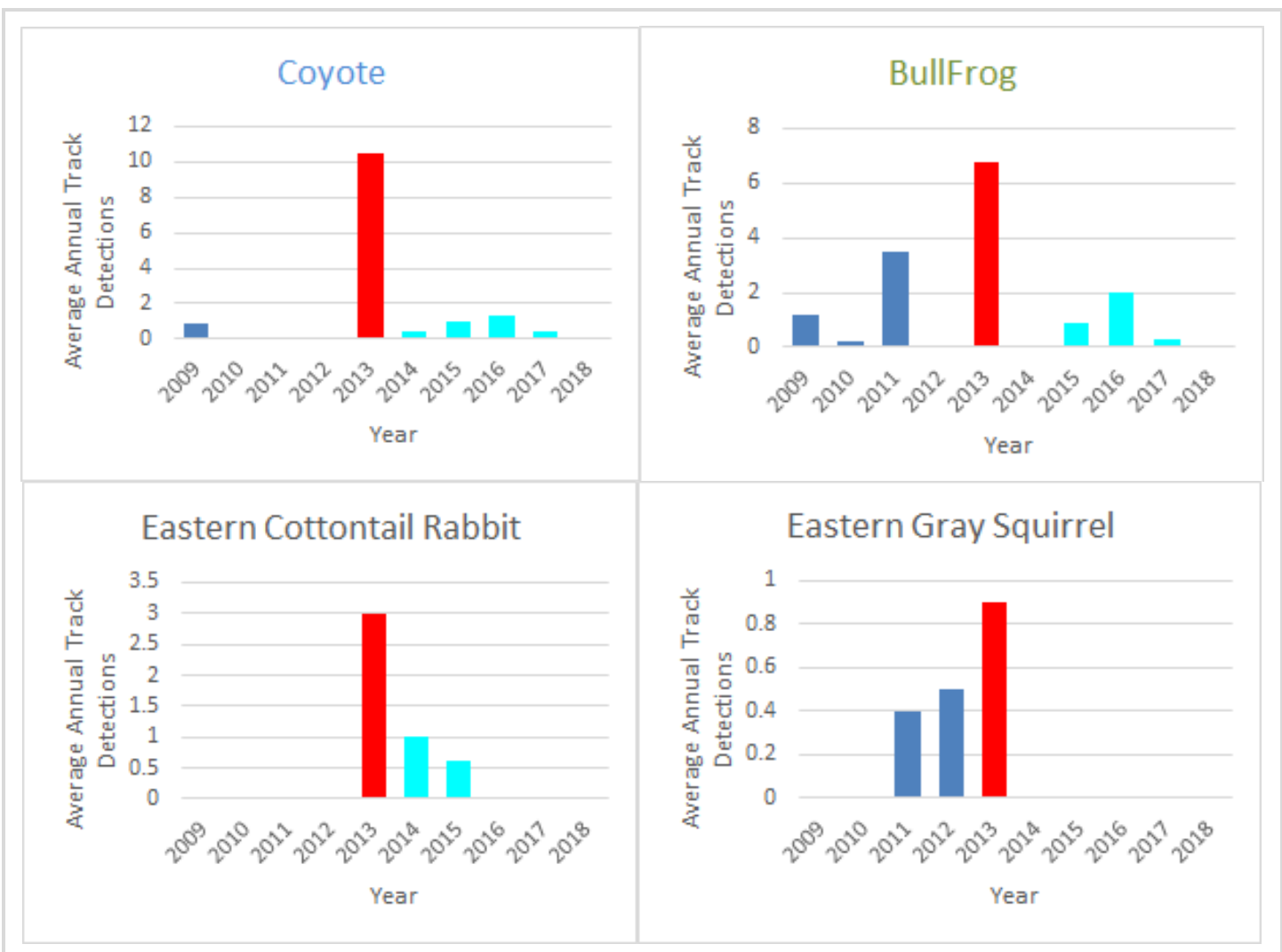

Figure 2.8: Species with the greatest frequency of detection during road closure Average annual frequency of detection for coyote, bullfrog, eastern cottontail rabbit, and eastern gray squirrel show the greatest values during the road closure period, particularly the second year of the closure in 2013. 


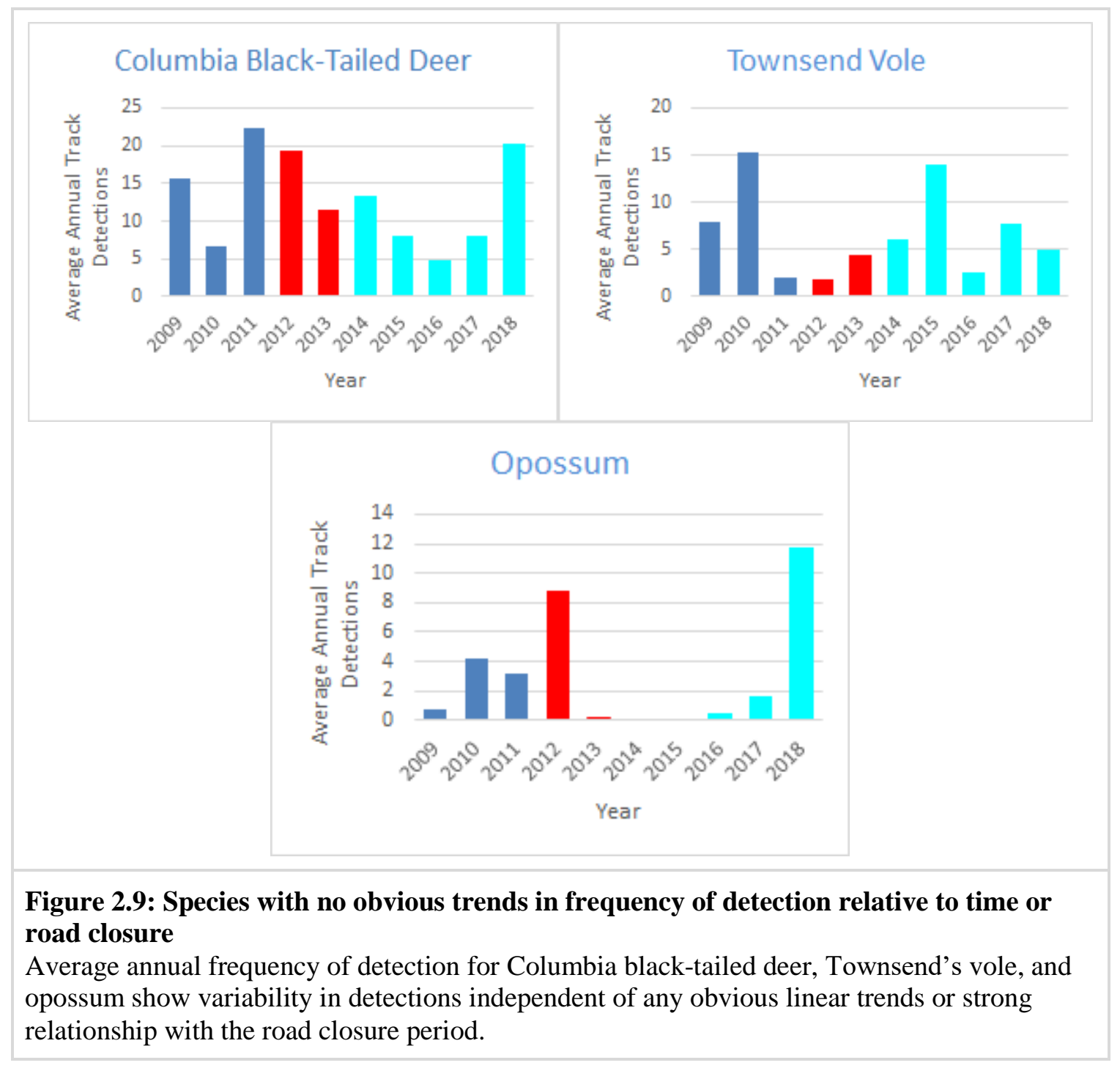

\section{GJAM Model building}

Significant beta values were found for select species in relationship to the level of canopy cover, traffic and construction disturbance, the presence of artificial light, and the location within the bridge structure where data was collected (Figure 2.10). 
Garter snake (Snake), red-legged frog (RLFrog) and raccoon were positively associated with canopy cover values of 25-50\% (CanopyC3) compared to canopy cover of less than $5 \%$. Red-legged frog and mink were positively associated with canopy cover values of 5$25 \%$ (CanopyC2) compared to canopy cover of less than 5\%. Skunk were negatively associated with canopy cover of 25-50\% (CanopyC3) compared to canopy cover of less than $5 \%$.

Columbia black-tailed deer (Deer) were negatively associated with the combined presence of traffic and construction activities compared to times when neither traffic or construction were present.

Mink, deer mouse, and the Columbia black-tailed deer were all positively associated with times during the artificial light experiment when all lights were off, while only deer mice were positively associated with times when light in only one section of the bridge was off. Deer mice and coyotes were also positively associated with times when the light level experiment was not active (all years except $2011 \& 2012$ ).

Townsend vole and Pacific chorus frog were negatively associated with both location B2 and $\mathrm{B} 3$ relative to $\mathrm{B}$; Columbia black-tailed deer was negatively associated with B2 relative to $\mathrm{B} 1$, and the garter snake was negatively associated with $\mathrm{B} 3$ relative to $\mathrm{B} 1$. 


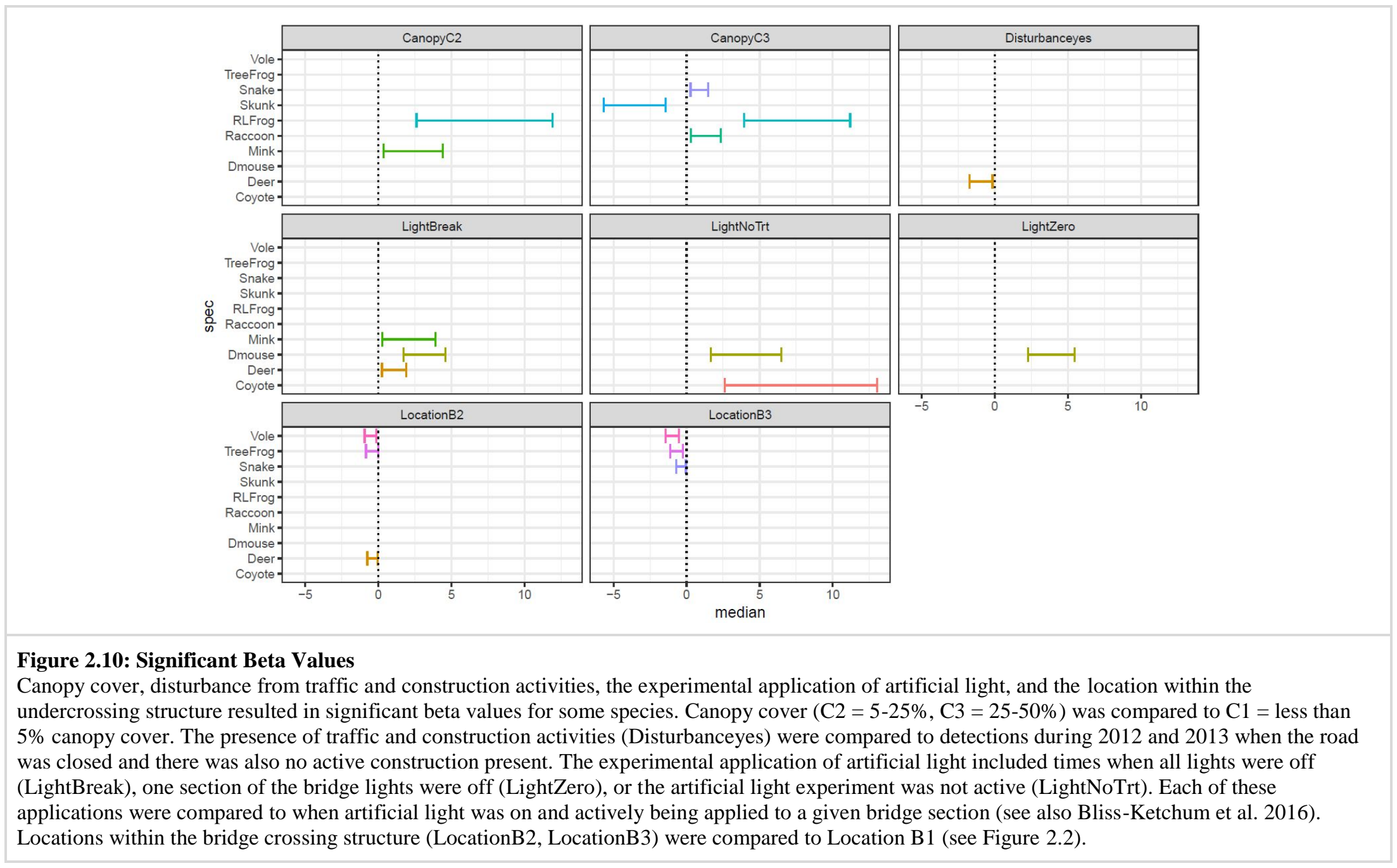


The mean random effects for 2013 were weak across all species. Interestingly, the year random effects for particular sets of species were similar across all years after accounting for predictors. For example, after accounting for predictors, newt, bullfrog, and coyote had similar posterior mean estimates for the yearly random effects overall years. Similarly, garter snakes, tree frogs, deer mice, and red-legged frogs were similarly affected by the yearly random effect but were affected quite differently from deer (Figure 2.11). The relative importance of the predictor variables over all species can be assessed with the Sensitivity (Figure 2.12), which shows that the location within the structure where the detection was collected is the least important (B2, B3) and canopy cover of 5$25 \%(\mathrm{C} 2)$ is the most important. 


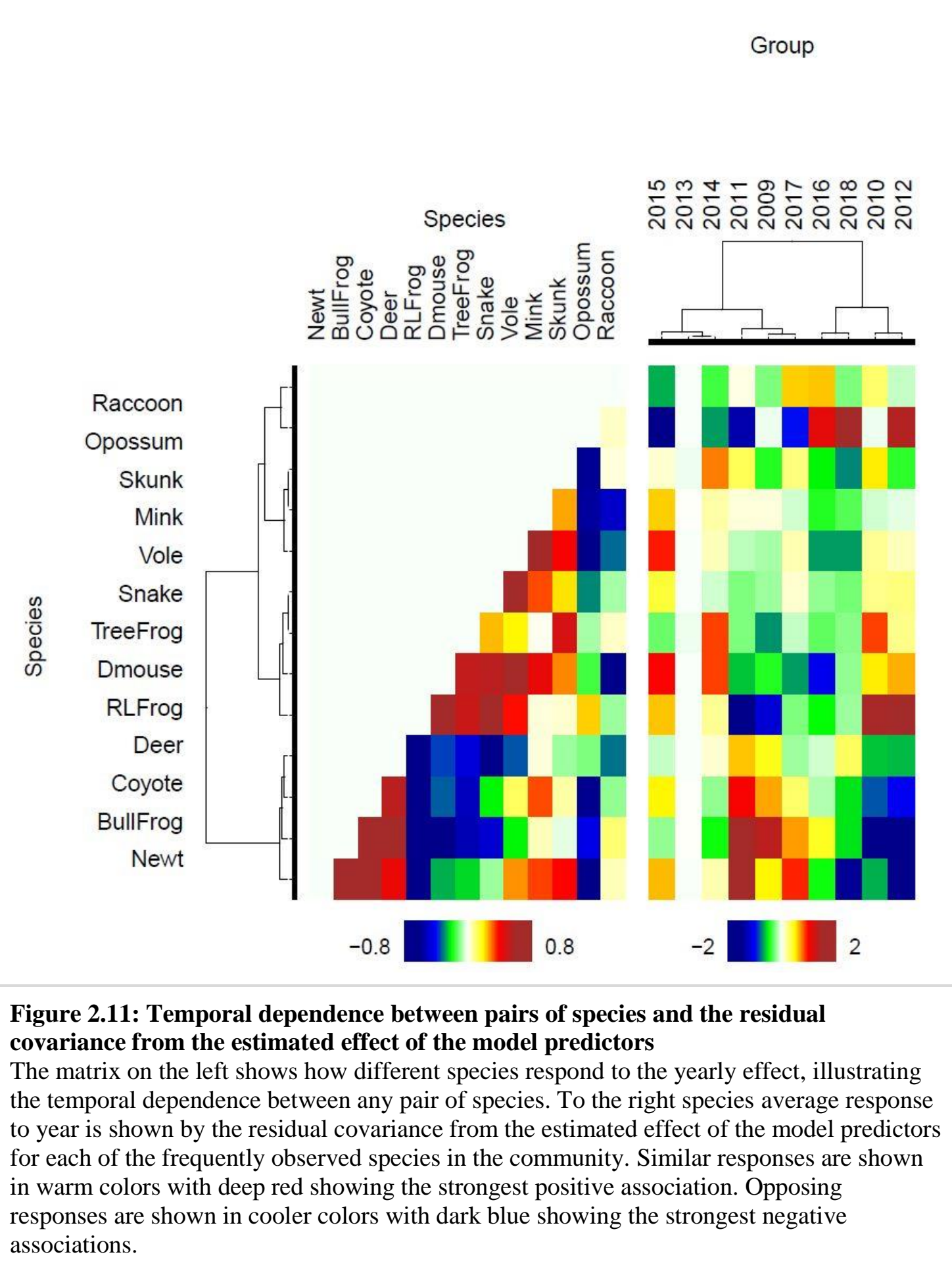




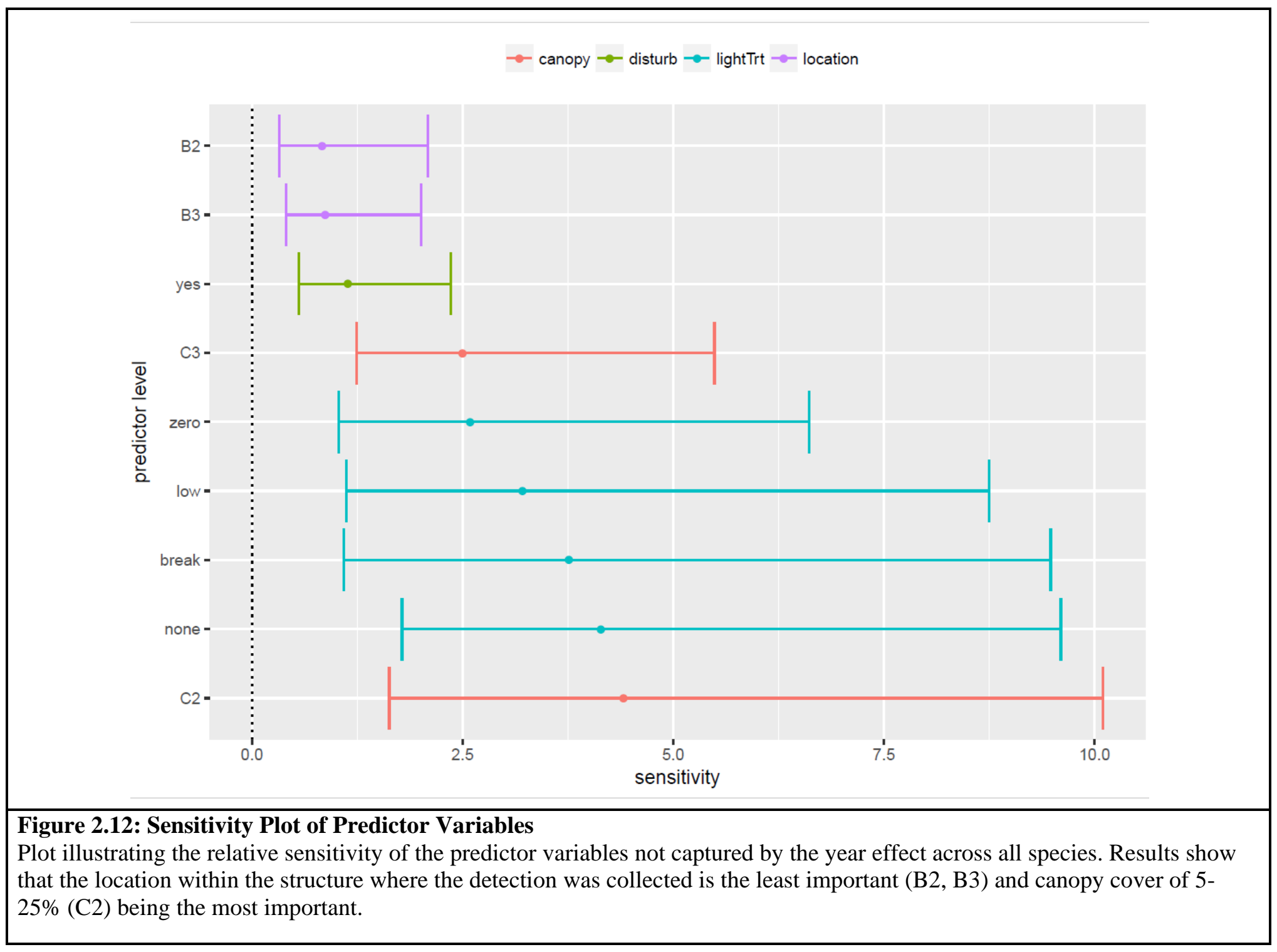




\section{Chapter 2 - Discussion}

Wildlife activity at the Boeckman Road undercrossing structure showed a significant community level response from year to year (Figure 5) and species-specific responses to vegetation, disturbance, detection area, and previous experimental additions of artificial light (Figure 10). Average annual detections for individual species varied, with some appearing to group by trends in the peaks in frequency of detection over time (Figures 69).

Coyote, black-tailed deer, and deer mice showed no significant response to vegetation changes, but deer did have a significant negative association with disturbance, i.e. the presence of traffic and construction activity (Figure 10). The response by black-tailed deer is similar to the avoidance response documented during the artificial light experiment (Figure 10) (also see Bliss-Ketchum et al. 2016). While coyote did not show significant results in GJAM analysis for disturbance, average annual detections demonstrate a dramatic response to the road closure period, as do detections for bullfrog, cottontail rabbit, and eastern gray squirrel (Figure 8). Coyote in particular is an interesting example of a species that is known to be highly urban adapted, but simultaneously wary of human interaction (Ghert 2007). Given that this species avoids people, it follows that they would avoid roads when vehicle and pedestrian traffic was present, and utilize those areas more frequently when human activity was reduced or absent. Other species with possible strong traffic responses did not have enough 
detections to evaluate, nor the behavioral research to support a prediction on a behavioral response. In addition, it appears that the transition between species with preferences for lower canopy cover, and those preferring greater canopy cover, co-occurs with the road closure period, particularly in 2013. This is also the year that invasive plant management activities (mowing and spraying) stopped (HDR 2009-2013). This habitat transition may be overwhelming the response signature to disturbance (traffic and construction) in community modeling efforts not accounted for by the year effect (Figure 12).

Species that correlate and/or showed trends in responding to changes in vegetative habitat structure are also correlated with time, presenting difficulty in interpreting results. Distinguishing between possible responses to vegetation changes versus habituation to the crossing structures is challenging, however consideration that Boeckman Road was a brand-new feature on the landscape with crossing structure opportunities in place simultaneously may play a role. In this case, species were not already habituated to a road barrier with no crossing structures, and therefore did not need to alter movement patterns to take advantage of safe passage opportunities. This, in combination with information about the natural history and habitat use of species, allows us to reasonably conclude that vegetation changes are likely contributing factors for several species (Figure 12).

As expected, the red-legged frog, garter snake and raccoon showed a positive association with increased canopy cover (Figure 10). In contrast to expectations based on habitat association, the pacific chorus frog was not significantly associated with any canopy 
cover levels, and in fact appear to be more positively associated with early habitat conditions (less canopy cover). Variability in detections of pacific chorus frog may also be a reflection of population size fluctuations (Figure 7). The pacific jumping mouse did not produce a significant result in relationship to canopy cover, however average annual detections suggest an association with habitat and/or possible habituation to the crossing structure (Figure 6). The eastern cottontail rabbit did not have enough detections to be analyzed by GJAM and in reviewing average annual detections did not appear to respond to vegetation trends, however did reflect a possible response to traffic (Figure 8).

As expected, skunk had a negative association with increased canopy cover, whereas mink was positively associated with mid-level canopy cover, contrary to the prediction that they would be more closely associated with open habitats (Figures 10). Townsend's vole was expected to respond negatively to increased canopy cover, however detections were not significant according to GJAM analysis and average annual detections show no obvious trend (Figure 9). Townsend's vole may be responding to other habitat characteristics and/or the variation in detections may be a reflection of population size variability. The ring-necked pheasant did not have enough detections to be analyzed in GJAM, however average annual detections suggest a negative response to increased canopy cover (Figure 7).

We cannot say, for any of these species, if actual population size changes are responsible for the frequency of detection, however we can note interesting trends and possible 
relationships between species. While deer mice show an association with reduced canopy cover, the average annual detections may be a reflection of this species ability to rapidly make use of new habitat resources created through mitigation efforts, resulting in a rapid response in population size (in 2010), then crashing shortly thereafter (Figure 7). Average annual detections of mink appear to follow the deer mice trends with a one-year delay suggesting possible predator-prey population dynamics. Another example is the opossum, a non-native species in Oregon, that have been documented to have very low annual survivorship in more northern latitudes (Gillette 1980, Ghert et al. 1997). While freezing temperatures are not as severe in Oregon as other areas across the native range of the opossum, it would be possible to explore if harsh winter conditions (and consequently reduced survivorship) may explain frequency of detection in this study.

The groupings that emerge from the GJAM output are distinct from the groups of individual species responses over time (see Figures 6-9 vs. Figure 10). For example, garter snake tracks increased over time as did red legged frog, deer mice decreased over time, and vole footprints fluctuated over time. This difference illustrates the importance of looking at the species in the community together along with predictor variables.

We cannot account for species that may have been present in the surrounding area, but never attempted to use the crossing structure. We can note however, that all species detected during the pre-construction mammal study were reflected in the monitoring data and documented utilizing the structure. Additional research (de Rivera \& Bliss-Ketchum 
2010) used motion detect cameras at transects away from the road to monitor species in the area that may not be approaching the road. That effort did not detect any unique species not also detected in crossing structures, though it is important to note that motion detect cameras did not reliably trigger on smaller species, particularly herptiles. This study focuses on how use within the structure varies over time under different traffic volume and vegetation changes, but is not able to speculate (other than within the first two years of monitoring (de Rivera \& Bliss-Ketchum 2010)) as to what species may have been in the surrounding area, but not utilizing the structure.

The results of this study reinforce earlier calls in the literature for more long-term monitoring efforts (Clevenger \& Waltho 2003, Gagnon 2011, Soanes et al. 2013) and the need to factor in population size. The barrier to widespread implementation of long term and population scale monitoring efforts is they are detailed and can be costly to implement, particularly when trying to describe community responses compared to a single species focus. The ongoing challenge is to determine how to conduct monitoring, and design studies, to best understand species use and presence at crossing structures with limited monitoring funds. Long term studies such as this one can help researchers and managers design monitoring programs to best account for variable responses over time by documenting changes in use and working to identify covariates and interactive effects that may be driving those changes. Project managers may decide to delay monitoring until vegetation communities and/or habituation responses have had time to stabilize, avoiding erroneous conclusions about structure use. Additional research on individual 
species responses to traffic volume will inform expectations of structure use and can guide mitigation efforts. We recognize these are complex and dynamic systems, and believe that we can best serve them by taking care in making broad conclusions from short term data sets. We hope that the relatively few long-term data sets available can help to characterize and inform our decision making and encourage other long-term data collection efforts. 
Chapter 2 - References

Bissonette J., Adair W. 2008. Restoring habitat permeability to roaded landscapes with isometrically-scaled wildlife crossings. Biological Conservation. Vol 141. Pages $482-488$

Bliss-Ketchum, L. L., de Rivera, C. E., Turner, B. C., \& Weisbaum, D. M. (2016). The effect of artificial light on wildlife use of a passage structure. Biological Conservation, 199, 25-28. http://doi.org/10.1016/j.biocon.2016.04.025

Bliss-Ketchum, L.L., Parker, C., de Rivera, C.E., Cramer, P. Lava Butte Wildlife Crossing Monitoring Project. Portland State University, 2015. Print.

Barrueto, M., Ford, A.T., Clevenger, A.P. 2014. Anthropogenic effects on activity patterns of wildlife at crossing structures. Ecosphere 5(3):27. http://dx.doi.org/10.1890/ES13-00382.1

Baxter-Gilbert, J.H., Riley, J.L., Lesbarreres, D., Litzgus, J.D. 2015. Mitigating Reptile Road Mortality: Fence Failures Compromise Ecopassage Effectiveness. PLOS One. Vol 10. Issue 3. 
Bond, A.R., Jones, D.N. 2008. Temporal trends in use of fauna-friendly underpasses and overpasses. Wildlife Research. Vol 35. Pages 103-112.

Cain, A.T., Tuovila, V.R., Hewitt, D.G., Tewes, M.E. 2003. Effects of a highway and mitigation projects on bobcats in Southern Texas. Biological Conservation. Vol 114. Pages 189-197.

Chambers, B., Bencini, R. 2015. Factors affecting the use of fauna underpasses by bandicoots and bobtail lizards. Animal Conservation. Vol 18. Issue 5. Pages 424432.

Colle, M., Lougheed, S.C., Otterbein, L., Litzgus, J.D. 2017. Wildlife Research. Vol 44(1). Pages 48-59. https://doi.org/10.1071/WR16130

Clark, J. S., Nemergut, D., Seyednasrollah, B., Turner, P. J., \& Zhang, S. (2017). Generalized joint attribute modeling for biodiversity analysis: median- zero, multivariate, multifarious data. Ecological Monographs, 87(1), 34-56. https://doi.org/10.1002/ecm.1241

Clevenger, A.P., Waltho, N. 2003. Long-term, year-round monitoring of wildlife crossing structures and the importance of temporal and spatial variability in performance 
studies. ICOET 2003 Proceedings. Pages 293 - 302.

https://escholarship.org/uc/item/3g69z4mn

Colley, M., Lougheed, S.C., Otterbein, K., Litzgus, J.D. Mitigation reduces road mortality of a threatened rattlesnake. Wildlife Research. Vol 44. Issue 1. Pages 4859.

D'Amico, M., Clevenger, A.P., Roman, J., Revilla, E. 2015. General versus specific surveys: Estimating the suitability of different road-crossing structures for small mammals. Journal of Wildlife Management. Vol. 79. Issue 5. Pages: 854-860.

de Rivera, C.E., Bliss-Ketchum, L.L., The Effectiveness of Vertebrate Passage and Prevention Structures: A Study of Boeckman Road in Wilsonville. Portland: Oregon Transportation Research and Education Consortium (OTREC). 2010. Print. OTREC-RR-07-01

DeVault, T.L., Blackwell, B.F., Seamans, T.W., Lima, S.L., Fernandez-Juricic, E. 2014. Effects of Vehicle Speed on Flight Initiation by Turkey Vultures: Implications

for Bird-Vehicle Collisions. PLoS ONE 9(2): e87944.

doi:10.1371/journal.pone.0087944 
Dickson, B.G., Jenness, J.S., Beier, P. 2005. Influence of Vegetation, Topography, and Roads on Cougar Movement in Southern California. The Journal of Wildlife Management, Vol. 69, No. 1 (Jan., 2005), pp. 264-276 https://www.jstor.org/stable/3803604

Donaldson, B. 2007. Use of highway underpasses by large mammals and other wildlife in Virginia - Factors influencing their effectiveness. Transportation Research Record. Issue 2011. Pages 157-164.

Fagart, S., Heurtebise, C., Quaintenne, G., Jourde, P., Micol, T. Use by small and medium mammals of wildlife crossing structures on two motorways in southwestern France. Revue D Ecologie-La Terre et la Vie. Vol 71. Issue 1. Pages 82-98.

Ford, A.T., M. Barrueto, A.P. Clevenger. 2017. Road mitigation is a demographic filter for grizzly bears. The Wildlife Society. Vol 41, Issue 4. Pages 712-719.

Foster, M.L., Humphrey, S.R. 1995. Use of Highway Underpasses by Florida Panthers and Other Wildlife. Wildlife Society Bulletin (1973-2006), Vol. 23, No. 1 (Spring, 1995), pp. 95-100. https://www.jstor.org/stable/3783202 
Gagnon, J.W., Theimer, T.C., Dodd, N.L., Manzo, A.L., Schweinsburg, R.E. 2007. Effects of traffic on elk use of wildlife underpasses in Arizona. Journal of Wildlife Management. Vol 71. Issue 7. Pages 2324-2328.

Gagnon, J.W., Dodd, N.L., Ogren, K.S., Schweinsburg, R.E. 2011. Factors Associated with Use of Wildlife Underpasses and Importance of Long-Term Monitoring. The Journal of Wildlife Management, Vol. 75, No. 6. Pages 1477-1487.

Gehrt, S.D., Clark, D.E., Fritzell, E.K. 1997. Population Dynamics and Ecology of Virginia Opossums in Southern Texas. The Southwestern Naturalist, Vol. 42, No. 2 (Jun., 1997), pp. 170-176. https://www.jstor.org/stable/30055257

Gehrt, S.D. 2007. Ecology of Coyotes in Urban Landscapes. Wildlife Damage Management Conferences -- Proceedings. 63.

Gillette, L.N. 1980. Movement Patterns of Radio-Tagged Opossums in Wisconsin. The American Midland Naturalist, Vol. 104, No. 1 (Jul., 1980), pp. 1-12. https://www.jstor.org/stable/2424953

Gloyne, C.C., Clevenger, A.P. 2001. Cougar Puma concolor use of wildlife crossing structures on the Trans-Canada highway in Banff National Park, Alberta. Wildlife Biology, 7(3). Pages 117-124. https://doi.org/10.2981/wlb.2001.009 
HDR Engineering. Boeckman Road-Tooze Avenue Compensatory Wetland Mitigation Monitoring Report. City of Wilsonville. 2009-2012. Print. Year 1, Year 2, Year 3, Year 4.

Jacobson, S. L., L. L. Bliss-Ketchum, C. E. de Rivera, and W. P. Smith. 2016. A behavior-based framework for assessing barrier effects to wildlife from vehicle traffic volume. Ecosphere 7(4):e01345. 10.1002/ecs2.1345

Johnson, D.H., O’Neil, T.A. 2001. Wildlife-Habitat relationships in Oregon and Washington. Corvallis: Oregon State University Press.

Little, S. 2003. The Influence of Predator-prey Relationships on Wildlife Passage Evaluation. ICOET 2003 Proceedings. Pages 227-292.

Martinig, A.R., Belanger-Smith, K. 2016. Factors influencing the discovery and use of wildlife passages for small fauna. Journal of Applied Ecology. Vol 53. Issue 3. Pages. 825-836.

Mata, C., Hervas, I., Herranz J., Suarez, F., Malo, J.E. Complementary use by vertebrates of crossing structures along a fenced Spanish motorway. Biological Conservation. Vol 124. Issue 3. Pages 397-405. 
Mata, C., Hervas, I., Herranz, J., Malo, J.E., Suarez, F. 2009. Seasonal changes in wildlife use of motorway crossing structures and their implication for monitoring programmes. Transportation Research Part D-Transport and Environment. Vol 14. Issue 7. Pages 447-452.

Mateus, A.R.A., Grilo, Cl, Santos-Reis, M. 2011. Surveying drainage culvert use by carnivores: sampling design and cost-benefit analyzes of track-pads vs. videosurveillance methods. Environmental Monitoring and Assessment. Vol 181. Issue 14. Pages: 101-109.

McCollister, M.F., Van Manen F.T. 2010. Effectiveness of Wildlife Underpasses and Fencing to Reduce Wildlife-Vehicle Collisions. Journal of Wildlife Management 74(8). Pages 1722-1731.

Myslajek, R.W., Nowak, S., Kurek, K., Tolkacz, K., Gewartowska, O. 2016. Utilization of a wide underpass by mammals on an expressway in the Western Carpathians, $\mathrm{S}$ Poland. Folia Zoologica. Vol. 65. Issue 3. Pages 225-232.

Ng, S.J., Dole, J.W., Sauvajot, R.M., Riley, S.P.D., Valone, T.J. 2004. Use of highway undercrossings by wildlife in southern California. 2004. Biological Conservation. Vol. 115. Issue 3. Pages 499-507. 
Olsson, M.P.O., Widen, P., Larkin, J.L. 2008. Effectiveness of a highway overpass to promote landscape connectivity and movement of moose and roe deer in Sweden. Landscape and Urban Planning. Vol 85 Pages 133-139.

Oregonian 2012 Summer road work, yearlong closure of Boeckman Road bridge coming soon to Wilsonville. Posted Jun 21, 2012, Viewed online in 2018 at: https://www.oregonlive.com/wilsonville/index.ssf/2012/06/post_19.html

Pagnucco, K.S., Paszkowski, C.A., Scrimgeour, G.J. 2011. Using Cameras to Monitor Tunnel use by Long-Toed Salamanders (Ambystoma Macrodactylum): An Informative, Cost-Efficient Technique. Herpetological Conservation and Biology. Vol. 6. Issue 2. Pages 277-286.

Puig, J., Sanz, L., Serrano, M., Elosegui, J. 2012. Wildlife Roadkills and Underpass Use in Northern Spain. Environmental engineering and management journal. Vol. 11. Issue 6. Pages 1141-1147.

Sawyer, H., Lebeau, C., Hart, T. 2012. Mitigating Roadway Impacts to Migratory Mule Deer-A Case Study with Underpasses and Continuous Fencing. Wildlife society bulletin. Vol. 36. Issue 3. Pages 492-498. 
Serronha, A.M., Mateus, A.R.A., Eaton, F., Santos-Reis, M., Grilo, C. 2013. Towards effective culvert design: monitoring seasonal use and behavior by Mediterranean mesocarnivores. Environmental Monitoring and Assessment. Vol. 185. Issue 8. Pages: 6235-6246.

Shannon, G., McKenna, M.F., Angeloni, L.M., Crooks, K.R., Fristrup, K.M., Brown, E., Warner, K.A., Nelson, M.D., White, C., Briggs, J., McFarland, S., Wittemyer, G. 2016. A synthesis of two decades of research documenting the effects of noise on wildlife. Biological Reviews. Vol 91. Pages. 982-1005. doi: 10.1111/brv.12207

Sheldon, Ian. 1997. Animal Tracks of Washington and Oregon. Edmonton, AB: Lone Pine Publishing.

Soanes et al. 2013. Movement re-established but not restored: Inferring the effectiveness of road-crossing mitigation for a gliding mammal by monitoring use. Biological Conservation. Volume 159, Pages 434-441. https://doi.org/10.1016/j.biocon.2012.10.016

Sparks, J.L., Gates, J.E. 2017. Seasonal and regional animal use of drainage structures to cross under roadways. Human-wildlife interactions. Vol 11. Issue 2. Pages 182-191. 
Šver L, Bielen A, Križan J, Gužvica G. 2016. Camera Traps on Wildlife Crossing Structures as a Tool in Gray Wolf (Canis lupus) Management - Five-Years Monitoring of Wolf Abundance Trends in Croatia. PLoS ONE. Vol 11(6): e0156748.doi:10.1371/journal.pone.0156748

Taylor, B.D., Goldengay, R.L. 2010. Roads and wildlife: impacts, mitigation and implications for wildlife management in Australia. Wildlife Research. Vol 37. Pages $320-331$.

Wang, Y., Guan, L., Piao, Z.J., Wang, Z.C., Kong, Y.P. 2017. Monitoring wildlife crossing structures along highways in Changbai Mountain, China. Transportation research part d-transport and environment. Vol. 50. Pages 119-128.

Yokochi, K., Chamber, B.K., Bencini, R. 2015. An artificial waterway and road restrict movements and alter home ranges of endangered arboreal marsupial. Journal of Mammalogy. Vol. 96. Issue 6. Pages 1284-1294. 
Chapter 3 - A Behavior-Based Framework for Assessing Barrier Effects to Wildlife from Vehicle Traffic Volume

This work has been previously published.

Citation:

Jacobson, S. L., L. L. Bliss-Ketchum, C. E. de Rivera, and W. P. Smith. 2016. A behavior-based framework for assessing barrier effects to wildlife from vehicle traffic volume. Ecosphere 7(4):e01345. 10.1002/ecs2.1345

Chapter 3 - Traffic Volume as an Indicator of Barrier Strength

Roads impede wildlife movement through a combination of direct mortality from collisions and road avoidance behavior by animals (Forman et al. 2003, Fahrig and Rytwinski 2009), yet a comprehensive approach toward identifying animal characteristics that increase effects has not been developed (Lima et al. 2015). The barrier effect of roads can reduce dispersal rates and so limit demographic rescue and gene flow, increasing the risk of local extinction (Clark et al. 2010). Vehicle-caused mortality and road avoidance behavior can create population-level reductions in a variety of species from freshwater turtles to Florida panthers (Puma concolor coryi, Dickson et al. 2005, Patrick and Gibbs 2010). Commonly, transportation planners develop mitigation measures for barrier effects specifically for a given population (Jacobson et al. 2010).

Traffic volume, the number of vehicles passing a point per day, has had mixed results as a predictor of adverse effects to wildlife (Hels and Buchwald 2001, Bissonette and Kassar 2008). Investigators initially predicted that effects to wildlife and the number of carcasses 
present would increase linearly with increasing traffic volume (Case 1978). The expectation of a similar and linear response by all species, and using a coarse scale to measure traffic volume (i.e., averaging traffic volume over 10s or 100s of miles) has led some investigators to conclude that traffic volume is not a useful indicator (Meek 2012). Colino-Rabanal and Lizana (2012) reviewed the plethora of responses by species of herpetofauna to traffic volume and concluded that animals show specific behaviors in response to traffic that reduce the accuracy of models. However, the effects of traffic volume on some species have been predicted reliably by using the traffic flow model (e.g., Hels and Buchwald 2001, Aresco 2005). The traffic flow model predicts that as traffic volume increases, an animal's probability of a lethal collision with a vehicle increases steeply at first then approaches an asymptote. The traffic flow model illustrates why mortality risk does not increase linearly with traffic volume. However, the model assumes animals will cross with little regard to vehicles, whereas some animals avoid roads or otherwise react to vehicles. Although many factors influence animal responses to roads, this article focuses on how traffic volume can be an effective explanatory variable for the barrier effect of roads on species, provided that animal behavior is also considered. We hypothesize that consideration of species-specific behavioral responses to risk will improve the ability of traffic volume, a readily measured explanatory variable, to predict barrier effects on populations.

Closely related species may exhibit different responses to traffic (Alexander et al. 2005, Andrews et al. 2005, Lee et al. 2010), although several studies have used taxonomic 
classifications as high as class as their guide (e.g., Clevenger and Huijser 2011). The variables that contribute most to mortality risk in the traffic flow model are the animal's crossing speed and its size relative to the vehicle's killing surface (van Langevelde and Jaarsma 2004). Slow animals have the greatest mortality risk. Therefore, species with antipredator adaptations that slow them further, such as freezing, have even higher risk of mortality from vehicles if they recognize and respond to approaching vehicles as threats. Using species-specific behavioral responses to risk therefore may improve interpretation of traffic effects on populations. 
Chapter 3 - Perceived Risk as the Foundation of Animal Response

Combining traffic volume with predictable wildlife behavioral responses to perceived risk can improve management efforts to reduce animal-vehicle collisions and the barrier effect of roads and root research about effectiveness of management in established ecological theory. Cook and Blumstein (2013) suggest that species traits affect animal responses to roads, but they focused on life history traits and diet not directly associated with response to vehicles. Rytwinski and Fahrig (2012) found large body size, low reproductive rates and large home ranges to be important predictors of road density effects but did not consider the effects of traffic volume. Food preferences and the need to move to forage and seek unoccupied habitat helps explain lack of response by some owl species to traffic volume (Grilo et al. 2014). The most comprehensive approach to date that directly addresses responses to vehicle traffic, an approach used in European transportation guidance, is based on a conceptual model that suggests vehicle-caused mortality decreases and avoidance increases as traffic volume increases (Müller and Berthoud 1997, Seiler and Helldin 2006).

Our framework is based on the risk-disturbance hypothesis (Frid and Dill 2002) and related research showing that risk assessment changes with the type of animal defense system (Stankowich and Blumstein 2005). The risk-disturbance hypothesis suggests that responses elicited from anthropogenic stimuli that cause deviations in behavior relative to patterns without human influence are analogous to responses to predation risk (Frid and 
Dill 2002). For some species, the cue that triggers a flight response is not very specific and therefore could include recent agents of disturbance such as vehicles approaching (Frid and Dill 2002). For example, the visual cue of an enlarging shape or rapid approach is enough to trigger antipredator response in a small fish (Dill 1974).

We expect that vehicle traffic is likely to trigger antipredator responses because of the risk of mortality from vehicles (Andrews et al. 2005). Moreover, the main predictions of the risk-disturbance hypothesis seem likely to be met with traffic and roads: risk response increases with a direct and fast approach, larger individual or group size, and distance to refuge (Frid and Dill 2002). Risk response increases with direct and rapid approach because such an approach can convey intent to kill (Stankowich and Blumstein 2005). Second, Frid and Dill (2002) predicted risk responses would increase when the approaching object was bigger or part of a larger group. When traffic volume is higher, vehicles likely appear as part of a larger group and increase perceived risk. Consistent with this hypothesis, Tibetan antelope (Pantholops hodgsoni) exhibit more risk-avoidance behavior during times of high traffic than low (Lian et al. 2011). The risk-disturbance hypothesis therefore incorporates ecological and evolutionary implications for animal behavior toward traffic.

We hypothesize that individuals perceive increased traffic as increased threat based on a risk response that is not a function of taxonomy (Alexander et al. 2005, Andrews et al. 2005, Lee et al. 2010, Clevenger and Huijser 2011). Furthermore, we hypothesize that 
species responses to traffic are reasonably predictable — individuals avoid roads, speed across roads, pause on roads, or fail to respond-based on their behavioral adaptations in response to perceived risk. 
Chapter 3 - Four Risk Avoidance Behavioral Responses to Traffic Volume

We propose a framework of four categories, primarily based on responses to perceived danger that subsume most observed responses to vehicle traffic: Nonresponders, Pausers, Speeders, and Avoiders. These categories reflect the interplay between avoidance behavior and vehicle-caused mortality that culminate in the overall barrier effect of traffic on wildlife and disruption of habitat connectivity. We propose that the traffic flow model (Hels and Buchwald 2001, van Langevelde and Jaarsma 2004) be modified to incorporate behavior, resulting in four different sets of mortality, avoidance, and total barrier curves (Figure 3.1). The responses and the traffic volumes at which these barrier effects manifest are species-specific but the species within a category still will follow general patterns (Figure 3.1). The height of the curves and carcass counts decrease over time whenever mortality exceeds reproductive output.

\section{$\underline{\text { Nonresponders }}$}

Nonresponders do not recognize moving vehicles as threats or are unable to detect a moving vehicle in time to avoid mortality regardless of traffic volume. The Nonresponder group includes species that do not respond to traffic either because they have limited sensory abilities or because the hunting styles of their predators are not analogous to approaching vehicles. The shape of the curve of barrier effect vs. traffic volume essentially follows the traffic flow model (Hels and Buchwald 2001, van Langevelde and Jaarsma 2004). 
As gaps between vehicles decrease, mortalities increase at an accelerating rate. As traffic volume and therefore the probability of an individual encountering a vehicle increases, the chance of a successful crossing approaches 0 and the road becomes a strong barrier (Figure 3.1a). Nonresponder populations near roads would predictably experience strong fragmentation effects and relatively high risk of local extinction. Predictably, Nonresponders are likely to be commonly found as roadkill victims, at least until the mortality rate exceeds recruitment.

Species with the Nonresponder behavior include many invertebrates, some frogs, some snakes, some turtles, and some owls (Grilo et al. 2014). Northern leopard frogs (Rana pipiens) were nonresponsive in experiments testing response to traffic in Canada (Bouchard et al. 2009). Western Barn Owls (Tyto alba), common victims of vehicles, were found to cross highways without regard to traffic intensity (Grilo et al. 2012), and were locally extirpated when a new highway was constructed (Joveniaux 1985), both results suggesting lack of suitable response to a new "predator" with no natural analog. In the case of Western Barn Owls, a species with few to no natural predators while on the wing, their undivided attention during foraging especially during food shortages (Grilo et al. 2014) predisposes them to fail to respond to potentially lethal, yet novel, sounds such as approaching vehicles. Juvenile bats showed greater mortality at higher traffic volumes (Lesiński 2007). Anecdotally, orange sulfur butterflies (Colias eurytheme) and California 
tortoiseshells (Nymphalis californica) during fall migration exhibited no evasive

maneuvers as vehicles approached.

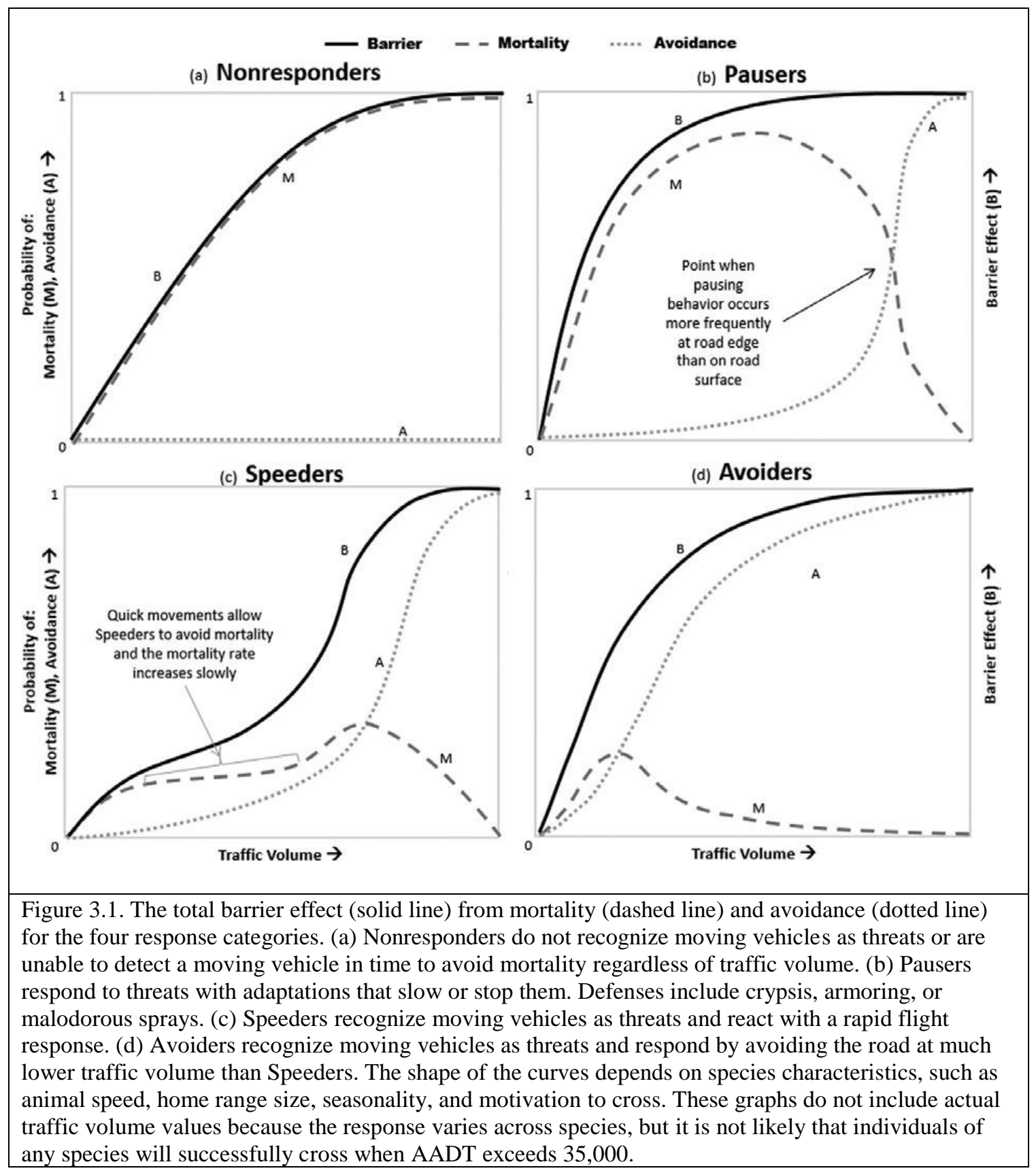




\section{$\underline{\text { Pausers }}$}

Pausers respond to a perceived risk of predation by relying on alternatives to fleeing, such as using crypsis, counter-threat, or an armored exterior. Pausers respond to the perceived threat by reducing their speed or freezing, which increases time spent on the roadway and therefore increases mortality risk (van Langevelde and Jaarsma 2004). When traffic has reached sufficient volume for an animal to pause before attempting crossing, the probability of avoidance becomes greater than the probability of mortality. Complete barrier effects are due to the combination of high mortality from pausing in the roadway and avoidance from halting at the roadside (Figure 3.1b). Pausers are abundantly represented as roadkill and include skunks (Mephitis sp.), porcupines (Erethizon dorsatum), opossums (Didelphis virginiana), gray kangaroos (Macropus robustus erubescens), cryptic snakes, some amphibians, and some turtles (Andrews et al. 2005, Mazerolle et al. 2005, Lee et al. 2010). Armadillos (Dasypus novemcinctus) are Pausers whose slow movements and inappropriate responses to danger-jumping then curling into their armored exterior-increase mortality risk as the gaps between vehicles decrease (Inbar and Mayer 1999). The majority of amphibians Mazerolle et al. (2005) studied met our criteria for Pausers although they found the stimuli needed to elicit a pause response varied.

\section{$\underline{\text { Speeders }}$}

Speeders are characterized by anatomical and behavioral adaptations to flee as a primary 
response to threat. Pausers may also temporarily flee, but unlike Speeders their primary defense is not flight. Speeders may stop to gather information on the threat of oncoming vehicles, but otherwise tend to flee from danger. Speeders can be ungulates, such as mule deer (Odocoileus hemionus; Geist 1981) and pronghorn (Antilocapra americana; Einarsen 1948), and are also represented by other groups such as rapidly moving snakes (Andrews et al. 2005) and red kangaroos (Macropus rufus, Lee et al. 2010). The probability of mortality increases slowly with increased traffic volume for a period when speeding allows them to exploit traffic gaps (Figure 3.1c). Eventually as traffic increases to a threshold in which quick fleeing movements are no longer sufficient to exploit gaps between vehicles, the probability of mortality increases steeply until the traffic volume elicits avoidance. Individuals may be hit at lower traffic volumes if they pause as a protective response to young or to update information about the threat. Barrier effects manifest at higher traffic volume more than the previous groups because their speed can reduce mortality risk at relatively low and moderate volumes; barrier effects occur both as a result of mortality and ultimate avoidance of the road. With high traffic volume, barrier effects result primarily from avoidance rather than mortality.

Pronghorn represent the ultimate Speeder, as pronghorn rely on endurance and speed as a predator avoidance strategy. Pronghorn increase their speed to cross highways, occasionally even racing to cross in front of vehicles (Einarsen 1948). As traffic volume increases, however, pronghorn avoid crossing (Dodd et al. 2009). Higher traffic volumes inhibit crossing attempts by deer as well; deer-vehicle collisions are most probable on 
two-lane highways of moderate traffic volume rather than high volume interstate highways (Huijser et al. 2008). The dragonfly Tramea lacerate is a Speeder that moves vertically out of the way of vehicles, but avoids crossing roads with high traffic volume (Soluk et al. 2011).

\section{$\underline{\text { Avoiders }}$}

Avoiders, such as bears (Ursus spp.), cougar (Puma concolor), and some bats are currently known to recognize moving vehicles as threats and respond by avoiding the road at much lower traffic volume and further distances from the road than Pausers and Speeders (Figure 3.1d). This response results in relatively low roadkill rates and suggests individuals more consistently recognize vehicles as dangerous and avoid interactions. Barrier effects occur mostly through avoidance instead of mortality as traffic volume increases.

Even moderate traffic volume can restrict movement of Avoiders. For example, grizzly bears (U. arctos) avoid roads starting as low as 10 vehicles/d (Mace et al. 1996). While flighted birds are frequently the taxon most killed by traffic despite their ability to fly (Erickson et al. 2005), some passerine birds respond to increasing traffic volume by avoiding roads and adjacent habitat (Reijnen et al. 1996), and therefore presumably face increased fragmentation and loss of habitat use. Woodland and grassland grouse (Tetraonidae) are displaced away from roads, especially when roads are associated 
with other infrastructure such as oil and gas extraction sites (Hovick et al. 2014), and are infrequently found as roadkill (Räty 1979). When vehicles were present, $60 \%$ of endangered Indiana bats (Myotis sodalis) avoided crossing roads, whereas only 32\% of bats reversed their course when no traffic was present (Zurcher et al. 2010). Orange tip butterflies (Anthocharis cardamines) turned around at a motorway and were much less likely to cross it than an adjacent meadow (Dennis 1986).

Some Avoiders reroute to cross elsewhere or cross roads only when traffic volume is low, which can reduce roadkill when traffic volume is high. Elk-vehicle collisions occurred more frequently on lower traffic volume weekdays than higher traffic volume weekend days in Arizona suggesting more crossings were attempted (Dodd et al. 2005). Forest bats avoid higher volume roads even if it involves a longer journey, but fly straight across similar-width roads with no traffic (Kerth and Melber 2009). Raccoons (Procyon lotor) attempt to cross lower volume roads and avoid higher volume roads (Gehrt 2002) or use wildlife crossing structures such as culverts ( $\mathrm{Ng}$ et al. 2004). Both grizzly and black bears (U. americanus) modify their crossing attempts to times of lower traffic volume (Waller and Servheen 2005, McCown et al. 2009). Similarly, moose (Alces alces) were found to cross roads at night when traffic volume was $33 \%$ lower than during daylight hours (Laurian et al. 2008). These findings are consistent with Seiler's (2005) finding that highway barrier effects to moose change from mortality to avoidance as traffic volume increased, and provide support for the shape of the avoidance curve for Avoiders in our framework. 
Chapter 3 - Considerations and Research Needs

Our framework is meant as a guide to enhance understanding of how and why animals react to vehicles across different traffic volumes. Although behaviors can vary among individuals, basic ecology can be used to predict the primary response of a population, thereby providing increased predictive ability about the barrier effect of roads based on evolved responses to risk. Even with some within-species variation, recognizing the behavior or behaviors typical of a population will help interpret roadkill and avoidance data and determine most appropriate mitigations given those behaviors and local traffic volume (see Application section). Individuals vary based on their motivation, experience, and individual characteristics including gender, age, and body size. At times the response can be situational; thus, we predict that if an animal is highly motivated to cross to meet an urgent survival or reproductive need, the onset of avoidance behavior would occur at a higher traffic volume for Pausers, Speeders, and Avoiders than otherwise (e.g., turtles; Aresco 2005) but not for Nonresponders. The effects of vehicle speed on animal response and collision risk are complex and require more investigation; for example, vehicle speed may affect mortality risk of Speeders because higher vehicle speeds reduce the response time within traffic gaps, thus decreasing the effectiveness of fleeing strategies. Withinspecies variation resulting from habituation to human disturbance may also cause considerable variation in response to perceived risk. For example, black bears appear less wary of vehicles in Florida than Idaho (McCown et al. 2009, Lewis et al. 2011). Some 
species conform closely to one type of response, whereas others have multiple-response strategies as a function of individual variation (Fig. 2). Sometimes the variation will be predictable, as with immature individuals exhibiting different behavior from adults. For example, moose can be generally classified as Avoiders; however, if encountering traffic, inexperienced young moose tend to run and older male moose may stand their ground and challenge vehicles in a confrontational form of Pausing (Child et al. 1991, Laurian et al. 2008).

A few species straddle more than one category (Figure 3.2). Bobcats (Felis rufus) may exhibit a gradation in the Speeder to Avoider categories because they flee from danger and also show avoidance behavior at relatively low traffic volumes. Lovallo and Anderson (1996) found bobcat patterns of response to various traffic volumes consistent with Speeder response, where they crossed less often than expected on roads with higher traffic volumes. Black racer snakes (Colubris constrictor) may represent a gradation between Pausers and Speeders because they use speed to escape predators and move quickly across roads, and also respond to passing traffic with immobilization. Black racers will stop and wait several minutes after a vehicle passes, indicating a barrier effect with traffic volume as low as 10 vehicles/h (less than 240 AADT; Andrews et al. 2005). 


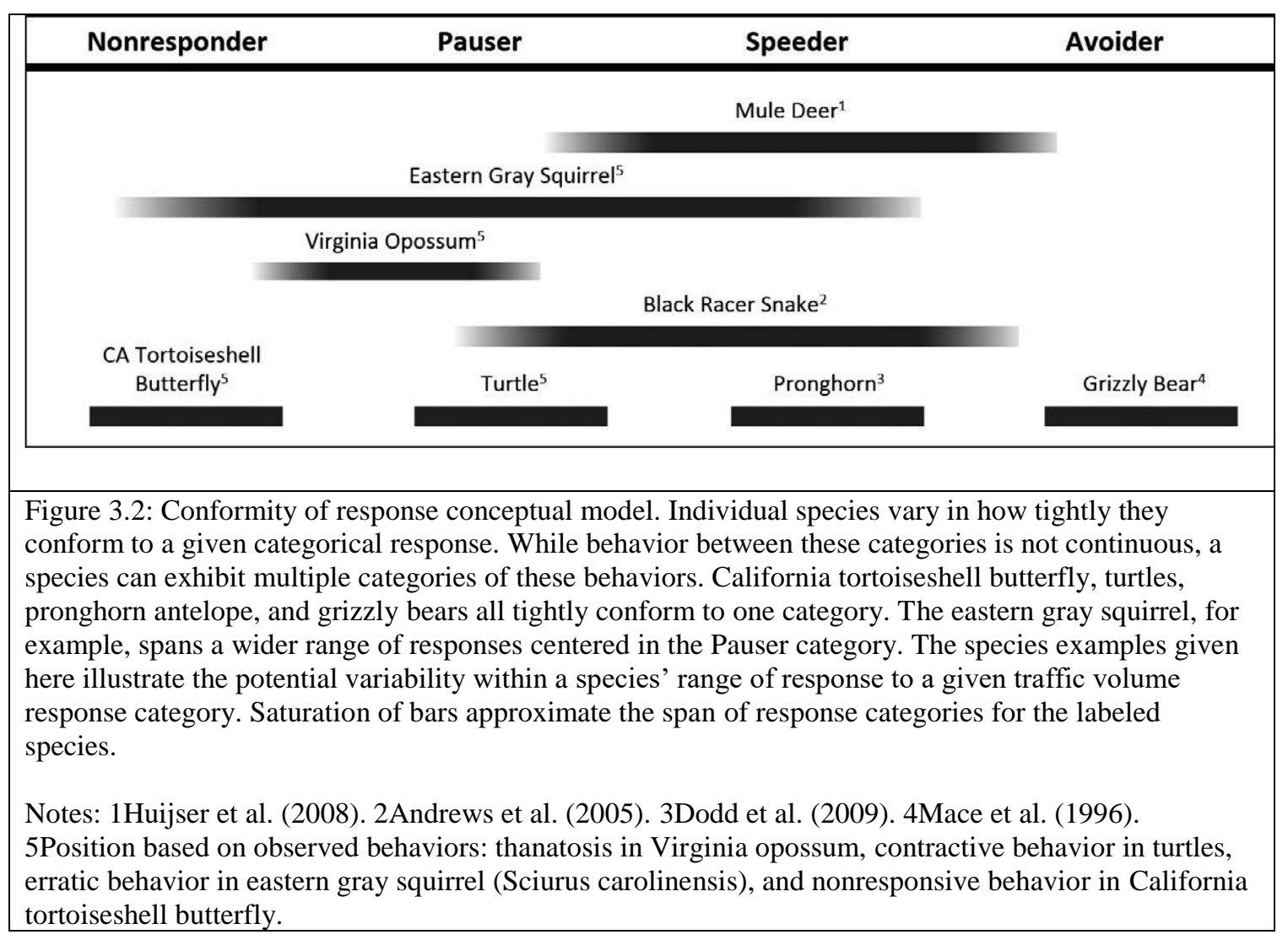

This framework will be most helpful for practitioners once a variety of traffic volumespecies combinations are tested across the four behavioral categories. Testing for each response type would allow researchers to create more exact functional relationships between organisms and traffic volume and therefore better predictions and management. Results are already available showing the effect of traffic volume for a few Speeders (Gagnon et al. 2007) and Avoiders (Mace et al. 1996). Data are also needed to verify that Pausers consistently stop at the edge of a road once traffic volume reaches a certain level. It is important to note that the basic shape will stay the same across organisms within a category but the traffic volume trigger points of switching from crossing to avoidance and of the cumulative barrier effect will differ across species within the group. It would 
be extremely useful for researchers to determine species-specific relationships of the effects of traffic volume that could be used to identify traffic volume thresholds above which mortality or barrier effects are unacceptably high. Threshold models have been used in Europe (Iuell et al. 2003, Helldin et al. 2010) and have been most useful for large ungulates that in our classification are Speeders. Caution in such generalizations is needed because of the variance in response of many animals even to the individual level.

We recommend several important characteristics of traffic volume to consider in studies of barrier effects on wildlife, based partly on the deficiencies shown in most existing studies that could be improved with more accurate and precise traffic volume data. We further recommend the use of standardized traffic volume categories, used by the Federal Highway Administration, to make better comparisons across studies. Currently, most studies use terms relative only to the roads within a study area. Traffic volume along with the risk response categories does not explain all variation in mortality and avoidance. Some roadkill at low traffic volume is due to intentional hits by drivers (Langley et al. 1989). Vehicle speed and road width also likely affect relative barrier strength to wildlife, though these are correlated with traffic volume because planners often increase road width to meet increased traffic volume demands; the increased capacity in turn results in increased speed limits (Falcocchio and Levinson 2015). Vehicle speed may affect animal behavior as well, interacting with traffic volume in complex ways that have had little investigation to date. Variation in mortality within a response category including among individuals of a species, can also be due to variations 
in their experience, speed, or processing ability, or in the terrain, that allows them to differentially perceive risk at longer distances, for instance. Our framework does not apply to species that avoid the road surface due to lack of cover or inhospitable surface conditions, or those that are attracted to the road for food or other reasons. These groups face a barrier effect independent of traffic volume. Research examining such nuances will also be useful for management. 


\section{Chapter 3 - Application}

This framework helps to accurately identify barrier effect type (mortality or avoidance), helps interpret roadkill data, facilitates predictions that indicate the urgency of management responses given the category of the affected species and the current or predicted traffic volume (Table 3.1), and helps to identify mitigation options (Table 3.2). Without such a framework that more carefully describes generalized patterns than has been available currently, transportation planners may miss important indications of barrier effects. Low traffic volume roads have been considered benign, but they likely limit populations of some species, especially Nonresponders. The framework presented here suggests mitigation will be needed at lower traffic volumes for Pausers and Nonresponders than most Speeders. Also, if Speeder mortality is unacceptably high, it may be more important to mitigate effects on moderate traffic volume highways than higher traffic roads (Jaeger and Fahrig 2004). If an Avoider species cannot access key habitats, barrier effects can be as lethal as vehicle collisions, yet less obvious. 
Table 3.1. Summary of population-level impacts from traffic based on species' risk response characteristics.

\begin{tabular}{|c|c|c|c|c|}
\hline \multirow{2}{*}{$\begin{array}{l}\text { Risk response } \\
\text { category }\end{array}$} & \multirow{2}{*}{$\begin{array}{c}\text { Species } \\
\text { characteristics }\end{array}$} & \multirow{2}{*}{$\begin{array}{l}\text { Key barrier effects of } \\
\text { traffic volume (TV) } \dagger \\
\text { across risk response } \\
\text { categories }\end{array}$} & \multicolumn{2}{|c|}{$\begin{array}{c}\text { Population-level } \\
\text { impacts due to animal-vehicle } \\
\text { collisions and avoidance }\end{array}$} \\
\hline & & & Initial impacts & $\begin{array}{l}\text { Advanced } \\
\text { impacts }\end{array}$ \\
\hline Nonresponder & $\begin{array}{l}\text { Little sensory } \\
\text { capacity to detect } \\
\text { vehicles OR failure } \\
\text { to interpret vehicles } \\
\text { as threats OR high } \\
\text { motivation to move } \\
\text { despite risk }\end{array}$ & $\begin{array}{l}\text { Mortality risk and } \\
\text { therefore barrier effect } \\
\text { increases as a saturating } \\
\text { hyperbola with } \\
\text { increasing TV until the } \\
\text { barrier is complete }\end{array}$ & $\begin{array}{l}\text { Reduced } \\
\text { population } \\
\text { size due to } \\
\text { direct } \\
\text { mortality }\end{array}$ & $\begin{array}{l}\text { Reduced } \\
\text { population } \\
\text { size, low } \\
\text { genetic } \\
\text { diversity, } \\
\text { inbreeding } \\
\text { depression, and } \\
\text { eventual } \\
\text { extirpation§ }\end{array}$ \\
\hline Pauser & $\begin{array}{l}\text { Primary predator } \\
\text { extirpation§ } \\
\text { avoidance strategy } \\
\text { involves slowing or } \\
\text { immobilization, e.g., } \\
\text { due to armature or } \\
\text { crypsis }\end{array}$ & $\begin{array}{l}\text { Mortality peaks at } \\
\text { moderate TV while } \\
\text { avoidance increases } \\
\text { sigmoidally, together } \\
\text { creating a barrier effect } \\
\text { that quickly increases } \\
\text { with TV and levels off at } \\
\text { moderately high TV }\end{array}$ & $\begin{array}{l}\text { Reduced } \\
\text { population } \\
\text { size due to } \\
\text { direct } \\
\text { mortality; } \\
\text { effects } \\
\text { manifest at low } \\
\text { TV } \\
\end{array}$ & \\
\hline Speeder & $\begin{array}{l}\text { Primary predator } \\
\text { avoidance strategy } \\
\text { is fleeing, evading } \\
\text { predator using } \\
\text { greater speed }\end{array}$ & $\begin{array}{l}\text { High levels of mortality at } \\
\text { moderate TV when } \\
\text { Speeders can no longer } \\
\text { outpace vehicles; barrier } \\
\text { effect is due mainly to } \\
\text { avoidance at higher TV } \\
\text { regardless of speed }\end{array}$ & $\begin{array}{l}\text { Reduced } \\
\text { population } \\
\text { size due to } \\
\text { direct mortality } \\
\text { at low to } \\
\text { moderate TVs; } \\
\text { at high TV, } \\
\text { lowered } \\
\text { fecundity, poor } \\
\text { condition, or } \\
\text { mortality due to } \\
\text { lack of access } \\
\text { to key resources }\end{array}$ & \\
\hline Avoider & $\begin{array}{l}\text { Primary predator } \\
\text { avoidance strategy } \\
\text { is fleeing, evading } \\
\text { predator using } \\
\text { greater speed }\end{array}$ & $\begin{array}{l}\text { Mortality relatively low } \\
\text { and peaks at low TV; } \\
\text { avoidance causes barrier } \\
\text { effect across traffic } \\
\text { volumes }\end{array}$ & $\begin{array}{l}\text { Lowered } \\
\text { fecundity, } \\
\text { poor condition, } \\
\text { or } \\
\text { mortality due to } \\
\text { lack of access } \\
\text { to } \\
\text { critical } \\
\text { resources }\end{array}$ & \\
\hline
\end{tabular}

$\dagger$ The TV at which mortality, avoidance, and the barrier effect peaks differs across populations, but within a category, all populations follow the same basic shapes and trends.

$\$$ Population-level effects will vary with quality of habitat, size of the source population, and the degree to which the barrier effect is due to mortality vs. avoidance.

$\S$ Saccheri et al. 1998. 
Table 3.2. Interpretation of carcass evidence and priority mitigation approaches across traffic volume levels and risk response categories.

\begin{tabular}{|c|c|c|c|c|c|c|}
\hline \multirow{3}{*}{$\begin{array}{l}\text { Risk } \\
\text { response } \\
\text { category }\end{array}$} & \multicolumn{3}{|c|}{$\begin{array}{l}\text { Relative carcass evidence expected } \\
\text { across traffic volumes (TV) } \dagger, \dagger\end{array}$} & \multicolumn{3}{|c|}{ Priority mitigation approach } \\
\hline & \multicolumn{6}{|c|}{ Relative traffic volume $\S$} \\
\hline & Low & Moderate & High & Low & Moderate & Highd \\
\hline 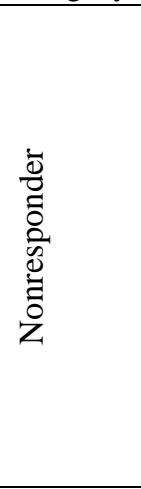 & $\begin{array}{l}\text { Moderate } \\
\text { carcasses } \\
\text { due to few } \\
\text { vehicles; } \\
\text { impacts may } \\
\text { be sustained } \\
\text { over time } \\
\text { when } \\
\text { reproductive } \\
\text { rate exceeds } \\
\text { mortality }\end{array}$ & $\begin{array}{l}\text { More } \\
\text { carcasses } \\
\text { than at low } \\
\text { TV }\end{array}$ & $\begin{array}{l}\text { Many } \\
\text { carcasses } \\
\text { over short } \\
\text { time until } \\
\text { population } \\
\text { size reduces, } \\
\text { then few to } \\
\text { no carcasses }\end{array}$ & $\begin{array}{l}\text { Reduce } \\
\text { mortality by } \\
\text { fencing then } \\
\text { reestablish } \\
\text { connectivity } \\
\text { with Wildlife } \\
\text { Crossing } \\
\text { Structures } \\
\text { (WCS); } \\
\text { Reducing speed } \\
\text { limit\# may be } \\
\text { effective }\end{array}$ & $\begin{array}{l}\text { Where high } \\
\text { mortality is } \\
\text { greater concern } \\
\text { than } \\
\text { connectivity, } \\
\text { install fencing; } \\
\text { where access } \\
\text { to key habitats } \\
\text { limits } \\
\text { population, } \\
\text { fencing and } \\
\text { WCS }\end{array}$ & $\begin{array}{l}\text { Fencing } \\
\text { and } \\
\text { WCS\| }\end{array}$ \\
\hline $\begin{array}{l}\dot{\bar{D}} \\
\stackrel{\Xi}{\tilde{\sigma}}\end{array}$ & $\begin{array}{l}\text { Carcasses } \\
\text { increase } \\
\text { rapidly with } \\
\text { TV, starting } \\
\text { at low TV } \\
\text { as Pausers } \\
\text { exploit } \\
\text { traffic gaps }\end{array}$ & $\begin{array}{l}\text { Carcasses } \\
\text { peak } \\
\text { at moderate } \\
\mathrm{TV} \text { as } \\
\text { animal } \\
\text { pauses in } \\
\text { traffic thus } \\
\text { maximizes } \\
\text { risk }\end{array}$ & $\begin{array}{l}\text { Fewer } \\
\text { carcasses } \\
\text { than at } \\
\text { moderate } \\
\text { TV because } \\
\text { pausing } \\
\text { begins prior } \\
\text { to entering } \\
\text { road }\end{array}$ & $\begin{array}{l}\text { Fencing reduces } \\
\text { mortality } \\
\text { until } \\
\text { connectivity } \\
\text { can be } \\
\text { reestablished } \\
\text { with WCS }\end{array}$ & $\begin{array}{l}\text { Fencing keeps } \\
\text { species off } \\
\text { road during } \\
\text { occasional } \\
\text { traffic gaps to } \\
\text { reduce } \\
\text { mortality, and } \\
\text { WCS restore } \\
\text { connectivity }\end{array}$ & $\begin{array}{l}\text { WCS } \\
\text { restore } \\
\text { access to } \\
\text { key } \\
\text { habitats }\end{array}$ \\
\hline $\begin{array}{l}\dot{\bar{d}} \\
\dot{d} \\
\stackrel{\check{n}}{\text { के }}\end{array}$ & $\begin{array}{l}\text { Few to } \\
\text { moderate } \\
\text { carcasses as } \\
\text { Speeders } \\
\text { exploit } \\
\text { traffic gaps }\end{array}$ & $\begin{array}{l}\text { Most } \\
\text { carcasses } \\
\text { as speed no } \\
\text { longer } \\
\text { suffices to } \\
\text { cross as } \\
\text { gaps } \\
\text { decrease } \\
\end{array}$ & $\begin{array}{l}\text { Fewer } \\
\text { carcasses } \\
\text { as } \\
\text { avoidance } \\
\text { reduces } \\
\text { mortality }\end{array}$ & $\begin{array}{l}\text { Rare species } \\
\text { may need } \\
\text { fencing; } \\
\text { reducing } \\
\text { speed limit to } \\
\text { the animal's } \\
\text { speed may be } \\
\text { effective }\end{array}$ & $\begin{array}{l}\text { WCS restore } \\
\text { connectivity; } \\
\text { simultaneously } \\
\text { install } \\
\text { fencing }\end{array}$ & $\begin{array}{l}\text { Fencing } \\
\text { less } \\
\text { necessary; } \\
\text { WCS } \\
\text { maintain } \\
\text { access to } \\
\text { key } \\
\text { habitats }\end{array}$ \\
\hline $\begin{array}{l}\frac{\dot{0}}{0} \\
\frac{\pi}{0} \\
\frac{3}{4}\end{array}$ & $\begin{array}{l}\text { Few to } \\
\text { moderate } \\
\text { carcasses } \\
\text { before } \\
\text { avoidance } \\
\text { response } \\
\text { begins }\end{array}$ & $\begin{array}{l}\text { Carcasses } \\
\text { reduce as } \\
\text { avoidance } \\
\text { begins }\end{array}$ & $\begin{array}{l}\text { Carcasses } \\
\text { remain few } \\
\text { as } \\
\text { avoidance } \\
\text { continues }\end{array}$ & $\begin{array}{l}\text { WCS imperative } \\
\text { for small } \\
\text { populations } \\
\text { and ones } \\
\text { blocked from } \\
\text { key habitats; } \\
\text { fencing } \\
\text { minimizes } \\
\text { mortality } \dagger \dagger\end{array}$ & $\begin{array}{l}\text { Fencing less } \\
\text { necessary; } \\
\text { WCS maintain } \\
\text { access to key } \\
\text { habitats }\end{array}$ & $\begin{array}{l}\text { Fencing } \\
\text { less } \\
\text { necessary; } \\
\text { WCS } \\
\text { maintain } \\
\text { access to } \\
\text { key } \\
\text { habitats }\end{array}$ \\
\hline
\end{tabular}

$\dagger$ Carcass quantities will vary with quality of habitat, size of the source population, and other factors (see main text). Large populations will produce relatively more carcasses than small populations relative to risk. Carcass quantities will vary for categories until local extirpation occurs.

+ Assuming sufficient population size (see Table 1).

$\S$ Values in table are relative. See Appendix S1 for standardized traffic volume terms (Low Traffic

Volume LT 500 AADT (Average Annual Daily Traffic); Moderate Traffic Volume = AADT between 500 and 4999; High Traffic Volume = AADT between 5000 and 9999). 
If For Very High or Extreme Traffic Volume roads (above 10,000 AADT), fencing is most likely to reduce mortality for terrestrial Nonresponders, and crossing structures are most likely to reduce barrier effects from both mortality and avoidance for all four response categories.

\# Speed limit reductions are unlikely to be effective unless they are lowered to be approximately equal to the animal's speed.

\|Ascensão et al. 2013.

$\dagger \dagger$ Fences may not be advisable, or may need to be marked, where grouse are vulnerable to fence collisions (Wolfe et al. 2009).

Management options to mitigate effects are suggested by understanding the primary barrier effect of each category (Table 3.2). For Nonresponders and Pausers, mortality is the primary barrier effect, whereas for Speeders and Avoiders avoidance is the primary barrier effect. While the management options for all behavior categories mainly include fences and crossing structures, they vary in three key components: priority, siting, and design. Pausers and Nonresponders suffer high levels of mortality across many traffic volumes, so installing fencing is a priority to immediately reduce population-level impacts of vehicles on these species (Jackson and Fahrig 2011). Populations of Speeders in areas of high traffic volumes, and Avoiders at relatively moderate to high traffic volume, conversely have a greater need for reestablishing connectivity because they are limited mostly by the avoidance barrier effect. With regard to siting, passages for Nonresponders and for Pausers will likely be the most effective when located in places of relatively high traffic and good habitat, and more frequently for animals with smaller home ranges (Bissonette and Adair 2008). Avoiders may need passages to be sited where topography decreases the reach of traffic effects, and may need passages installed at sites even with low traffic volume. In real-life applications of these mitigation measures, some solutions for one group or species can increase adverse effects on others. For example, fences may reduce mortality for some species while restricting movement for others. 
Response to predation risk can also inform design and barrier effects of structures and fences as is discussed in Kintsch et al. (2015).

Our framework is valuable not only for determining appropriate mitigation measures but also for diagnosing the problem accurately. Considering risk response along with traffic volume helps reduce the chance of missing or misinterpreting data about barrier effects from mortality and avoidance, and helps identify the type of risk a population is experiencing given current traffic volume (Tables 3.1 and 3.2). The nature of the increasing barrier varies across the categories, with Nonresponders experiencing direct mortality across traffic volumes, and the other categories switching from mortalityinduced to avoidance-induced barriers (Figure 3.1, Table 3.2). Behavioral responses to risk can be used to determine effects of traffic on wildlife populations rather than attempting to interpret the problem from roadkill data. Interpreting roadkill data can be misleading because few carcasses can indicate either no problem or an advanced barrier effect resulting from near extirpation (Eberhardt et al. 2013), strong avoidance, or displacement. Genetic differentiation may provide evidence of an advanced barrier effect from avoidance when carcasses are rare, and such evidence may support or refute our framework.

Few mortalities will occur independent of traffic volume after the onset of avoidance behavior in Pausers, Speeders, and Avoiders, or if population abundance is low for all categories (Fahrig et al. 1995). For example, Rudolph et al. (1999) noted that some snake 
species may be so susceptible to vehicle-caused mortality that roads can remove nearly all individuals in an area. Such extirpation, consistent with the expected result of the behavior of Nonresponders or Pausers, prevents evidence of a correlation between traffic volume and mortality. In response to TV increasing beyond a daily average of 8000 vehicles, mule deer, a Speeder, rerouted their migration, locally reducing collisions with vehicles but causing the deer to parallel the highway for $45 \mathrm{~km}$ until they reach an area with lower TV (Coe et al. 2015).

Resource managers could fail to foresee an imminent threshold of population risk if risk response behavior is not used, or if the range of traffic volume investigated is too narrow, or traffic volume categories too broad to detect responses. For investigations on Nonresponder, Pauser and Avoider response categories, precise traffic volume is needed because small numbers of vehicles per day can affect these species. For example, European toads (Bufo bufo) experienced a $30 \%$ mortality rate at an equivalent of 240 ADT (van Gelder 1973). Our conceptual model suggests that the range of traffic volume that needs to be measured is species-specific; therefore, the point at which the road becomes a complete barrier varies even within one response category. For rare species, research to indicate the exact shape of the response curves as well as likely thresholds could be of critical importance in developing mitigation measures to reduce barrier effects. To determine the road threats to a species and how to best mitigate them, both the risk response category and the animal's speed are needed as they both affect the shape of the animal's response to traffic volume (Figure 3.1, Hels and Buchwald 2001, 
van Langevelde and Jaarsma 2004). In fact, 1000 to 12,000 ADT must be measured to detect changes in the behavioral response to traffic of most large Speeders (Seiler and Helldin 2006, Gagnon et al. 2007). Pooling data for even closely related species in different response categories may mask traffic volume effects.

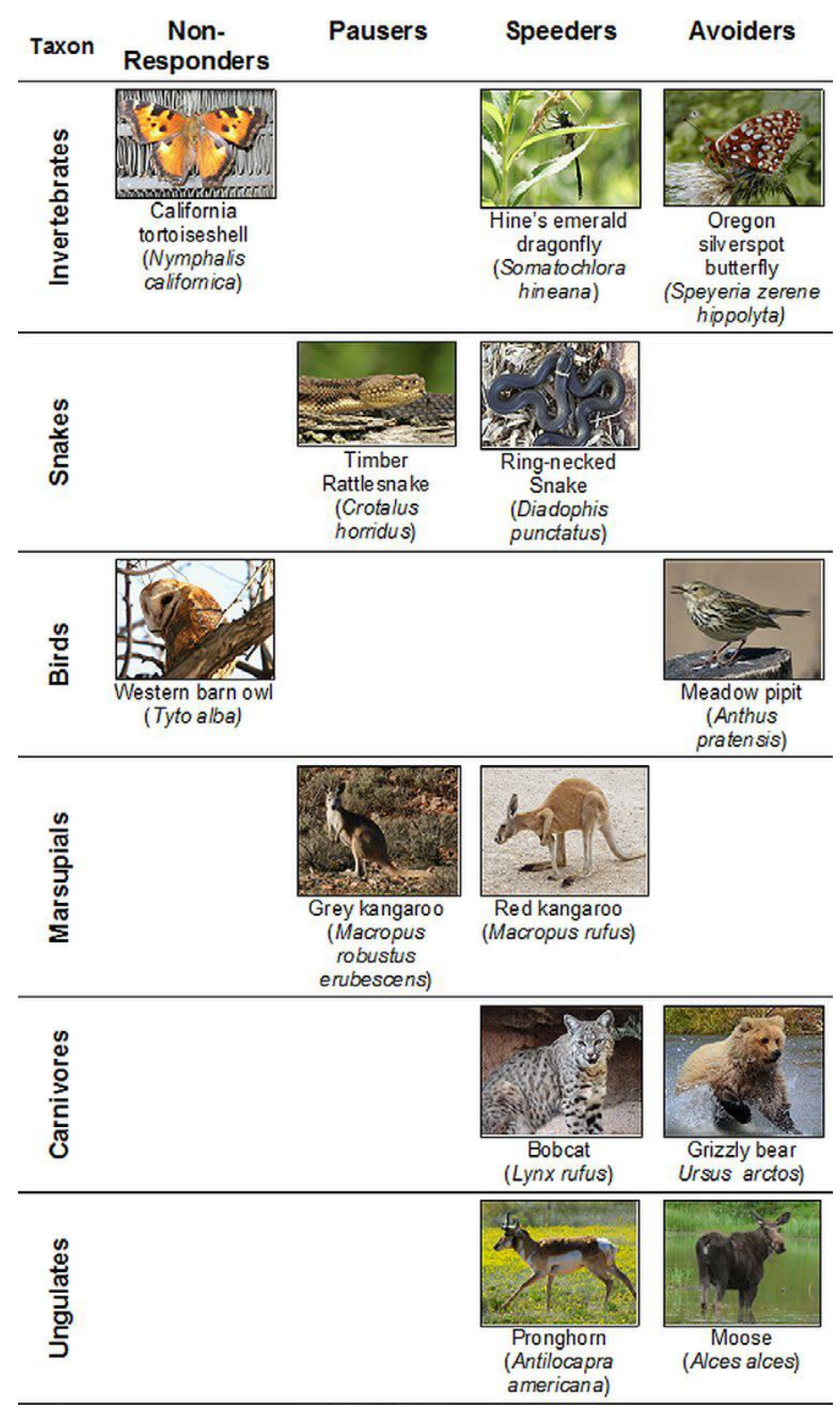

Figure 3.3: Diverse behavioral response to traffic by closely related taxa. Species response to traffic is driven behaviorally rather than taxonomically, and closely related species can fall into different behavioral response categories. 
Photo sources: ring-necked snake, timber rattlesnake, western barn owl, bobcat, moose from USDA Forest Service. Meadow pipit courtesy of Ruud Foppen, taken by Menno Hornman. Gray and red kangaroos courtesy Enhua Lee. Grizzly bear taken by K. Mueller and Hine's emerald dragonfly from U.S. Fish and Wildlife Service. Pronghorn and silverspot butterfly taken by Steve Hillebrand.

This framework encompasses many species and highlights the important concepts that species do not respond to traffic volume linearly or along taxonomic lines (Fig. 3). Child et al. (1991) argued that biologists may not discover appropriate solutions to vehiclecaused mortality to moose without a research focus on avoidance-flight responses. As in most ecological investigations, behavioral responses in the real world are complex and a framework that includes animal behavior, such as the one presented here, is therefore crucial to understanding the effects of highways on wildlife. Fortunately, effective mitigation measures such as wildlife crossing structures are becoming available to reduce barrier effects across highways (Gagnon et al. 2007). Our proposed framework can advance the understanding of wildlife and road interactions. We encourage nuanced investigations that evaluate how traffic volume affects behavior and connectivity, and evaluate the effectiveness of management options given the combination of traffic volume and the response of local populations to traffic. 


\section{Chapter 3 - References}

Alexander, S. M., N. M. Waters, and P. C. Paquet. 2005. Traffic volume and highway permeability for a mammalian community in the Canadian Rocky Mountains. Canadian Geographer/Le Géographe Canadien 49:321-331.

Andrews, K. M., J. W. Gibbons, and T. Reeder. 2005. How do highways influence snake movement? Behavioral responses to roads and vehicles. Copeia 2005:772-782.

Aresco, M. J. 2005. Mitigation measures to reduce highway mortality of turtles and other herpetofauna at a north Florida lake. Journal of Wildlife Management 69:549-560.

Ascensão, F., A. Clevenger, M. Santos-Reis, P. Urbano, and N. Jackson. 2013. Wildlifevehicle collision mitigation: Is partial fencing the answer? An agent-based model approach. Ecological Modelling 257:36-43.

Bissonette, J. A., and W. Adair. 2008. Restoring habitat permeability to roaded landscapes with isometrically-scaled wildlife crossings. Biological Conservation $141: 482-488$. 
Bissonette, J. A., and C. A. Kassar. 2008. Locations of deer-vehicle collisions are unrelated to traffic volume or posted speed limit. Human-Wildlife Interactions 2:122-130.

Bouchard, J., A. T. Ford, F. E. Eigenbrod, and L. Fahrig. 2009. Behavioral responses of northern leopard frogs (Rana pipiens) to roads and traffic: implications for population persistence. Ecology and Society 14:23.

Case, R. M. 1978. Interstate highway road killed animals: a data source for biologists. Wildlife Society Bulletin 6:8-13.

Child, K. N., S. P. Barry, and D. A. Aitken. 1991. Moose mortality on highways and railways in British Columbia. Alces 27:41-49.

Clark, R. W., W. S. Brown, R. Stechert, and K. R. Zamudio. 2010. Roads, interrupted dispersal, and genetic diversity in timber rattlesnakes. Conservation Biology 24:1059-1069.

Clevenger, A. P., and M. P. Huijser. 2011. Wildlife crossing structure handbook: design and evaluation in North America. FHWA-CFL/TD-11-003. US DOT, Federal Highway Administration, Lakewood, Colorado, USA. 
Coe, P. K., R. M. Nielson, D. H. Jackson, J. B. Cupples, N. E. Seidel, B. K. Johnson, S. C. Gregory, G. A. Bjornstrom, A. N. Larkins, and D. A. Speten. 2015. Identifying migration corridors of mule deer threatened by highway development. Wildlife Society Bulletin 39:256-267.

Colino-Rabanal, V., and M. Lizana. 2012. Herpetofauna and roads: a review. Basic and Applied Herpetology 26:5-31.

Cook, T. C., and D. T. Blumstein. 2013. The omnivore's dilemma: diet explains variation in vulnerability to vehicle collision mortality. Biological Conservation 167:310-315.

Dennis, R. 1986. Motorways and cross-movements. An insect's 'mental map' of the M56 in Cheshire. Bulletin of the Amateur Entomologists' Society 45:228-243.

Dickson, B. G., J. S. Jenness, and P. Beier. 2005. Influence of vegetation, topography, and roads on cougar movement in southern California. Journal of Wildlife Management 69:264-276.

Dill, L. M. 1974. The escape response of the zebra danio (Brachydanio rerio) I. The stimulus for escape. Animal Behaviour 22:711-722. 
Dodd, N. L., J. W. Gagnon, S. Boe, and R. E. Schweinsburg. 2005. Characteristics of elkvehicle collisions and comparison to GPS-determined highway crossing patterns. Pages 461-477 in C. L. Irwin, P. Garrett, and K. P. McDermott, editors. Proceedings of the 2005 International Conference on Ecology and Transportation, Raleigh, NC, USA: Center for Transportation and the Environment. North Carolina State University, Raleigh, North Carolina, USA.

Dodd, N. L., J. W. Gagnon, S. Sprague, S. Boe, and R. E. Schweinsburg. 2009. Assessment of pronghorn movements and strategies to promote highway permeability - U.S. Highway 89. FHWA-AZ-10-619 Final project report 619, Arizona Transportation Research Center, Arizona Department of Transportation, Phoenix, Arizona, USA.

Eberhardt, E., S. Mitchell, and L. Fahrig. 2013. Road kill hotspots do not effectively indicate mitigation locations when past road kill has depressed populations. Journal of Wildlife Management 77:1353-1359.

Einarsen, A. S.. 1948. The pronghorn antelope: and its management. Wildlife Management Institute, Washington, D.C., USA.

Erickson, W. P., G. D. Johnson, and D. P. Young Jr. 2005. A summary and comparison of bird mortality from anthropogenic causes with an emphasis on collisions. Pages 
1029-1042 in C. John Ralph, and T. D. Rich, editors. Bird Conservation Implementation and Integration in the Americas: Proceedings of the Third International Partners in Flight Conference, Asilomar, California, March 20-24, 2002. PSW-GTR-191. USDA Forest Service, Pacific Southwest Research Station, Albany, California, USA.

Fahrig, L., and T. Rytwinski. 2009. Effects of roads on animal abundance: an empirical review and synthesis. Ecology and Society 14:21.

Fahrig, L., J. H. Pedlar, S. E. Pope, P. D. Taylor, and J. F. Wegner. 1995. Effect of road traffic on amphibian density. Biological Conservation 73:177-182.

Falcocchio, J. C., and H. S. Levinson. 2015. Road traffic congestion: a concise guide. Springer Tracts on Transportation and Traffic No. 7. Springer International Publishing, Cham, Switzerland.

Forman, R. T., et al. 2003. Road ecology: science and solutions. Island Press, Washington, D.C., USA.

Frid, A., and L. M. Dill. 2002. Human-caused disturbance stimuli as a form of predation risk. Conservation Ecology 6:11. 
Gagnon, J. W., T. C. Theimer, S. Boe, N. L. Dodd, and R. E. Schweinsburg. 2007. Traffic volume alters elk distribution and highway crossings in Arizona. Journal of Wildlife Management 71:2318-2323. Gehrt, S. D. 2002. Evaluation of spotlight and road-kill surveys as indicators of local raccoon abundance. Wildlife Society Bulletin 30:449-456.

Geist, V. 1981. Behavior: adaptive strategies in mule deer. Pages 157-233 in O. C. Wallmo, editor. Mule and black-tailed deer of North America. University of Nebraska Press, Lincoln, Nebraska, USA.

van Gelder, J. J. 1973. A quantitative approach to the mortality resulting from traffic in a population of Bufo bufo L. Oecologia 13:93-95.

Grilo, C., J. Sousa, F. Ascensão, H. Matos, I. Leitão, P. Pinheiro, M. Costa, J. Bernardo, D. Reto, and R. Lourenço. 2012. Individual spatial responses towards roads: implications for mortality risk. PLoS One 7:e43811.

Grilo, C., D. Reto, J. Filipe, F. Ascensão, and E. Revilla. 2014. Understanding the mechanisms behind road effects: linking occurrence with road mortality in owls. Animal Conservation 17:555-564. 
Helldin, J.-O., A. Seiler, and M. Olsson. 2010. Vägar och järnvägar: barriärer i landskapet. Triekol Rapport CBM Skriftserie 42. Centrum för Biologisk Mångfald, Uppsala, Sweden. http://media.triekol.se/2013/10/Triekol-CBM-skrift-42.pdf

Hels, T., and E. Buchwald. 2001. The effect of road kills on amphibian populations. Biological Conservation 99:331-340.

Hovick, T. J., R. D. Elmore, D. K. Dahlgren, S. D. Fuhlendorf, and D. M. Engle. 2014. Evidence of negative effects of anthropogenic structures on wildlife: a review of grouse survival and behaviour. Journal of Applied Ecology 51:1680-1689.

Huijser, M. P., P. T. McGowen, J. Fuller, A. Hardy, A. Kociolek, A. P. Clevenger, D. Smith, and R. Ament. 2008. Wildlife-vehicle collision reduction study: Report to Congress. FHWA-HRT-08-034. Federal Highway Administration, McLean, Virginia, USA.

Inbar, M., and R. T. Mayer. 1999. Spatio-temporal trends in armadillo diurnal activity and road-kills in central Florida. Wildlife Society Bulletin 27:865-872.

Iuell, B., et al., editors. 2003. Wildlife and traffic: a European handbook for identifying conflicts and designing solutions. Prepared by Cost 341 - Habitat fragmentation due to transportation infrastructure. Ministry of Transport, Public Works and Water 
Management, Road and Hydraulic Engineering division, Delft, The Netherlands. http://www.iene.info/wp-content/uploads/COST341_Handbook.pdf

Jackson, N. D., and L. Fahrig. 2011. Relative effects of road mortality and decreased connectivity on population genetic diversity. Biological Conservation 144:31433148.

Jacobson, S. L., L. L. Bliss-Ketchum, C. E. de Rivera, and W. P. Smith. 2016. A behavior-based framework for assessing barrier effects to wildlife from vehicle traffic volume. Ecosphere 7(4):e01345. 10.1002/ecs2.1345

Jacobson, S., de Rivera C., K. Armstrong, R. Aaby, and N. Jones. 2010. Rapid assessment of 2008-2012 highway development projects in Region 6: threats and opportunities to terrestrial wildlife resources. Report. USDA Forest Service, Region 6 (Oregon and Washington) Portland, Oregon, USA.

Jaeger, J. A., and L. Fahrig. 2004. Effects of road fencing on population persistence. Conservation Biology 18:1651-1657.

Joveniaux, A. 1985. Influence de la mise en service d'une autoroute sur la faune sauvage: étude de mortalité animale sur l'autoroute A36, quatre années de suivi. Pages 211228 in J.-M. Bernard, M. Lansiart, C. Kempf, and M. Tille, editors. Proceedings of 
the Highway and Wildlife Relationships Symposium, Strasbourg, France, June 5-7, 1985. Council of Europe, Colmar, France.

Kerth, G., and M. Melber. 2009. Species-specific barrier effects of a motorway on the habitat use of two threatened forest-living bat species. Biological Conservation 142:270-279.

Kintsch, J., S. Jacobson, and P. Cramer. 2015. The Wildlife Crossing Guilds decision framework: A behavior-based approach to designing effective wildlife crossing structures. Proceedings of the 2015 International Conference on Ecology and Transportation. Raleigh, North Carolina, USA. http://www.icoet.net/ICOET_2015/program-proceedings.asp

Langley, W. M., H. W. Lipps, and J. F. Theis. 1989. Responses of Kansas motorists to snake models on a rural highway. Transactions of the Kansas Academy of Science 1903:43-48.

Laurian, C., C. Dussault, J. P. Ouellet, R. Courtois, M. Poulin, and L. Breton. 2008. Behavior of moose relative to a road network. Journal of Wildlife Management 72:1550-1557. 
Lee, E., D. Croft, and D. Ramp. 2010. 26 Flight response as a causative factor in kangaroo-vehicle collisions. Macropods: the Biology of Kangaroos, Wallabies, and Rat-kangaroos. CSIRO, Collingwood, Australia

Lesiński, G. 2007. Bat road casualties and factors determining their number. Mammalia $71: 138-142$.

Lewis, J. S., J. L. Rachlow, J. S. Horne, E. O. Garton, W. L. Wakkinen, J. Hayden, and P. Zager. 2011. Identifying habitat characteristics to predict highway crossing areas for black bears within a human-modified landscape. Landscape and Urban Planning 101:99-107.

Lian, X., T. Zhang, Y. Cao, J. Su, and S. Thirgood. 2011. Road proximity and traffic flow perceived as potential predation risks: evidence from the Tibetan antelope in the Kekexili National Nature Reserve, China. Wildlife Research 38:141-146.

Lima, S. L., B. F. Blackwell, T. L. DeVault, and E. Fernández-Juricic. 2015. Animal reactions to oncoming vehicles: a conceptual review. Biological Reviews 90:60-76.

Lovallo, M. J., and E. M. Anderson. 1996. Bobcat movements and home ranges relative to roads in Wisconsin. Wildlife Society Bulletin 24:71-76. 
Mace, R. D., J. S. Waller, T. L. Manley, L. J. Lyon, and H. Zuuring. 1996. Relationships among grizzly bears, roads and habitat in the Swan Mountains Montana. Journal of Applied Ecology 33:1395-1404.

Mazerolle, M. J., M. Huot, and M. Gravel. 2005. Behavior of amphibians on the road in response to car traffic. Herpetologica 61:380-388.

McCown, J. W., P. Kubilis, T. H. Eason, and B. K. Scheick. 2009. Effect of traffic volume on American black bears in central Florida, USA. Ursus 20:39-46.

Meek, R. 2012. Patterns of amphibian road-kills in the Vendée region of western France. Herpetological Journal 22:51-58.

Müller, S., and G. Berthoud. 1997. Fauna/traffic safety manual for civil engineers. LAVOC Lausanne: Ecole Polytechnique Federale de Lausanne, Switzerland.

Ng, S. J., J. W. Dole, R. M. Sauvajot, S. P. Riley, and T. J. Valone. 2004. Use of highway undercrossings by wildlife in southern California. Biological Conservation 115:499507.

Patrick, D. A., and J. P. Gibbs. 2010. Population structure and movements of freshwater turtles across a road-density gradient. Landscape Ecology 25:791-801. 
Räty, M. 1979. Effect of highway traffic on tetraonid densities. Ornis Fennica 56:169170.

Reijnen, R., R. Foppen, and H. Meeuwsen. 1996. The effects of traffic on the density of breeding birds in Dutch agricultural grasslands. Biological Conservation 75:255260.

Rudolph, D. C., S. J. Burgdorf, R. N. Conner, and R. R. Schaefer. 1999. Preliminary evaluation of the impact of roads and associated vehicular traffic on snake populations in eastern Texas. Pages 129-136 in G. L. Evink, P. Garrett, and D. Ziegler, editors. Proceedings of the International Conference on Wildlife Ecology and Transportation. Florida Department of Transportation, Tallahassee, Florida, USA. Fl-ER-73-99.

Rytwinski, T., and L. Fahrig. 2012. Do species life history traits explain population responses to roads? A meta-analysis. Biological Conservation 147:87-98.

Saccheri, I., M. Kuussaari, M. Kankare, P. Vikman, W. Fortelius, and I. Hanski. 1998. Inbreeding and extinction in a butterfly metapopulation. Nature 392:491-494. 
Seiler, A. 2005. Predicting locations of moose-vehicle collisions in Sweden. Journal of Applied Ecology 42:371-382.

Seiler, A., and J.-O. Helldin. 2006. Mortality in wildlife due to transportation. Pages 165190 in J. Davenport, and J. L. Davenport, editors. The ecology of transportation: managing mobility for the environment. Kluwer, The Netherlands. http://www.wildlifeandtraffic.se/en/Reports_files/Seiler\%26Helldin2006compl.pdf

Soluk, D. A., D. S. Zercher, and A. M. Worthington. 2011. Influence of roadways on patterns of mortality and flight behavior of adult dragonflies near wetland areas. Biological Conservation 144:1638-1643.

Stankowich, T., and D. T. Blumstein. 2005. Fear in animals: a meta-analysis and review of risk assessment. Proceedings of the Royal Society Biological Sciences Series B $272: 2627-2634$.

van Langevelde, F., and C. F. Jaarsma. 2004. Using traffic flow theory to model traffic mortality in mammals. Landscape Ecology 19:895-907.

Waller, J. S., and C. Servheen. 2005. Effects of transportation infrastructure on grizzly bears in northwestern Montana. Journal of Wildlife Management 69:985-1000. 
Wolfe, D. H., M. A. Patten, and S. K. Sherrod. 2009. Reducing grouse collision mortality by marking fences. Ecological Restoration 27:141-143.

Zurcher, A. A., D. W. Sparks, and V. J. Bennett. 2010. Why the bat did not cross the road? Acta Chiropterologica 12:337-340. 
Chapter 4 - The Effect of Artificial Light on Wildlife Use of a Passage Structure

This work has been previously published.

Citation:

L.L. Bliss-Ketchum, C. E. de Rivera, B. C. Turner, D. M. Weisbaum. 2016. The Effect of Artificial Light on Wildlife Use of a Passage Structure. Biological Conservation 199 (2016) 25-28

Chapter 4 - Introduction

Artificial light is used pervasively at night in conjunction with the built environment, creating 'ecological light pollution' (Longcore and Rich, 2004) that can alter behavior and physiology and disrupt habitat connectivity (Bennie et al., 2014, Gaston et al., 2014, 2015 and Rotics et al., 2011). Light provides key information to organisms by enabling their vision, regulating circadian cycles and phenological events (Gaston et al., 2012). Even so, few studies have investigated the effects of artificial light on movement patterns, especially in an experimental setting, for terrestrial vertebrate communities (Gaston et al., 2015, and Longcore and Rich, 2004). Such information is needed to inform mitigation of habitat fragmentation in the face of expanding urbanization. Artificial light can affect foraging, reproduction, communication and other critical behaviors (Bird et al., 2004, Kempenaers et al., 2010, Longcore and Rich, 2004, and Rotics et al., 2011). For example, it disrupts migratory behavior in birds, sea turtles, bats, and other species (Sella et al., 2006, Rich and Longcore, 2005, and Rodrigues et al., 2012). It also alters movement and foraging patterns, creating an underexploited 
temporal niche that may promote invasion by less light sensitive species (Rotics et al., 2011). Responses to artificial light vary among species, however, ranging from increased orientation (van Langevelde et al., 2011) to disorientation (Riley et al., 2013) and from attraction (Polak et al., 2011) to avoidance of light (Beier, 1995, and Bird et al., 2004). Organisms varywidely in their sensitivities to light and this sensitivity is highly dependent on design and size of the animal's eye (Gaston et al., 2012). Mammals in particular are theorized to be most affected behaviorally by artificial light because of the physical structure of the mammalian eye (Davies et al., 2013). Thus, some species will be more affected by certain types, intensities, and directionality of light than others. Wildlife populations depend on the ability to traverse habitats, but for some species artificial lighting impacts these movements, fragmenting habitats and disrupting connectivity (Beier, 1995, Coelho et al., 2012, Grigione and Mrykalo, 2004, and Threlfall et al., 2013). Barriers to connectivity on the landscape, especially roads, can isolate populations, reducing their ability to maintain genetic diversity, increasing their susceptibility to disturbance and disease, and limiting their access to resources (Clark et al., 2010, Dixon et al., 2006, and Shepard et al., 2008). Many of the barrier effects of roads may be at least partially mitigated by under- or over-road passages, which increase safe animal movement across roads (Clevenger et al., 2001). Given the cost associated with constructing crossing structures, it is important that we ensure they are as effective as possible. Increasingly, crossing structures are proposed for use by foot or bike traffic as well as for wildlife. Structures built for human use typically include artificial light for safety. However, studies have yet to examine the effect of artificial light on wildlife 
passage use. Examining wildlife response to artificial light in the context of an underroad passage allows for efficient sampling and separates out the effect of illumination from traffic volume and many other barrier effects of roads. Hence, examining artificial light in passages informs the larger question about the role of artificial light on connectivity as well as the specifics about passage structures. We conducted an experimental study on the effect of light pollution on animal usage of an under-road passage structure in an urbanizing environment. This study aims to determine the effect of artificial light on wildlife use of passage structures by investigating if the presence of light influences use of a crossing structure by species in the local community of terrestrial vertebrates. We hypothesized that the presence of artificial light would decrease use of an under-road crossing structure especially for mammals, and that higher intensity light would elicit a greater response. 
Chapter 4 - Methods

\section{$\underline{\text { Site description }}$}

We conducted the light-level experiment in a wetland portion of the Boeckman Road Extension, which was recently constructed (2006-2008) in Wilsonville, Oregon, USA (45.316245, -122.783933). Wilsonville lies at the edge of Portland's urban growth boundary. The Extension spans diverse land uses including wetlands, forests, farms, industrial land, and housing. Maintaining animal passage was an important goal of this Extension project because this area was deemed important for habitat connectivity between the Willamette River and the Rock Creek Unit of the Tualatin River National Wildlife Refuge for the area's diverse animal community.

\section{$\underline{\text { Passage structure \& light treatment design }}$}

A variety of species cross under the structure we used for this experiment, a bridge at the Boeckman site (de Rivera and Bliss-Ketchum, 2009). The bridge ranges from 1.5 to 2.7 $\mathrm{m}$ tall, spans $122 \mathrm{~m}$, and is $18 \mathrm{~m}$ wide. We used only a portion of the bridge at its east end, three consecutive $25 \mathrm{~m}$ long sections separated by $\sim 1 \mathrm{~m}$ of support pylons topped by concrete supports perpendicular to the span. We established a sand pad (0.6mwide, 0.025mdeep, 73mlong) spanning the midline of the three sections for wildlife tracking (Fig. A1c). The terrain leading up to the bridge is similar across sections. We added lights under the bridge in the three sections used in our experiment. Light treatments were rotated weekly (Table A1) and consisted of High (172 1x), Low (54 1x), or Zero (b1 1x) 
light level treatments. Street lighting standards adopted by Portland, Oregon list $32 \mathrm{~lx}$ as the average acceptable horizontal illumination (Portland, 1984); however, measurements of street and parking garage lighting ranged from 65 to $646 \mathrm{~lx}$ (Bliss-Ketchum, unpublished data). During these treatments, lights were on for $24 \mathrm{~h}$ a day to avoid startling, temporary blindness, or other effects of sudden illumination from the lights turning on in the evening. Before the experiment started each year and at the end of each 3-week experimental light-manipulation period,we turned off the lights in all sections for aweek-long unlit reference period (herein referred to as "Reference"). This patternwas repeated throughout the 18 weeks of the study period for a total of 13 samples each of the High, Low and Zero treatments and 15 samples of the Reference period. To provide artificial light to the experimental area under the bridge, three Lithonia Lighting 2-Light Wall-Mount Outdoor Floodlight housings (Model \#OFTH300PR120PWHM12) were mounted to the ceiling in each of the three sections, equally spaced across the span of each section. Each light housing supported two halogen flood lights. For the High light treatment, six Phillips 100 watt 130 V halogen PAR38 flood light bulbs (1750 lm,warmth $2730 \mathrm{~K}$ ) were used; for the Low treatment six, Philips 45 watt 120-130 V halogen PAR38 Flood light bulbs were used (470 lm, warmth $3000 \mathrm{~K}$ ). All bulbs in the given bridge section were removed for the Zero treatment and all bulbs in all sections were removed during the Reference. All treatmentswere exposed to ambient lighting, including from moonlight and shielded streetlights on the roadway above. Lights were directed at the sand tracking pad. An Extech Instruments Foot-Candle/Lux Light Meter model 401,025 with a minimum resolution of $1 \mathrm{~lx}$ was used to measure light levels in each 
section and to verify that artificial light from one section was not detectable across the boundary between sections. It should be noted that a full moon on a clear night can produce illumination ranging from 0.27 to $1.0 \mathrm{~lx}$ and so this light meter would mostly likely not be able to detect illumination from moonlight in the passages (Bunning and Moser, 1969). At the end of each week, wildlife track data were recorded to determine use by terrestrial vertebrates. Datawere collected August-October 2011 and July through October 2012, for a total of 18weekswhenwater levels were low enough to collect sand track data (Table A1). We collected data once per week to minimize our presence; our pilot data showed this week-long interval was suitable for detecting all tracks in summer, the dry season. Tracks were identified in the field using Sheldon (1997) track identification guide. Tracks were measured and photographed for later identification if the identity of the species was in question. We consider a set of footprints leading across the pad in one direction as a track. After all sand tracks were recorded, the sand tracking beds were re-graded. Then, the light treatments were rotated or, in the case of a Reference period, all lights were removed.

\section{$\underline{\text { Data analysis }}$}

Data collected during Reference treatments were compared to the Zero light treatments for each of the nine species that created at least 30 tracks. Ifmore (N95\% CI) trackswere left during the Reference period than during the Zero treatment we concluded that the species avoided the bridge undercrossing during light treatments and the bridge sections 
were not functioning independently; if, however, the number of tracks was similar between the Reference periods and Zero treatments, we also analyzed the effect of light on usage within the bridge sections. Species detections were analyzed for eight of the nine most commonly detected species (all but deer) using Generalized Linear Models (GLM) and a quasi-Poisson error distribution. These analyses examined the effects of light level, passage section, year, week nested within year, and average moon phase for the week on species detection. We used diagnostic plots to ensure the data met the assumptions of the statistical tests. Analyses were conducted using R statistical software (version 2.15.2, R Development Core Team, 2012). 
Chapter 4 - Results

Track data documented 23 species and over 1500 tracks. Detections of individual species varied from a minimum of one to a maximum of 459 tracks during the study. The crepuscular Columbia black-tailed deer (Odocoileus hemionus columbianus) showed sensitivity to even nearby artificial light, crossing much less even in the Zero level treatment $(4.15 \pm 3.08$, Mean $\pm 95 \% \mathrm{CI})$ than in the Reference period $(14.2 \pm 7.3)$ when all under-passage lights were off (Figure 4.1).

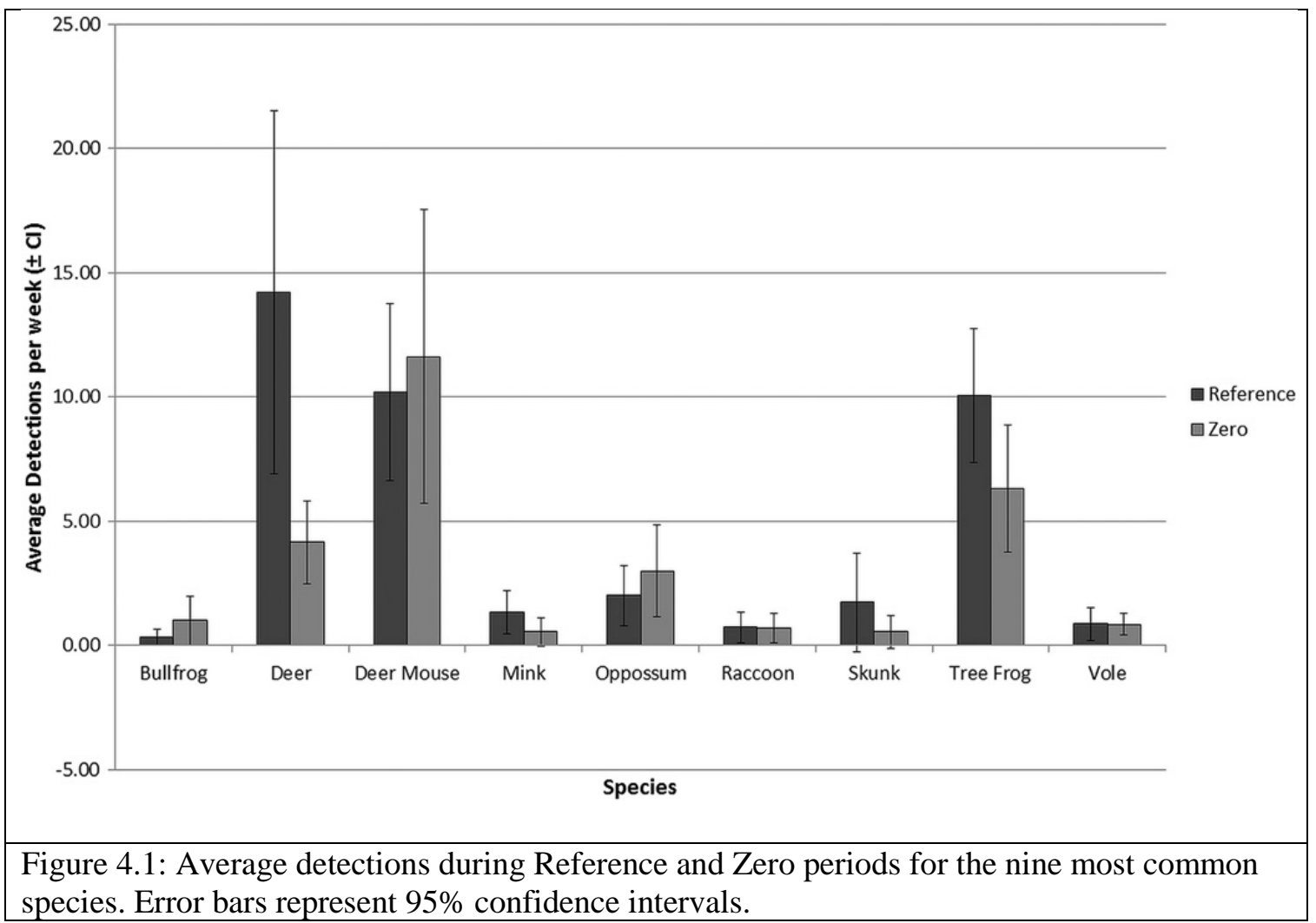


Deer mouse (Peromyscus maniculatus) crossings also showed sensitivity to light with significantly more crossings in the Zero treatment $(11.62 \pm 5.91)$ than lit sections (Low: 1.0 \pm 1.09 ; High: $0.23 \pm 0.33$; GLM: Low vs. Zero: $\mathrm{t}=-0.433$, p b 0.001; High vs. Zero: $\mathrm{t}$ $=-3.24, \mathrm{p} \mathrm{b} 0.001$; Fig. 2; Table A2). Similarly, opossum (Didelphis virginiana) tracks were significantly more numerous in Zero $(3.0 \pm 1.87)$ than High treatments $(1.08 \pm 0.81$; $\mathrm{t}=-2.46, \mathrm{p}=0.02)$. No other species left significantly more tracks in Zero than lit sections, though the number of tracks left by Bullfrogs (Lithobates catesbeianus) was affected by temporal and spatial factors (Figure 4.2).

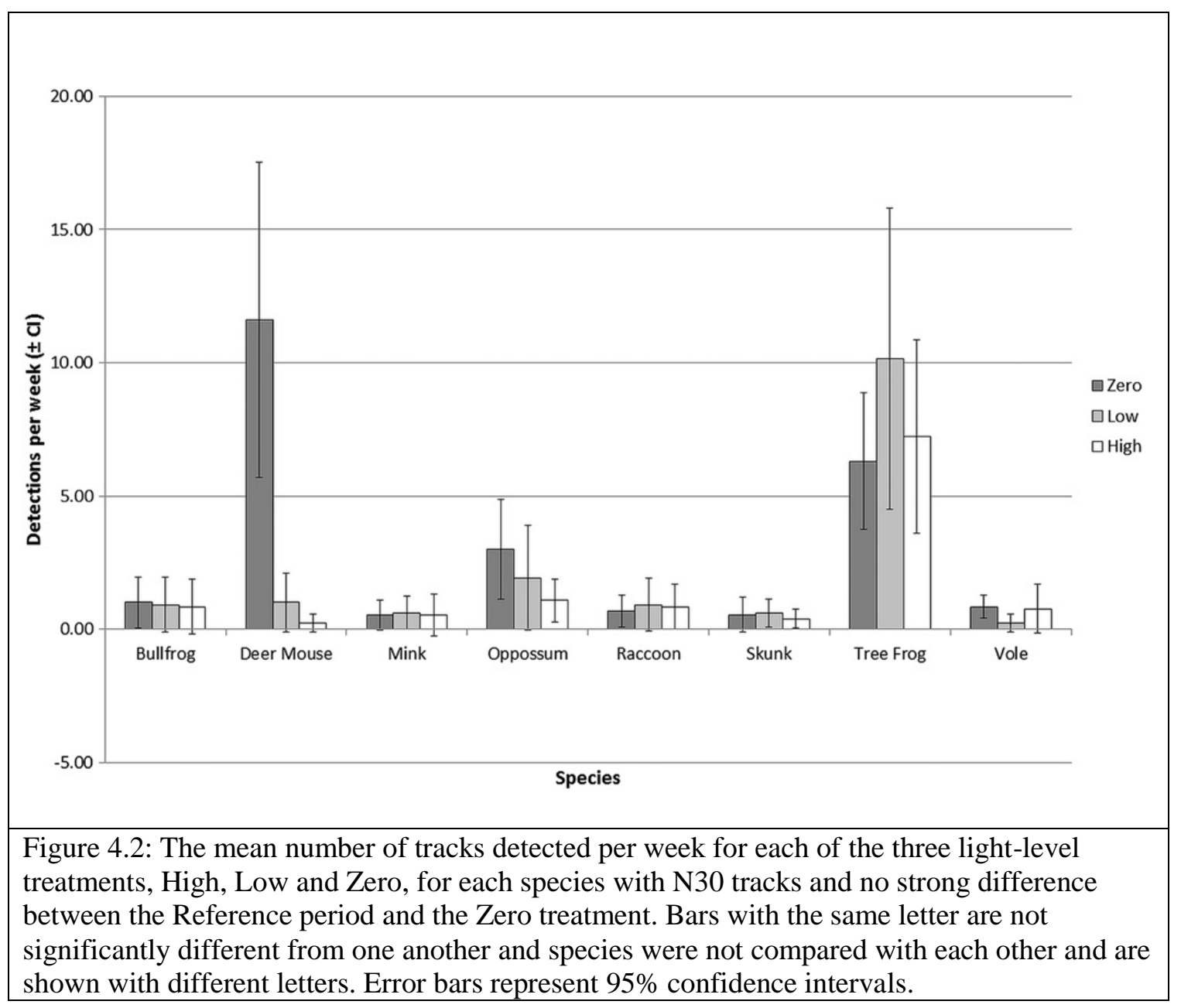




\section{Chapter 4 - Discussion}

The current presence and spread of ecological light pollution may be creating a partial “species filter" preventing habitat connectivity of species that are negatively influenced by light, but maintaining connectivity for those more tolerant of artificial light. Our experiment showed that species responses to artificial light were variable. Use of the undercrossing decreased and therefore habitat connectivity was disrupted in the presence of artificial light for three species. In contrast, six other species showed no obvious light avoidance. While light did not affect use of the under-road passage structure for a majority of the terrestrial vertebrate species, habitat connectivity was disrupted by the presence of artificial light for Columbia black-tailed deer (O. hemionus columbianus), deer mice (P. maniculatus), and opossum (D. virginiana). Changes in use of the crossing structures by deer are of particular importance given a key objective of such structures is preventing animal-vehicle collisions with large animals that are a safety concern for motorists. Deer crossed through the passage sections much less when some sections contained light than when lights were off in all sections. The potential effects of this avoidance response include reduced connectivity and re-routing over the road, risking collision with vehicles. The observed strong effect of light on deer mice could greatly reduce habitat connectivity across the road when the main option for movement is over a well-lit road or through a lit passage. Anecdotally, camera traps caught predation by cats on mice in lit passages, perhaps offering an explanation for why mice typically avoided well-lit crossings. Because of their high fertility and the likelihood that some mice in the 
extensive population can cross the road in some areas, genetic connectivity likely can be maintained for deer mice as can a rescue effect if well-lit passages and roads create a metapopulation structure.

Organisms averse to artificial light but with lower population replacement rates, may suffer genetic differentiation across the road and decreased population size from fragmentation and vehicle collision risk in darker stretches (Clark et al., 2010, Steen et al., 2006, and Shepard et al., 2008). As opossum only slightly decreased use of passages in low light, they would be less likely to suffer strong fragmentation effects under many lighting scenarios but may preferentially cross over roads rather than through lit passages. The lack of response to artificial light seen in the Northern raccoon (Procyon lotor), Pacific tree frog (Pseudacris regilla) and four of the other observed species could be a common trait of animals that use urban areas. Studies have referred to artificial light as a new nocturnal niche, the light night niche (Henderson and Powell, 2001, and Rotics et al., 2011). This temporal niche is less attractive to some species and, conversely, can promote usage of an area by species that do not avoid lit areas, like raccoons (Randa and Yunger, 2006). We do not expect strong population-level effects from lighting for these species but the partial filter allowing these species but not others such as the deer mice through could have consequences to their populations due to shifts in community composition.

These results could help inform management. Structures that also are meant for human use could have portions left unlit or could include a push button system that would turn 
lights on only as a person passes through. Building on research by Spoelstra et al. (2015), spectra may also be able to be manipulated to facilitate connectivity by particular species. Additionally, artificial light could be used to influence movement. For example, lights could be used like a fence to prevent animals from crossing roads, while darkness could be used to encourage them to use crossing structures. If, however, the motivation to move through a lit area is high or the energy expenditure to go around is extreme, the avoidance response might be muted.

Ecological light pollution influences natural systems and contributes to the cumulative effects of urbanization on wildlife and ecosystems. With a greater understanding of the effect of artificial light we can make informed decisions about removing or reducing lighting and test additional methods to reduce the impacts of ecological light pollution in order to preserve habitat connectivity. 
Chapter 4 - References

Beier, P., 1995. Dispersal of juvenile cougars in fragmented habitat. J. Wildl. Manag. $228-237$.

Bennie, J., Davies, T.W., Inger, R., Gaston, K.J., 2014. Mapping artificial lightscapes for ecological studies. Methods Ecol. Evol. 5, 534-540.

Bird, B.L., Branch, L.C., Miller, D.L., 2004. Effects of coastal lighting on foraging behavior of beach mice. Conserv. Biol. 18, 1435-1439.

Bliss-Ketchum, L.L, C. E. de Rivera, B. C. Turner, D. M. Weisbaum. 2016. The Effect of Artificial Light on Wildlife Use of a Passage Structure. Biological Conservation 199 (2016) $25-28$

Bunning, E., Moser, I., 1969. Interference of moonlight with the photoperiodic measurement of time by plants, and their adaptive reaction. Proc. Natl. Acad. Sci. U. S. A. $62,1018-1022$.

Clark, R.W., Brown, W.S., Stechert, R., Zamudio, K.R., 2010. Roads, interrupted dispersal, and genetic diversity in timber rattlesnakes. Conserv. Biol. 24, 10591069. 
Clevenger, A.P., Chruszcz, B., Gunson, K., 2001. Drainage culverts as habitat linkages and factors affecting passage by mammals. J. Appl. Ecol. 38, 1340-1349.

Coelho, I.P., Teixeira, F.Z., Colombo, P., Coelho, A.V.P., Kindel, A., 2012. Anuran roadkills neighboring a peri-urban reserve in the Atlantic Forest, Brazil. J. Environ. Manag. 112, 17-26.

Davies, T.W., Bennie, J., Inger, R., Ibarra, N.H., Gaston, K.J., 2013. Artificial light pollution: are shifting spectral signatures changing the balance of species interactions? Glob. Chang. Biol. 19, 1417-1423.

de Rivera, C.E., Bliss-Ketchum, L.L., 2009. The Effectiveness of Vertebrate Passage and Prevention Structures: A Study of Boeckman Road in Wilsonville. Research Final Report OTREC-RR-10-14. Oregon - Transportation Research and Education Center, Portland (Retrieved from http://trec.pdx.edu/research/project/239).

Dixon, J.D., Oli, M.K., Wooten, M.C., Eason, T.H., McCOWN, J.W., Paetkau, D., 2006. Effectiveness of a regional corridor in connecting two Florida black bear populations. Conserv. Biol. 20, 155-162.

Gaston, K.J., Davies, T.W., Bennie, J., Hopkins, J., 2012. REVIEW: reducing the 
ecological consequences of night-time light pollution: options and developments. J. Appl. Ecol. 49, 1256-1266.

Gaston, K.J., Duffy, J.P., Gaston, S., Bennie, J., Davies, T.W., 2014. Human alteration of natural light cycles: causes and ecological consequences. Oecologia 176, 917-931.

Gaston, K.J., Visser,M.E., Hölker, F., 2015. The biological impacts of artificial light at night: the research challenge. Philos. Trans. R. Soc. Lond. B Biol. Sci. 370, 20140133.

Grigione,M.M.,Mrykalo, R., 2004. Effects of artificial night lighting on endangered ocelots (Leopardus paradalis) and nocturnal prey along the United States-Mexico border: a literature review and hypotheses of potential impacts. Urban Ecosyst. 7, $65-77$.

Henderson, R.W., Powell, R., 2001. Responses by the West Indian herpetofauna to human influenced resources. Caribb. J. Sci. 37, 41-54.

Kempenaers, B., Borgström, P., Loës, P., Schlicht, E., Valcu,M., 2010. Artificial night lighting affects dawn song, extra-pair siring success, and lay date in songbirds. Curr. Biol. 20, 1735-1739. 
Longcore, T., Rich, C., 2004. Ecological light pollution. Front. Ecol. Environ. 2, 191198.

Polak, T., Korine, C., Yair, S., Holderied, M., 2011. Differential effects of artificial lighting on flight and foraging behaviour of two sympatric bat species in a desert. J. Zool. 285, 21-27.

Portland, C.o., 1984. Street lighting standards. (Retrieved September 2013 from) http:// www.portlandonline.com/shared/cfm/image.cfm?id=36176.

R_Development_Core_Team, 2012. R: A Language and Environment for Statistical Computing, Reference Index Version 2.15.2. R Foundation for Statistical Computing, Vienna, Austria (Retrieved March 2013 from) http://www.Rproject.org.

Randa, L.A., Yunger, J.A., 2006. Carnivore occurrence along an urban-rural gradient: a landscape-level analysis. J. Mammal. 87, 1154-1164.

Rich, C., Longcore, T. (Eds.), 2005. Ecological Consequences of Artificial Night Lighting. Island Press.

Riley,W., Davison, P.,Maxwell, D., Bendall, B., 2013. Street lighting delays and disrupts 
the dispersal of Atlantic salmon (Salmo salar) fry. Biol. Conserv. 158, 140-146.

Rodrigues, P., Aubrecht, C., Gil, A., Longcore, T., Elvidge, C., 2012. Remote sensing to map influence of light pollution on Cory's shearwater in São Miguel Island, Azores Archipelago. Eur. J. Wildl. Res. 58, 147-155.

Rotics, S., Dayan, T., Kronfeld-Schor, N., 2011. Effect of artificial night lighting on temporally partitioned spiny mice. J. Mammal. 92, 159-168.

Sella, K.N., Salmon, M.,Witherington, B.E., 2006. Filtered streetlights attract hatchling marine turtles. Chelonian Conserv. Biol. 5, 255-261.

Sheldon, I., 1997. Animal Tracks ofWashington and Oregon. Lone Pine, Edmonton, Alberta, Canada.

Shepard, D., Kuhns, A., Dreslik, M., Phillips, C., 2008. Roads as barriers to animal movement in fragmented landscapes. Anim. Conserv. 11, 288-296.

Spoelstra, K., van Grunsven, R.H., Donners, M., Gienapp, P., Huigens, M.E., Slaterus, R., Berendse, F., Visser, M.E., Veenendaal, E., 2015. Experimental illumination of natural habitat - an experimental set-up to assess the direct and indirect ecological 
consequences of artificial light of different spectral composition. Philos. Trans. R. Soc. Of Lond. B Biol. Sci. 370, 20140129.

Steen, D.A., Aresco, M.J., Beilke, S.G., Compton, B.W., Condon, E.P., Kenneth Dodd, C., Forrester, H., Gibbons, J.W., Greene, J.L., Johnson, G., Langen, T.A., Oldham, M.J., Oxier, D.N., Saumure, R.A., Schueler, F.W., Sleeman, J.M., Smith, L.L., Tucker, J.K., Gibbs, J.P., 2006. Relative vulnerability of female turtles to road mortality. Anim. Conserv. 9, 269-273.

Threlfall, C., Law, B., Banks, P., 2013. The urban matrix and artificial light restricts the nightly ranging behaviour of Gould's long-eared bat (Nyctophilus gouldi). Austral Ecol. 38, 921-930.

van Langevelde, F., Ettema, J.A., Donners, M., WallisDeVries, M.F., Groenendijk, D., 2011. Effect of spectral composition of artificial light on the attraction of moths. Biol. Conserv. 144, 2274-2281. 
Chapter 5 - Goals-Based Species Selection Process for Connectivity Modeling and Planning

Chapter 5 - Introduction

Maintaining and establishing ecological connections among habitats ranks as one of the key immediate challenges for maintaining wildlife diversity given the extensive global land use change and habitat fragmentation. Wildlife require the ability to move across the landscape in order to access resources and conspecifics on a daily and/or seasonal basis (Theobald et al. 1997, Forman et al. 2003, Lindenmayer \& Fischer 2006, van der Ree et al. 2015, Gutierrez-Arellano \& Mulligan 2018). The scale and frequency of movement needs are species specific and may influence different levels of organization within and across populations (Cushman 2006, Keinath et al. 2017, Hatfield et al. 2018). Species movements can be limited by the presence and distribution of barriers including infrastructure (e.g., roads, powerlines, and development), anthropogenic habitats (e.g., agriculture, managed forest, urban neighborhoods), and even natural areas that do not function as habitat for the species in question (e.g., prairie to an exclusive forest species). The degree to which these barriers limit movement varies across species, meaning that conservation efforts designed to broadly address habitat connectivity require strategic approaches that can effectively account for variable species responses. Therefore, determining how best to achieve this connectivity first requires approaches that work effectively across species and habitats. 
Given limited resources, it is infeasible to model the movement needs of and create species-specific landscape connectivity plans for every species. Therefore, modeling activities must be restricted to a subset of species, making an approach that can utilize few species to represent others particularly useful. Carefully selecting species with attention to specific project goals will enable effective outcomes despite scarce resources. The concept of using a subset of species, or rather, surrogate species, is not new, with several terms and associated definitions prevalent in the literature (Caro 2010, Table 10.1). Surrogate species are defined by the United States Fish and Wildlife Service (USFWS) as "a commonly-used scientific term for system-based conservation planning that uses a species as an indicator of landscape, habitat and system conditions" (USFWS 2014a).

The goal of a surrogate species approach is to use a few species to best represent the needs of the larger community (Weins et al. 2008). The term surrogate species is inclusive of several subcategories of species, such as umbrella, indicator, keystone and others. Each of these subcategories has been proposed to narrow the focus of species selections to support specific conservation efforts (Caro 2010). However, the application of a single surrogate species subcategory can prohibit practitioners from considering other species that may meet project objectives better, but are not part of that category. While the terms and suggested definitions of various surrogate species have been thoroughly considered, well researched, and suggested with the best intentions, adherence 
to the intended use and applications of these suggestions has generally not been followed well (Armstrong $2002 \&$ Caro 2002), and/or the theoretical approach has restrictive applications that require specific conditions and narrow species representations to function well (Diniz et al. 2018, Banks et al. 2014). Two prominent subcategories of surrogate species that have been suggested for habitat connectivity modeling and planning have been "umbrella" species and "focal species".

Connectivity planning efforts typically use umbrella species, "a species with such demanding habitat requirements and large area requirements that saving it will automatically save many other species" (Simberloff 1998), or at least theoretically do. Across species and ecosystems, most studies examining the effectiveness of utilizing umbrella species as surrogates found this approach had limited effectiveness in its application to real world scenarios (Meurant et al. 2018, Diniz et al. 2018, Cushman and Landguth 2012, Seddon \& Leech 2008, Ozaki et al. 2006, Jones et al 2016). Most recently, Meurant et al. (2018) found that selecting 5-7 species to represent movement needs and diverse habitat was the most effective approach, while using a single umbrella species was the least so. Furthermore, umbrella species performed poorly when fragmentation patterns and the amount of available habitat varied across the landscape (Dinz et al. 2018). The larger the scale of application for connectivity modeling and planning, the lower the likelihood that fragmentation patterns and available habitat will be held constant. With prevalent criticism of the exclusive use of an umbrella species 
approach, the question remains how to best approach connectivity modeling and planning efforts using limited species.

A frequently cited alternative to the umbrella species approach for connectivity planning has been the use of focal species. The focal species approach aims at selecting a species most sensitive to a threat (e.g. invasive species encroachment, fire, fragmentation) and that also represents requirements of less sensitive species; often a suite of focal species are used to represent a collection of threats (Lambeck, 1997). While this definition, applied to habitat connectivity modeling and planning, requires selection of the species most sensitive to fragmentation, in application, focal species approaches have more frequently resulted in the use of umbrella species and/or a species proposed due to an immediate need for conservation (species is under immediate threatened due to connectivity issues, or is a species of particular economic interest such as large carnivores and game animals), rather than these species being a particularly good representative of other species connectivity needs (Andelman \& Fagan 2000, Norvell et al 2014, Roberge \& Angelstam 2004). Nonetheless, it is important that the value of species with immediate conservation need and those of economic importance is not overlooked, and that other multi-species approaches are able to accommodate species of special concern (species with less value in representing other species, but additional factors lending to its need to be prominent in the project), while explicitly stating the justification and reasoning for including those species. 
Although umbrella and focal species have not fared well as a way to select surrogates for connectivity modeling and planning to date, the need to use well selected surrogates is still essential to the best application of limited resources (Weins et al. 2008, Caro 2010, Meurant et al. 2018, Diniz et al. 2018, Cushman and Landguth 2012, Seddon \& Leech 2008, Ozaki et al. 2006, Jones et al 2016, Andelman \& Fagan 2000, Norvell et al 2014, Roberge \& Angelstam 2004). What seems to be missing is an effective process that allows selection of species that will best represent 1 . habitats and 2 . connectivity among habitat patches, including connectivity across multiple habitat types

A methodology for selecting species based on the landscape characteristics they depend on, rather than a given subcategory of surrogate species (e.g. umbrella or focal species) may provide the way to better model, map and plan for connectivity. Fischer and Lindenmayer (2007) define three concepts of connectivity. They define habitat connectivity as "The connectedness of habitat patches for a given species (single species perspective)." Landscape connectivity is "The connectedness of vegetation cover within a given landscape (human perspective)" whereas Ecological connectivity is "The connectedness of ecological processes at multiple scales (ecosystem perspective)." Connectivity modeling is inherently attempting to bridge the gap between Habitat connectivity and Landscape connectivity, with likely positive results for Ecological connectivity. 
We argue that the most appropriate suite of surrogates for representing a communities' ecological connectivity needs would be species that represent a range of movement abilities and that represent habitat functions such as specific habitat features, patch size, geographic placement and accessibility. Therefore, it is critical that we look for surrogate species that fill the spaces between generalist and specialist. In addition, while many of these species are very intentionally selected to represent habitat movement needs well, there needs to be stakeholder support for using most of them or it will be difficult to successfully implement connectivity plans. Input from diverse participants supports a more robust process scientifically as well as stakeholder engagement that can serve to promote and support connectivity projects and their products.

Here we propose a goals-based species selection perspective to identify surrogate species in a project-specific way by defining the criteria used for selection, such as specific habitat types and species closely tied to those habitats, then building a set of surrogates that represent diverse mobility (taxa) and an array of species-specific needs and functions across the area of interest. With this approach we can best select species to address two key issues in connectivity planning and management: habitat permeability (barriers) and habitat quality. The goals-based selection process includes recommendations for selecting species on a regional basis, using input from a variety of biologist, conservation planners, species experts, and potential end-users of the products. In order to provide clear tracking of the process to select these species, we propose a method that uses project goals to 
drive species selection in a transparent and tractable way that is also able to engage stakeholders throughout the process. 


\section{Chapter 5 - Goals-Based Species Selection (GBSS) Process}

The goals-based species selection (GBSS) process follows a sequence of steps that provides several points at which the project leads can engage with partners and species experts to provide feedback on the selections. The major steps in the species selection process also include several points where stakeholder engagement options can be utilized, indicated by $*$ in the list below:

1. Clarifying and articulating project goals*

2. Data acquisition to prepare for analysis

3. Hierarchical cluster analysis

4. Interpretation and refinement*

5. Literature review and/or feedback from species experts to support selections*

6. Final species selections*

This surrogate species selection methodology begins with statistical analysis and exploration of species habitat associations to determine appropriate groupings. Once the data, composed of a comprehensive list of species and habitat associations, has been compiled, it can be analyzed through hierarchical clustering into groups (Glenn 2002). This clustering provides an objective grouping of species by habitat association. If statistical experience to conduct the clustering analysis is not available to the practitioner, an alternative, but more time consuming, approach may be to group species manually under the habitat types with which they are strongly associated. Additional consideration should be given to species found to be strongly associated with multiple habitat types; for example, pond breeding amphibians with terrestrial adult life stages such as the Northern 
Red-Legged frog (Rana aurora). Because of the utilization of both terrestrial and aquatic habitat types, this species can represent connectivity both between and within upland and aquatic sites.

Cluster analysis requires practitioners to determine approximately how many groups are appropriate for the data at hand given the number of habitats they intend to represent. Although the number of groups may directly correlate with the number of individual habitat types or habitat combinations under consideration for conservation action, it can be useful to explore the effects of using different numbers of clusters. Exploring several iterations of cluster groups, then reviewing the resulting clusters of habitat associations and species assemblages produced by multiple, replicable analyses, provides insight into the number of clustering groupings needed to best capture habitat-specific representations of species groups. The analysis should be repeated with different numbers of cluster categories until a balance is reached such that an increase in clusters creates small groupings that, when compared with other species groupings, seem like random subgroupings within a habitat type; and a decrease in clusters merge these species groups so much that at least one of the species groupings produced spans use of unrelated habitats across the suite of species (in contrast to including some species that use multiple habitats). A balance in the number of groupings is reached when the habitat variability is adequately captured with the fewest number of cluster groups. Depending on project resources and objectives as well as the composition of the communities potentially using 
the habitats, one or several species may ultimately be selected from each cluster group to serve as surrogates for that cluster of species and their habitat.

Once the complete list of species and associated habitats has been clustered into groups, species that do not meet additional project specific criteria can be removed from consideration as surrogates. Example criteria may include the following:

- Species must be native and noninvasive;

- Species should have close year-round or seasonal associations with (most often found in or obligate to) habitats of interest;

- Species' current or projected ranges should occur primarily within the region under consideration;

- Species should be neither very rare nor overly common.

Additional filtering may be applied depending on project specific parameters that consider what the group of species is intended to accomplish. For example, the group of species selected for each habitat type should, across the suite of surrogates, represent a diversity of:

- taxa (mammals, birds, amphibians, reptiles, and maybe invertebrates or fish);

- mobility and dispersal capabilities;

- responses to landscape elements that are potential barriers;

- different life history strategies;

- different habitat structural components (seral stage, canopy layers, etc.);

- susceptibility to different threats to persistence (such as land clearing/vegetation removal, development, roads/traffic, people/domestic animals, energy development/transmission lines, fire impacts, etc.). 
Once this process of refinement and filtering is complete a draft list of proposed species can be selected. Depending on the collaborative nature and scope of the project the first draft of proposed species may be selected by a small group, then presented to a larger group of species experts and stakeholders, or a larger group may be asked to provide additional species information in advance of any draft selections. For projects that are relatively small in scope and where local species experts are readily identified, it may be advantageous for a small group of individuals central to the project to propose a first draft of species selections for those species. Those compiling the draft list should consult the literature and other information applicable to the project region to support and justify the species selected and to provide evidence that those species satisfy the project requirements as described in the preceding steps. The compiled information is then presented to species experts familiar with the regional scope of the project and species presence and behavior in the area. Feedback and consideration for alternative species selections can be considered, and with consultation with the group, final species selections can be made.

For projects that are large in scope, either in complexity or geography, and where regional species experts are not as easily identified, a slightly different approach to solicit feedback is proposed. Following initial species filtering, a group of biologists, species experts, and other practitioners from the region can score candidate surrogate species with a shared worksheet, evaluating the project specific filtering criteria for each species individually (Table 5.1). Once the information has been compiled for all candidate 
species a workshop will be held during which interested parties will convene to evaluate the species' scoring, rank species, and finalize species selection for that region. Other approaches may be useful in soliciting feedback from a dispersed group of species experts and/or relevant stakeholders, therefore practitioners are encouraged to utilize additional outreach techniques as appropriate.

So far, this process has been successfully applied to connectivity mapping in projects with variable geographic scale, two of which are discussed below as case studies in order to illustrate how this approach can be implemented.

\section{Table 5.1: Example Candidate Species Scoring Worksheet}

Following initial species filtering, a group of biologists, species experts, and other practitioners from the region can score candidate surrogate species with a shared worksheet, evaluating the project-specific filtering criteria for each species individually.

\begin{tabular}{|l|l|}
\hline Category or Question & Description \\
\hline Habitat Association & $\begin{array}{l}\text { The habitat the species under consideration is associated with and } \\
\text { intended to represent }\end{array}$ \\
\hline Species & The species under consideration \\
\hline $\begin{array}{l}\text { Taxa } \\
\text { Ways threatened by land } \\
\text { clearing or vegetation } \\
\text { removal? }\end{array}$ & $\begin{array}{l}\text { The taxa group that the species under consideration belongs to } \\
\text { inhospitable environment (e.g., desiccating conditions for amphibians); } \\
\text { alienation due to lack of forage or prey; increases in competing species, } \\
\text { predators, invasive exotics }\end{array}$ \\
\hline $\begin{array}{l}\text { Threatened by } \\
\text { urban/exurban } \\
\text { development? } \\
\text { (Yes/No) }\end{array}$ & $\begin{array}{l}\text { Examples include: barriers to movement created by fences, walls, } \\
\text { buildings, asphalt, canals, etc.; alienation due to noise, lighting, lack of } \\
\text { forage or prey; increases in competing species, predators, and invasive } \\
\text { exotics; reduced accessibility of important habitat areas (e.g., streams } \\
\text { put into culverts) }\end{array}$ \\
\hline
\end{tabular}


Threatened by roads and/or traffic?

(Yes/No)

Threatened by people and/or domestic animals? (Yes/No)

Climate Sensitivity

$(1-10)$

Mobility

(1-10)

Susceptibility to barriers $(1-10)$

Type of barrier sensitivity linkage?

(Yes/No)

Association with specific seral stage?

(Yes/No, Type)

Association with other structural habitat components?

Particular socio-economic consideration?
Examples include: creation of inhospitable conditions (e.g., desiccating conditions for amphibians); creation of a physical barrier (e.g. right-ofway fences); fatal attraction (e.g., attraction of snakes to warm road surface); increased mortality due to vehicle collisions; behavioral alienation (e.g., avoidance of roads or high traffic volumes)

Examples include: legal and illegal harvest; harassment/disturbance; disease transmission; intolerance (e.g., involving depredation for conflict resolution)

A rank of 1 indicates lowest climate sensitivity, 10 the highest. Consider: how specialized the species' habitat or niche is; the species' sensitivity to temperature or precipitation changes; whether the species' reproductive rates are generally low; if the species depends on a sensitive habitat type (e.g., vernal pools); if the species' latitudinal range limit falls within the region under consideration; if the species is endemic to the region under consideration

A rank of 1 represents the lowest possible mobility, while 10 represents the highest. For example, most salamander species would receive a score closer to 1 , while most large carnivores would receive a score closer to 10 .

A rank of 1 represents the lowest susceptibility to barriers, while 10 represents the highest. For example, raccoons are habitat generalist that have little difficulty moving through and around anthropogenic structures and would receive a score closer to 1 , while a northwestern salamander requires specific habitat conditions and is challenged by most anthropogenic barriers would receive a score closer to 10 .

Examples include: canopy gaps over a certain size; bodies of water above a certain size/depth/flow rate; fencing; roads of a given size/traffic volume

Does the species depend on both aquatic and terrestrial habitats to fulfill its life history needs?

Is the species generally associated with a specific seral stage (i.e. early, mid, late)? If so, which stage?

Does the species depend on any other structural habitat components?

Can these habitat components be mapped across the species' range?

For example: is the species considered a "pest"? Is the species culturally important? Economically important? 


\begin{tabular}{|l|l|}
\hline Data Availability? & $\begin{array}{l}\text { Is there enough information on the species to support modeling efforts? } \\
\text { Do we know enough about conditions that promote or deter movement? } \\
\text { Are the species' movement choices based on features that can be } \\
\text { modeled? }\end{array}$ \\
\hline Represents other species? & $\begin{array}{l}\text { Would the species' habitat requirements and movement be representative } \\
\text { of a broader group of species? If so, what other species might this } \\
\text { candidate represent? }\end{array}$ \\
\hline $\begin{array}{l}\text { Comments/Literature } \\
\text { Citations }\end{array}$ & Additional information, justification or literature \\
\hline
\end{tabular}


Chapter 5 - Case Studies

\section{Metro Habitat Connectivity Toolkit (median scale: medium to large sized metropolitan area and surrounding habitats)}

Project synopsis and background: Habitat loss and fragmentation is a serious threat to maintaining biodiversity particularly in urbanizing areas. The greater metropolitan area of Portland, Oregon, which is maintained by the government body, 'Metro', has many large natural areas in and around its urban growth boundary, providing habitat that can support a diversity of organisms. As the human population of the area grows, open space within and surrounding the metro area is at greatest risk of development. In order to protect and enhance habitat connectivity in these at-risk areas we must first identify potential habitat corridors and assess their condition. Joint with collaborators from Metro's natural resources staff, we employed a surrogate species approach to address connectivity needs of the wildlife community in a way that can incorporate empirical data.

Articulating Project goals: The Metro regional government headquartered in Portland, Oregon and researchers from Portland State University developed a partnership in order to quantify and describe connectivity in a dynamic urban and urbanizing environment. Based on existing efforts and conservation objectives of the region, partners established four primary habitats of interest, forest, wetland, oak woodland, and prairie (RCS 2012). To best use limited resources, the goal was to select no more than 8-10 species to 
represent connectivity for native wildlife, excluding fish, across and within these habitat types.

Data acquisition: Vertebrate species known to the region, composed of 229 birds, 78 mammals, 16 reptiles, and 20 amphibians, were provided by the Biodiversity Guide for the greater Portland-Vancouver Region (2012), a companion document to the Regional Conservation Strategy (RCS 2012). Species-habitat associations were determined using the data provided by Wildlife-Habitat Relationships in Oregon and Washington (Johnson and O'Neil, 2001). Habitat types used in this analysis, as defined by Johnson \& O’Neil, include Westside Lowlands Conifer-Hardwood Forest, Westside Oak and Dry Douglasfir Forest and Woodlands, Westside Upland Grasslands, Agricultural lands, Urban and Mixed Environs, Open Water - Lakes, Rivers, and Streams, Herbaceous Wetlands, and Westside Riparian-wetlands.

Cluster analysis: Ten groups were initially selected for the hierarchical cluster analysis output as this was the maximum number of species we ultimately planned to select. These groups included all habitats a given species was associated with as described by Johnson and O'Neil (2001). The resulting groups were reviewed and further categorized as they pertained to the four habitat types of interest established as project goals (forest, wetland, oak woodland, and prairie). For example, the largest group, composed of 85 species, was associated with all possible habitat types and primarily comprised generalist species. Smaller groups were more clearly associated with individual habitat types, 
although not exclusively so. For example, group seven was associated with herbaceous wetland, open water, and agricultural lands and was composed entirely of waterfowl and marshland birds. Because of the lack of diversity in taxa, group seven was combined with group five to represent herbaceous wetland habitats. After further consideration six groups were ultimately formed from which we continued the process to select surrogate species.

Filter/interpretation and refinement: Once the final species and habitat association groups were compiled that best represented the four habitats of interest, we further refined the potential candidates for selection as surrogate species to narrow the candidate pool in line with our goals. We therefore removed non-native species as well as those species known to be highly adapted to urban and agricultural habitats. Non-native species were removed from consideration given the project objectives of representing connectivity for native species in addition to the fact that most non-native species are generalists and adaptable to multiple habitat types. Species highly adapted to urban and agricultural habitats were removed because we can infer that the lack of sensitivity to these matrix habitats would mean ag and urban adapted species would not be particularly good habitat indicators for more sensitive species.

The remaining species were further categorized within each habitat association by taxa in order to best consider mobility types. Project partners, Metro and Portland State University, reviewed the remaining species and aimed to select species that are typically 
found in or are obligate to a given habitat type of good quality and are neither very rare (which would require more species-specific information) or overly common (indicating habitat generalists). The proposed species selections intentionally highlighted a range of mobility types but primarily focused on species most susceptible to barriers. The group of surrogate species selected provide a representation of use of the different regional habitats and of the different classes of native terrestrial vertebrates. The primary focus was on species' needs and ability to move between patches to access quality habitat areas. Extensive literature reviews were conducted for each proposed species and a report was drafted detailing habitat associations, home range and expected movement needs, as well as additional species expected to be represented by the surrogate.

Feedback and literature review: Once the project partners compiled a final list of proposed surrogates, several local species experts were contacted to provide peer review of the overall project goals and process as well as the proposed surrogate species. These reviewers were contacted based on in depth and lengthy careers contributing to local knowledge of species and associated habitat connectivity challenges. Ultimately eight reviewers provided comments that were incorporated with associated justifications for species selection. The responses resulted in the replacement of some species due to habituation to human feeding (Anna's hummingbird), status as an agricultural pest (graytailed vole), and highly limited mobility (western red-backed salamander). 
Final selections: The proposed final species selections were discussed once more by project partners and peer reviewers. A final list of eight species were ultimately selected to represent connectivity needs and provide the framework for assessing connectivity across and within habitats of interest using modeling and field assessments that address habitat quality and barrier strength (Table 5.2). American beaver was considered particularly impactful as a keystone species (Stoffyn-Egli and Willison 2011). Parallel efforts by the USFWS to identify surrogate species in the Willamette Valley (USFWS 2014b) provided opportunities for collaboration and several species selected for the Metro Toolkit project overlap with the USFWS effort.

\section{Table 5.2: Metro Connectivity Toolkit Project Final Species Selections \& Associated \\ Habitats}

Species selected as surrogates to represent the habitat connectivity needs of most species in the Metro region. American beaver, red-legged frog and southern alligator lizard require or are closely associated with multiple habitat types and are therefore listed under more than one habitat type. Forested habitats are more variable and in order to best represent them, each vertebrate group was represented.

\begin{tabular}{|c|c|c|c|c|}
\hline $\begin{array}{c}\text { Vertebrate } \\
\text { Group }\end{array}$ & $\begin{array}{c}\text { Forested Habitats } \\
\text { (Includes upland forest, } \\
\text { upland shrub, riparian \& } \\
\text { wetland forest) }\end{array}$ & $\begin{array}{l}\text { Wetlands } \\
\text { (Includes willow/shrub } \\
\text { wetland and emergent } \\
\text { wetland) }\end{array}$ & $\begin{array}{c}\text { Oak } \\
\text { (Includes savannah and } \\
\text { woodlands) }\end{array}$ & $\begin{array}{l}\text { Prairie } \\
\text { and } \\
\text { Grassland }\end{array}$ \\
\hline Amphibians & $\begin{array}{l}\text { Red-legged Frog } \\
\text { (Rana aurora) }\end{array}$ & $\begin{array}{l}\text { Red-legged Frog } \\
\text { (Rana aurora) }\end{array}$ & & \\
\hline Reptiles & $\begin{array}{c}\text { Rubber Boa } \\
\text { (Charina bottae) }\end{array}$ & & $\begin{array}{c}\text { Southern Alligator Lizard } \\
\text { (Elgaria multicarinata) }\end{array}$ & $\begin{array}{c}\text { Southern Alligator Lizard } \\
\text { (Elgaria multicarinata) }\end{array}$ \\
\hline Birds & $\begin{array}{l}\text { Swainson's Thrush } \\
\text { (Catharus ustulatus) }\end{array}$ & & $\begin{array}{l}\text { Slender-Billed Nuthatch } \\
\text { (Sitta carolinensis } \\
\text { aculeata) }\end{array}$ & $\begin{array}{l}\text { Western Meadowlark } \\
\text { (Sturnella neglecta) }\end{array}$ \\
\hline $\begin{array}{c}\text { Small } \\
\text { Mammal }\end{array}$ & $\begin{array}{c}\text { Douglas' Squirrel } \\
\text { (Tamiasciurus douglasii) }\end{array}$ & & $\begin{array}{l}\text { Western Gray Squirrel } \\
\text { (Sciurus griseus) }\end{array}$ & \\
\hline $\begin{array}{l}\text { Medium } \\
\text { Mammal }\end{array}$ & $\begin{array}{c}\text { Beaver } \\
\text { (Castor canadensis) }\end{array}$ & $\begin{array}{c}\text { Beaver } \\
\text { (Castor canadensis) }\end{array}$ & & \\
\hline
\end{tabular}


Oregon Connectivity Assessment and Mapping Project (OCAMP) - Coastal Ecoregion Focus (large scale: ecoregion approach as part of statewide effort)

\section{Project description and background:}

Identifying priority conservation areas is a critical step in maintaining landscape connectivity across large scales and can be accomplished by generating maps using geospatial models (Baldwin et al. 2010, Spencer et al. 2010, WHCWG 2012, McRae et al. 2012). The Oregon Connectivity and Mapping Project (OCAMP) is an initiative led by the Oregon Department of Fish and Wildlife in partnership with federal, state, nonprofit, and university participants. This project will ultimately produce connectivity maps for up to 60 species across their respective ranges in Oregon, representing different taxa, habitat associations, life history strategies, and dispersal capabilities. In order to accomplish these goals OCAMP will work with additional partners, end users, and stakeholders from each major ecoregion across the state to identify surrogate species that can be used to generate connectivity maps. The coast range ecoregion is the first in the state where this process has been applied, with the following example focusing on the species selection process for that location. The efforts in the coast range ecoregion were conducted in partnership with the Pacific Northwest Coast Landscape Conservation Design (LCD) initiative (PNWCLCD 2019).

Articulating project goals: The goal of the coast range ecoregion portion of the OCAMP project is to advance priority conservation planning aimed at understanding and mitigating barriers to wildlife movement in Oregon. Through collaborative work with the 
Oregon Habitat Connectivity Consortium, ODFW initiated this effort in order to fill critical knowledge gaps by completing connectivity assessment and mapping at fine resolution across Oregon. We are conducting extensive outreach to encourage a diverse group of partners to utilize and implement findings from the assessment, and to make all data and results from our analyses easy to find, view, and understand. The initial step in this process was to select ten surrogate species from the coast range ecoregion for modeling with the desired outcome of best applying limited resources to represent connectivity needs of the larger community.

Data acquisition: The list of candidate species and species-habitat associations were determined using the data provided by Wildlife-Habitat Relationships in Oregon and Washington (Johnson and O'Neil, 2001). The complete list of species was initially considered, then filtered to only include those species associated with habitat types also found in the coast range. Johnson and O'Neil (2001) include the strength of association for each habitat species relationship as well as the confidence level of that association. We ultimately considered only those species categorized as "highly associated with high confidence" resulting in a list of 271 mammal, bird, reptile, and amphibian species used in analysis.

Cluster analysis: With the goal of ultimately selecting eight to sixteen species to represent the coast range ecoregion of Oregon, eight groups were selected for initial cluster analysis. In reviewing the clustering analysis output, some groups included only a 
handful of species $(<5)$ and/or were composed of a single taxa (shorebirds). The coast range ecoregion, while composed of several habitat types, is most geographically represented by conifer-hardwood forests explaining why some groups were so apparently underrepresented. Ultimately, small and single taxa groupings were merged to form four habitat associations representing 1. Conifer-hardwood forests, 2. Open water, riparian, wetlands, 3. Bays, estuaries, coastal dunes and headlands, 4 . Montane mixed conifer forest and alpine grassland and shrubland.

Filtering/Interpretation and refinement of cluster results: Once the cluster results were finalized, we further refined the list by removing non-native species, marine mammals, and migratory birds that do not breed in Oregon. Non-native species were removed because project goals included connectivity for native species; marine mammals were removed because project goals are currently only considering terrestrial connectivity; and non-breeding migrants were removed (while still recognizing the need for stopover habitat) because it was thought that their connectivity needs would be represented by a surrogate that breeds in Oregon.

Several of the habitat types found in the coast range are also found in other areas around the state and a given species that is highly associated with one of those habitat types may not have a distribution overlapping with the coast range ecosystem. For this reason, species distribution maps for all candidate species were also reviewed to ensure adequate representation in the coast range ecoregion (Csuti et al 2001). Species whose distributions 
had no overlap with the coast range ecoregion were removed. In addition, we took note of (but did not remove) species whose distribution extended significantly beyond the coast range ecoregion. These species generally had distributions close to or beyond statewide and while not excluded, were flagged as potential statewide generalist species rather than species that would be most representative of the coast range ecoregion.

Feedback and literature review: A worksheet was developed with species grouped by the associated habitat of interest and species-specific fields where reviewers can add information to provide a framework where species qualities and sensitivities could be more easily compared (Table 3; See Table 1 for more information on the categories). Fields included species mobility, climate change sensitivity, level of impact of roads and other barriers, and an association with specific habitat components such as forest seral stage, among others (Table 5.3). Over fifty regional species experts were contacted based on their affiliations, research contributions, and/or titles as wildlife biologists and asked to provide information for species they were knowledgeable about and also were encouraged to share the worksheet with colleagues they felt could contribute. A webinar was recorded to provide experts the background and goals of the project and guide them in contributing to the species selection process. In addition, reviewers and contributors were encouraged to include species for consideration if they felt such species were not represented in the original list. 
Final selections: Once worksheet scoring was completed the core project team ranked potential surrogates and developed a list of proposed final species selections. An inperson workshop (with remote participation options) was then held to continue discussion and provide a platform for further debate on the features and project goals represented by the final species selections. Final species selections will then be used to model connectivity across their range with a focus on representation of habitats in the coast range ecoregion. 


\section{Table 5.3: Species Information Worksheet}

This table shows questions and a sample of the associated species for one habitat grouping in the coast range ecoregion, (open water, riparian, wetlands). Color coding quickly communicates the taxa grouping of the species in question.

\section{Habitat Association: Coast Range Ecoregion - Open Water, Riparian Wetlands, and Herbaceous Wetlands}

\begin{tabular}{|c|c|c|c|c|c|c|c|c|c|c|}
\hline Species & 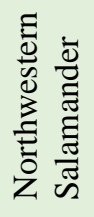 & 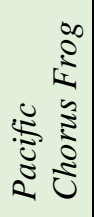 & 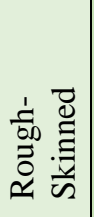 & 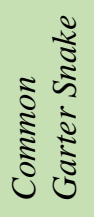 & 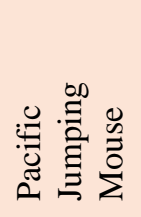 & 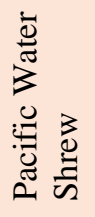 & $\begin{array}{l}\infty \\
0 \\
0 \\
0 \\
0 \\
0 \\
0 \\
0\end{array}$ & 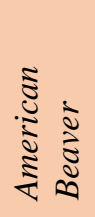 & 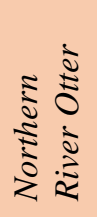 & 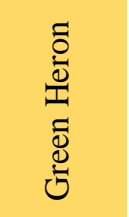 \\
\hline Taxa & 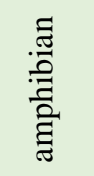 & 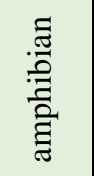 & 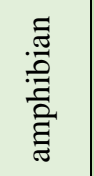 & $\frac{0}{\stackrel{0}{0}}$ & 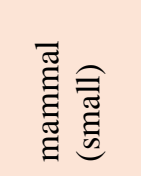 & 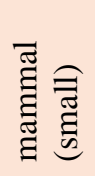 & 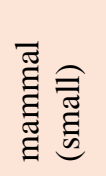 & 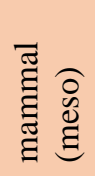 & 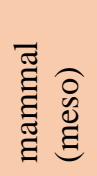 & 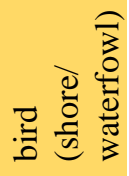 \\
\hline \multicolumn{11}{|l|}{ Threatened by land clearing and/or vegetation removal? } \\
\hline \multicolumn{11}{|l|}{ Threatened by development? } \\
\hline \multicolumn{11}{|l|}{ Threatened by roads/traffic? } \\
\hline \multicolumn{11}{|l|}{ Threatened by people and/or domestic animals? } \\
\hline \multicolumn{11}{|l|}{ Climate Sensitivity $(1-10)$} \\
\hline \multicolumn{11}{|l|}{ Mobility (1-10) } \\
\hline \multicolumn{11}{|l|}{ Susceptibility to barriers (1-10) } \\
\hline \multicolumn{11}{|l|}{ Type of barrier sensitivity } \\
\hline \multicolumn{11}{|l|}{ Aquatic \& Terrestrial linkage? (yes/no) } \\
\hline \multicolumn{11}{|l|}{ Association with specific seral stage? } \\
\hline \multicolumn{11}{|l|}{ Association with other structural habitat components? } \\
\hline \multicolumn{11}{|l|}{ Particular socioeconomic consideration? } \\
\hline Comments/Literature Citations & & & & & & & & & & \\
\hline
\end{tabular}


Chapter 5 - Discussion

The goals-based species selection approach asks practitioners to address specific questions about what a given suite of species is intended to accomplish within a project. These project driven objectives are then used to refine the species list to the point where limited project resources can adequately be applied. Rather than stressing the importance of how species are categorized, the objective of this approach is to provide a repeatable process where species can be objectively considered as representatives of specific conservation goals.

While one focus of this goals-based species selection process is to select species that fill the spaces between generalist and extreme specialists there is nonetheless, room for consideration for species that may fall into alternative categories, especially in order to gain more support for the whole project. Goals-based species selection does not require that a practitioner ignore any category of species, but rather that it explicitly describes what those species represent and what value they bring to the project as a whole. The flexibility in decision making means that this approach may also end up including some species that may not be the best surrogates for the movement needs of other species, but are only being included because they are species of interest in their own right. Having such focal species as part of the mix can work well to ensure goals regarding movement needs for specific species are also captured. Moreover, sometimes these focal species also 
still represent the movement needs of others. This transparency in process allows for better evaluation, both internally and externally, of project goals and the products generated through the modeling and planning effort.

In addition to the benefits of better tracking and justification for decision making in species selections this approach includes the ability to enhance engagement with the professional community and develop local buy-in for project objectives and goals (Higgins et al 2007, Turner et al 2016, Madliger et al 2017). Early engagement can promote agreement and common terminology, helping ensure that stakeholders have the same vision for project outcomes (Meredith et al. 2018). Through soliciting input and review of species selections and inviting other professionals and stakeholders to engage with the process there is an inherent increased awareness of project and the potential for greater utilization of products generated.

Given the flexibility inherent in this approach, the goals-based species selection process could also be utilized in conservation applications outside connectivity modeling where the selection of a subset of species is needed. One example could be biodiversity monitoring in cities. The Urban Biodiversity Inventory Framework is one example where the selection of surrogate species was proposed to best use limited resources for longterm, cross taxa monitoring of biodiversity in cities (UBIF 2017). 
Multi-species conservation efforts are inherently complex and challenging; however, we hope with a focus on process and engagement we can better work to address conservation goals with limited resources. This and other proposed approaches require additional applications and assessment to test limitations and ensure applications of these processes will meet project needs. 


\section{Chapter 5 - References}

Andelman, S.J., Fagan, W.F., 2000. Umbrellas and flagships: Efficient conservation surrogates or expensive mistakes? PNAS. Vol. 97, no. 11. Pages 5954-5959.

Anthony P. Clevenger, Carol D. Cutshall, Charles R. Goldman, Daniel. Sperling, Frederick John Swanson, John A. Bissonette, Julia Jones, Kevin Heanue, Lenore Fahrig, Richard Forman, Robert L. France, Thomas C. Winter, Thomas Turrentine, and Virginia H. Dale

Armstrong D. 2002. Focal and surrogate species: Getting the language right. Conservation Biology 16: 285-286.

Baldwin, R. F., R. M. Perkl, S. C. Tombulak, and W. B. Burwell. 2010. Modeling Ecoregional Connectivity. Pages 349-367 in S. C. Tombulak and R. F. Baldwin, editors. Landscape-Scale Conservation Planning. Springer Netherlands, Netherlands.

Banks, J.E., Stark, J.D., Vargas, R.I., Ackleh, A.S. 2014. Deconstructing the surrogate species concept: a life history approach to the protection of ecosystem services. Ecological Applications. 24(4), pp. 770-778. 
Bliss-Ketchum, L. L., Littlejohn, R. J., Riehl, J., Hepner, M., Escobedo-Land, A. Urban Biodiversity Inventory Framework. Samara Group. 2017. Print.

Caro T. 2002. [Reply to Armstrong]. Conservation Biology 16: 286-287.

Caro, T. 2010. Conservation by Proxy Indicator, Umbrella, Keystone, Flagship, and other Surrogate Species. Island Press, 1718 Connecticut Avenue NW, Suite 300, Washington, DC 20009.

Cushman, Sam A. 2006. Effects of habitat loss and fragmentation on amphibians: a review and prospectus. Biological Conservation. Volume 128, Issue 2, March 2006, Pages 231-240.

Cushman, S.A., Landguth, E.L. 2012. Multi-taxa population connectivity in the Northern Rocky Mountains. Ecological Modelling 231 (2012) 101-112.

Csuti, B. O’Neil, T.A., Shaughnessy, M.M., Gaines, E.P., Hak, J.C. 2001. Atlas of Oregon Wildlife Distribution, Habitat, and Natural History second edition. Oregon State University Press. Corvallis.

Diniz, M.F., Machado, R.B., Bispo, A.A., Junior, P.M. Can we face different types of storms under the same umbrella? Efficiency and consistency of connectivity 
umbrellas across different patchy landscape patterns. Landscape Ecol (2018) $33: 1911-1923$

Fischer, J., Lindenmayer, D.B. 2007. Landscape modification and habitat fragmentation: a synthesis. Global Ecology and Biogeorgraphy. Vol 16. Pages 265-280.

Forman, R.T., D. Sperling, et al. 2003. Road Ecology: Science and Solutions. Island Press, Washington D.C..

Gutierrez-Arellano, C., Mulligan, M. 2018. A review of regulation ecosystem services and disservices from faunal populations and potential impacts of agriculturalisation on their provision, globally. Nature Conservation-Bulgaria. Issue 30, 1-39.

Hatfield, Jack H., Orme, C. David L., Tobias, Joseph A., Banks-leite, Cristina. 2018. Trait-based indicators of bird species sensitivity to habitat loss are effective within but not across data sets. Ecological Applications. 28(1), 2018. pp. 28-34.

Higgins, A, Serbesoff-King, K, King, M, O'Reilly-Doyle, K. 2007. The power of partnerships: Landscape scale conservation through public/private collaboration. NATURAL AREAS JOURNAL. Vol 27(3) Pages: 236-250 
The Intertwine Alliance. 2012. Regional Conservation Strategy for the Greater PortlandVancouver Region. A. Sihler, editor. The Intertwine Alliance, Portland, OR. www.theintertwine.org

The Intertwine Alliance. 2012. Biodiversity Guide for the greater Portland-Vancouver Region. A. Sihler, editor. The Intertwine Alliance, Portland, OR. www.theintertwine.org

Johnson, D.H., O’Neil, T.A. 2001. Wildlife-Habitat relationships in Oregon and Washington. Corvallis: Oregon State Univ. Press.

Jones, K.R., Plumptre, AJ., Watson, J.E.M., Possingham, H.A., Ayebarebe, S., Rwetsiba, A.., Wanyama, F., kujirakwinja, D., Klein, C.J. 2016. Testing the effectiveness of surrogate species for conservation planning in the Greater Virunga Landscape, Africa. Landscape and Urban Planning. Vol 145, Pages 1-11.

Keinath, Douglas A., Doak, Daniel F., Hodges, Karen E., Prugh, Laura R., Fagan, William, Sekercioglu, Cagan H., Buchart, Stuart H. M., Kauffman, Matthew. 2017. A global analysis of traits predicting species sensitivity to habitat fragmentation. Global Ecology and Biogeography, 26, 115-127. 
Lambeck, R.J. 1997. Focal Species: A Multi-Species Umbrella for Nature Conservation. Conservation Biology. Volume 11, No. 4. Pages 849-856

Lindenmayer, David B., Fischer, Joern. Habitat Fragmentation and Landscape Change: An Ecological and Conservation Synthesis. Washington D.C., Island Press. 2006.

Madliger, C.L., Franklin, C.E., Hultine, K.R., van Kleunen, M., Lennox, R.J., Love, O.P., Rummer, J.L., Cooke, S.J. 2017. Conservation physiology and the quest for a 'good' Anthropocene. Conservation Physiology. Vol 5. Article Number: cox003.

McRae, B. H., S. A. Hall, P. Beier, and D. M. Theobald. 2012. Where to Restore Ecological Connectivity? Detecting Barriers and Quantifying Restoration Benefits. PLOS ONE 7:e52604.

Meredith, H.M.R., St John, F.A.V., Collen, B., Black, S.A., Griffiths, R.A. 2018. Practitioner and scientist perceptions of successful amphibian conservation. Conservation Biology. Vol.32(2) Pages: 366-375.

Meurant, M., Gonzalez, A., Doxa, A., Albert, C. H. 2018. Selecting surrogate species for connectivity conservation. Biological Conservation. 227, pp.326 - 334. 
Norvell, R.E., Edwards Jr., T.C., Howe, F.P. 2014. Habitat Management for Surrogate Species has Mixed Effects on Non-Target Species in the Sagebrush Steppe. The Journal of Wildlife Management. 78(3):456-462.

Ozaki K., Isono M., Kawahara T., Iida S., Kudo T., Fukuyama K. 2006. A Mechanistic Approach to Evaluation of Umbrella Species as Conservation Surrogates. Conservation Biology. 20(5):1507-15

Pacific Northwest Coast Landscape Conservation Design (PNWCLCD). viewed December 2019. A blueprint for a climate resilient landscape in the Lower Columbia and outer coasts of Oregon and Washington. Internet at: http://columbiacoastblueprint.org/

Roberge, J., Angelstam, P. 2004. Usefulness of the Umbrella Species Concept as a Conservation Tool. Conservation Biology. Vol (18) No. 1. Pages 76-85

Seddon PJ, Leech T. 2008. Conservation shortcut, or long and winding road? A critique of umbrella species criteria. Oryx 42:240-245

Simberloff, D. 1998. Flagships, umbrellas, and keystones: is single-species management passé in the landscape era?'. Biological conservation, 83(3), pp.247-257. 
Spencer, W. D., P. Beier, K. Penrod, K. Winters, C. Paulman, H. Rustigian-Romsos, J. Strittholt, M. Parisi, and A. Pettler. 2010. California Essential Habitat Connectivity Project: A Strategy for Conserving a Connected California. Prepared for the California Department of Transportation, California Department of Fish and Game, and Federal Highways Administration.

Stoffyn-Egli, Patricia, and JH Martin Willison. Including wildlife habitat in the definition of riparian areas: The beaver (Castor canadensis) as an umbrella species for riparian obligate animals. Environmental Reviews 19: 479-494.

Turner, BL, Esler, KJ, Bridgewater, P, Tewksbury, J, Sitas, N, Abrahams, B, Chapin, FS, Chowdhury, RR, Christie, P, Diaz, S. 2016. Socio-Environmental Systems (SES) Research: what have we learned and how can we use this information in future research programs. Current Opinion in Environmental Sustainability. Vol 19. Pages: $160-168$

Theobald, David M., Miller, James R., Hobbs, N. Thompson. 1997. Estimating the cumulative effects of development on wildlife habitat. Landscape and Urban Planning 39 (1997) 25-36. 
U.S. Fish and Wildlife Service (USFWS). 2014.a. Surrogate Species. USFWS Science webpage. Internet at: http://www.fws.gov/mountainprairie/science/surrogate_species.cfm

U.S. Fish and Wildlife Service (USFWS). 2014.b. Strategic Conservation Management in Oregon's Willamette Valley: Surrogate Species Pilot 1.0. Review Copy. Region 1, Portland, Oregon. Internet at: https://www.fws.gov/oregonfwo/documents/SurrogateSpeciesPilot1.0.pdf

van der Ree, Rodney, Smith, Daniel J., Grilo, Clara. 2015. Handbook of Road Ecology. John Wiley \& Sons, Ltd. West Sussex.

Washington Wildlife Habitat Connectivity Working Group (WWHCWG). 2012. Washington Connected Landscapes Project: Statewide Analysis. Olympia, WA.

Wiens, John A., et al. Using surrogate species and groups for conservation planning and management. Bioscience 58.3 (2008): 241-252. 
Chapter 6 - Conclusion to the Dissertation

Each chapter presented in this dissertation was conducted in an effort to better describe and understand how wildlife interact with the built environment and how we can best plan for and mitigate negative impacts. These efforts encompass a range of geographic and temporal scales, either directly through monitoring and experimentation, or more abstractly through hypothesized responses and recommended process.

\section{The Influence of Traffic, Habitat Change, \& Time: Long Term Monitoring of a} Wildlife Crossing Structure: In Chapter 2 we identify that the results of this study reinforce earlier calls in the literature for more long-term monitoring efforts (Clevenger \& Waltho 2003, Gagnon 2011, Soanes et al. 2013) and the need to factor in population size. The barrier to widespread implementation of long term and population scale monitoring efforts is they are detailed and can be costly to implement, particularly when trying to describe community responses compared to a single species focus. The ongoing challenge is to determine how to conduct monitoring, and design studies, to best understand species use and presence at crossing structures with limited monitoring funds. Long term studies such as this one can help researchers and managers design monitoring programs to best account for variable responses over time by documenting changes in use and working to identify covariates and interactive effects that may be driving those changes. 
Additional work examining smaller passage structures (box culverts $2.75 \mathrm{~m} \times 1.2 \mathrm{~m}$ ) were conducted at the Boeckman Road Extension project and found that the presence of standing water will reduce use of crossing structures (Appendix A).

Project managers may decide to delay monitoring until vegetation communities and/or habituation responses have had time to stabilize after mitigation or construction activities, avoiding erroneous conclusions about structure use. Additional research on individual species responses to traffic volume will inform expectations of structure use and can guide mitigation efforts. We recognize these are complex and dynamic systems, and believe that we can best serve them by taking care in making broad conclusions from short term data sets. We hope that the relatively few long-term data sets available can help to characterize and inform our decision making and encourage other long-term data collection efforts.

Data collection will continue at the Boeckman Road wildlife crossing structure in order to maintain record of wildlife use over time. Through continued partnership with the city of Wilsonville we have also conducted pre-construction monitoring of wildlife activity and movement patterns at the Kinsman Road area, and are currently collected postconstruction data on wildlife movement in the three wildlife crossing structures that were included in construction. 


\section{A Behavior-Based Framework for Assessing Barrier Effects to Wildlife from \\ Vehicle Traffic Volume: Categories of response described in Chapter 3 provide}

important guidance for resource managers making decisions about how and where to attempt to mitigate road impacts to wildlife. Resource managers could fail to foresee an imminent threshold of population risk if risk response behavior is not used, or if the range of traffic volume investigated is too narrow, or traffic volume categories too broad to detect responses. This framework encompasses many species and highlights the important concepts that species do not respond to traffic volume linearly or along taxonomic lines. As in most ecological investigations, behavioral responses in the real world are complex and a framework that includes animal behavior, such as the one presented here, is therefore crucial to understanding the effects of highways on wildlife. Fortunately, effective mitigation measures such as wildlife crossing structures are becoming available to reduce barrier effects across highways (Gagnon et al. 2007). This proposed framework can advance the understanding of wildlife and road interactions. We encourage nuanced investigations that evaluate how traffic volume affects behavior and connectivity, and evaluate the effectiveness of management options given the combination of traffic volume and the response of local populations to traffic.

While we found strong support in the literature for the four proposed categories of response, additional testing of the behavioral response categories will further strengthen or provide nuance to the approach. Observational or, if possible, manipulative 
experiments explicitly designed to test the barrier impacts of roads and traffic would be most useful.

\section{The Effect of Artificial Light on Wildlife Use of a Passage Structure: Chapter 4} examined how artificial light impacts wildlife use of an undercrossing structure and determined that species, particularly those with nocturnal and crepuscular behavior, were most impacted. At the time of publication, this was the first research to experimentally test how a community of terrestrial vertebrates would change use of crossing structures in responds to artificial light. We indeed found community level responses to the addition of artificial light (Appendix B). As a group, nocturnal species had a significant response to even low levels of artificial light, and surprisingly that the crepuscular Columbia blacktailed deer avoided the entire area when light was present in adjacent sections. Even with the significant responses of nocturnal species, individuals responded with more or less apparent impact. Raccoon, an urban adapted species, showed no obvious response to the

presence of artificial light, while mink responded similarly to black-tailed deer, avoiding the entire area when light was present in adjacent sections. These responses and the significant community response, suggest that the presence of artificial light on the landscape is creating a filtering affect, preventing some species from utilizing movement pathways and habitats as they would otherwise. In urban and urbanizing areas, available habitat is a limited resource and is subject to many sources of disturbance. For land managers and others working to preserve urban wildlife habitat and connectivity, knowing that artificial light will impact species ability to move to and utilize habitat areas 
can promote better practices and inform policies designed to reduce the impact.

Ecological light pollution influences natural systems and contributes to the cumulative effects of urbanization on wildlife and ecosystems. With a greater understanding of the effect of artificial light we can make informed decisions about removing or reducing lighting and test additional methods to reduce the impacts of ecological light pollution in order to preserve habitat connectivity.

Future work to build on the results from Chapter 4 include exploration of artificial light impacts of a variety of light spectrums and brightness to determine thresholds of response for individual species and the wildlife community. The community showed very little difference in response between high ( $\sim 16$ foot-candles) and low treatment levels ( $\sim 5$ footcandles), suggesting that the threshold of response was already exceeded even at the low light level. This work was conducted using white halogen bulbs with a warm spectrum. It is increasingly common for LED bulbs, which tend to be cooler on the spectrum, to be used. Further work could also explore barrier effects of warm and cool spectrums.

\section{Goals-Based Species Selection Process for Connectivity Modeling and Planning}

Chapter 5 proposes the Goals-Based Species Selection approach, asking practitioners to address specific questions about what a given suite of species is intended to accomplish within a project. These project driven objectives are then used to refine the species list to the point where limited project resources can adequately be applied. Rather than stressing the importance of how species are categorized, the objective of this approach is to 
provide a replicable process where species can be objectively considered as representatives of specific conservation goals. In addition to the benefits of better tracking and justification for decision making in species selections this approach includes the ability to enhance engagement with the professional community and develop local buy-in for project objectives and goals (Higgins et al 2007, Turner et al 2016, Madliger et al 2017). Early engagement can promote agreement and common terminology, helping ensure that stakeholders have the same vision for project outcomes (Meredith et al. 2018). Through soliciting input and review of species selections and inviting other professionals and stakeholders to engage with the process there is an inherent increased awareness of project and the potential for greater utilization of products generated. Multispecies conservation efforts are inherently complex and challenging; however, we hope with a focus on process and engagement we can better work to address conservation goals with limited resources. This and other proposed approaches require additional applications and testing to explore limitations and ensure the application of these processes will meet project needs.

The Metro project, as described in the case study section of Chapter 5, is an ongoing effort that works toward an effective method of assessing habitat connectivity on the landscape at an actionable scale. We continue to refine descriptions and a scoring process for how our selected surrogate species respond to fragmented habitats. In addition, we are exploring novel approaches to adapt this work to be inclusive of community engagement and local ownership of connectivity zones. As a partner effort to developing better 
functioning models of connectivity for surrogate species associated with this project, we are utilizing telemetry methods to track surrogate species movements in urban and urbanizing habitats. Not only will this work inform the Metro Connectivity Toolkit effort, but we can also contribute to understanding of range sizes and dispersal patterns in these systems, which are likely to differ from those described in more contiguous habitats. More research is needed overall to help inform the patterns and process contributing to movements and habitat use of wildlife exposed to fragmentation effects but not yet extirpated.

The Oregon Connectivity Assessment and Mapping Project (OCAMP), the second case study described in Chapter 5 is also an ongoing project. The Coast Range is the first of eight major ecoregions in the state of Oregon that will also go through the Goals-Based Species Selection process to determine surrogate species. Connectivity of these species will then be modeled to ultimately develop a regional and statewide connectivity map. The resulting map can then be used to help focus resources and facilitate collaborative efforts across Oregon seeking to preserve and enhance connectivity for wildlife.

Curriculum development for the GK-12 Program: Support during my graduate program was provided in part by GK-12 program. During the course of the GK-12 program I worked with a teacher partner to develop curriculum engaging with 7th and 8th graders on various science topics and developing curriculum exploring water quality issues and connecting students to their local source of drinking water (Appendix C). 
Final conclusions: Through the work conducted herein we provide contributions to the understanding of how elements of the built environment impact wildlife communities ability to move across the landscape. Additionally, we provide new tools to support resource managers in barrier mitigation and connectivity planning. Habitat fragmentation effects are a complex set of issues that require resources and collaboration to reach meaningful solutions. The work presented here can also support decision making, communication, and collaborative efforts that will ultimately result in on-the-ground impacts to reduce fragmentation effects and mitigate existing barriers effectively to promote the long-term viability of wildlife and the systems they depend on. 
Chapter 6 - References

Clevenger, A.P., Waltho, N. 2003. Long-term, year-round monitoring of wildlife crossing structures and the importance of temporal and spatial variability in performance studies. ICOET 2003 Proceedings. Pages 293 - 302. https://escholarship.org/uc/item/3g69z4mn

Gagnon, J.W., Theimer, T.C., Dodd, N.L., Manzo, A.L., Schweinsburg, R.E. 2007. Effects of traffic on elk use of wildlife underpasses in Arizona. Journal of Wildlife Management. Vol 71. Issue 7. Pages 2324-2328.

Gagnon, J.W., Dodd, N.L., Ogren, K.S., Schweinsburg, R.E. 2011. Factors Associated with Use of Wildlife Underpasses and Importance of Long-Term Monitoring. The Journal of Wildlife Management, Vol. 75, No. 6. Pages 1477-1487.

Higgins, A, Serbesoff-King, K, King, M, O'Reilly-Doyle, K. 2007. The power of partnerships: Landscape scale conservation through public/private collaboration. Natural Areas Journal. Vol 27(3) Pages 236-250.

Madliger, C.L., Franklin, C.E., Hultine, K.R., van Kleunen, M., Lennox, R.J., Love, O.P., Rummer, J.L., Cooke, S.J. 2017. Conservation physiology and the quest for a 'good' Anthropocene. Conservation Physiology. Vol 5. Article Number: cox003. 
Meredith, H.M.R., St John, F.A.V., Collen, B., Black, S.A., Griffiths, R.A. 2018. Practitioner and scientist perceptions of successful amphibian conservation. Conservation Biology. Vol 32. Issue 2. Pages 366-375.

Soanes et al. 2013. Movement re-established but not restored: Inferring the effectiveness of road-crossing mitigation for a gliding mammal by monitoring use. Biological Conservation. Volume 159, Pages 434-441.

Turner, BL, Esler, KJ, Bridgewater, P, Tewksbury, J, Sitas, N, Abrahams, B, Chapin, FS, Chowdhury, RR, Christie, P, Diaz, S. 2016. Socio-Environmental Systems (SES) Research: what have we learned and how can we use this information in future research programs. Current Opinion in Environmental Sustainability. Vol 19. Pages 160-168. 
Appendix A - Species Use of A Passage Structure Before and After the Addition of a Dry Passage Option

Table A.1: Species use of a passage structure before and after the addition of a dry passage option. Total number of species detected passing through a 2.7 x $1.2 \mathrm{~m}$ open bottom concrete box culvert. Species detections were recorded thorugh motion detection camera (Reconyx RM45) monitoring conducted seasonally from June to November from 2009 to 2012.

\begin{tabular}{|c|c|c|}
\hline & $\begin{array}{l}\text { Pre Dry Passage Installation } \\
2009-2010\end{array}$ & $\begin{array}{l}\text { Post Dry Passage Installion } \\
2011-2012\end{array}$ \\
\hline \multirow{4}{*}{$\stackrel{n}{\frac{n}{0}}$} & Mallard Duck & - \\
\hline & Virginia Rail & Virginia Rail \\
\hline & Great Blue Heron & Great Blue Heron \\
\hline & -- & Snipe \\
\hline \multirow{9}{*}{ 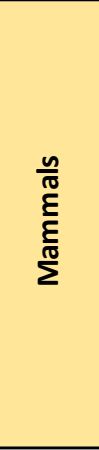 } & Mink & Mink \\
\hline & Raccoon & Raccoon \\
\hline & -- & Nutria \\
\hline & -- & Vole \\
\hline & -- & Deer Mouse \\
\hline & -- & Domestic Cat \\
\hline & -- & Muskrat \\
\hline & -- & Opossum \\
\hline & -- & Skunk \\
\hline 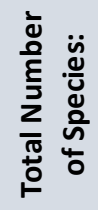 & $\begin{array}{c}5 \\
\text { (3 birds, } 2 \text { mammals) }\end{array}$ & $\begin{array}{c}11 \\
\text { (3 birds, } 9 \text { mammals) }\end{array}$ \\
\hline
\end{tabular}


Appendix B - Community Response to Artificial Light

\section{Effect of light treatment on the terrestrial vertebrate community}

Data were analyzed using Nonmetric Multidimensional Scaling (NMDS) ordination plots and Analysis of Similarity (ANOSIM) to determine if there was a significant relationship between the frequency of species detections and light level treatment (High, Low and Zero). Stress was calculated and testing proceeded if values were $<0.2$. ANOSIM tests were run using 999 permutations. If a significant difference was found amongst the groupings then pair-wise ANOSIM tests using a Bonferroni-corrected $\alpha(0.008)$ were conducted to determine which treatments were significantly different from one another. The frequency of wildlife crossings differed among light treatments $(p=0.002)$. ANOSIM pairwise comparison showed that wildlife crossing frequency was significantly different for all treatment combinations except between High and Low treatments $(p=0.99)$ (Table A1, Figure A1).

\begin{tabular}{|c|c|c|c|}
\hline \multicolumn{4}{|l|}{$\begin{array}{l}\text { Table B.1: ANOSIM Results from pairwise comparison of differences in the wildlife } \\
\text { community detected using the passage structure during light treatment }\end{array}$} \\
\hline Treatments Compared & ANOSIM R & $\boldsymbol{\alpha}$ & P \\
\hline All & 0.18 & 0.05 & $0.001^{*}$ \\
\hline Break, Low & 0.28 & 0.008 & $0.001^{*}$ \\
\hline Break, High & 0.35 & 0.008 & $0.001^{*}$ \\
\hline Zero, Low & 0.18 & 0.008 & $0.006^{*}$ \\
\hline Zero, High & 0.24 & 0.008 & $0.001^{*}$ \\
\hline Break, Zero & 0.1 & 0.008 & 0.037 \\
\hline Low, High & -0.08 & 0.008 & 0.99 \\
\hline
\end{tabular}




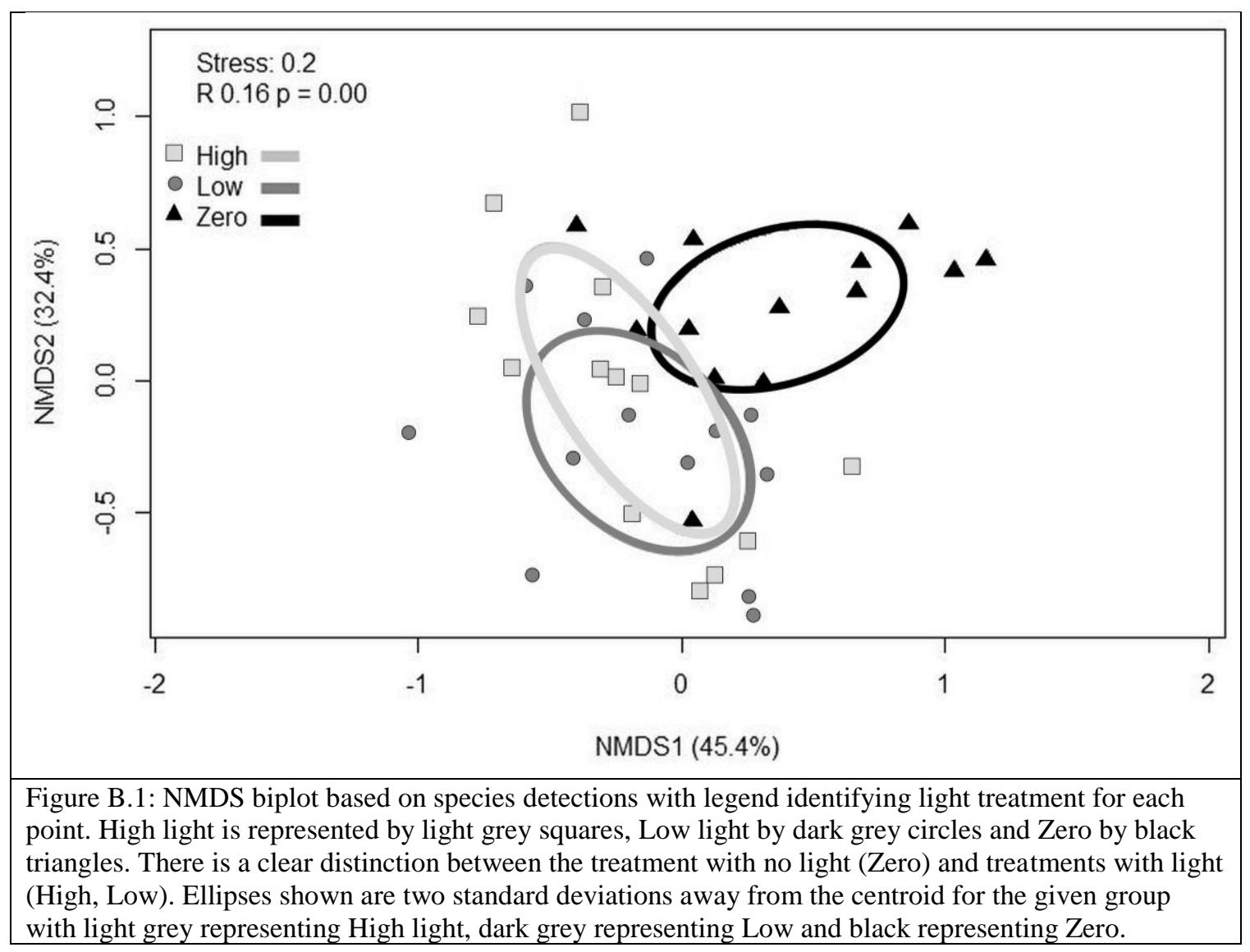




\title{
Appendix C - Drinking Water Inquiry Curriculum
}

\section{CKI2FELLOWSHIP

\author{
Drinking Water Inquiry \\ Cascades to Coast GK-12 Curriculum \\ Fellow: Leslie Bliss-Ketchum (PSU Environmental Science) \\ Teacher: Lia Cunningham (Evergreen Middle School) \\ Advisor: Catherine de Rivera (PSU Environmental Science)
}

Learning goal:

Students will analyze the connections between drinking water, natural surface water and the water cycle and will design an investigation into a regional water quality issue.

Students learning objectives:

- Explain the process of the water cycle and how this cycle relates to landform and weather.

- Identify the local source of drinking water

- Analyze the chemical composition of the local drinking water.

- Evaluate the importance of ecosystem services related to drinking water.

- Interpret, and distill articles about local drinking water.

- Develop a research question and accompanying hypothesis, and design and conduct an experiment with controls related to local drinking water.

- Organize, display, and analyze the data from their water quality experiments, then construct an evidence-based explanation of the results.

- Critique their experimental design, discuss how identified errors could have affected their results, and propose solutions to those errors

- Create experimental hypotheses and designs that build upon the student's findings.

Target Grade: $8^{\text {th }}$

Oregon State Standards:

6.2E. 1 - Explain the water cycle and the relationship to landforms and weather.

8.3S.1 - Based on observations and science principles propose questions or hypotheses that can be examined through scientific investigation. Design and conduct a scientific investigation that uses appropriate tools, techniques, independent and dependent variables, and controls to collect relevant data.

8.3S.2- Organize, display, and analyze relevant data, construct an evidence-based explanation of the results of a scientific investigation, and communicate the conclusions including possible sources of error. Suggest new investigations based on analysis of results. 


\section{Curriculum Summary:}

Students will learn about and compare the composition of drinking water to surface water in their watershed. Findings from this unit will be used to design, conduct and present research on a regional water quality issue. Before the inquiry activity, students are familiarized with their local drinking water system, including sources of surface and ground water, as well as the treatment processing procedures. Students are also trained on how to use Vernier equipment to measure turbidity, $\mathrm{pH}$ and nitrates. The key activity in this curriculum is a guided inquiry in which students investigate water chemistry for multiple water sources, including natural sources that form the drinking water system of the school as well as tap and bottled water. The students combine their data with class data and discuss results. Results vary within natural water sources depending on land use and geology; however, tap and bottled water consistently give zero, neutral (when measuring $\mathrm{pH}$ ) and minimal values. Conclusions will reflect the variability of natural water sources, even those clearly connected within the watershed (such as hydrologically connected lake, stream and river systems), as compared to the same water after treatment at municipal sources. Emphasis will also be placed on the fact that even if the hypothesis is not correct, the student has accomplished their goal by following the scientific process. Final steps include discussion of additional research questions and presenting both accurate and visually appealing summaries of the project in poster form.

Major curricular objectives:

1) To form the framework for their inquiry, students will gain background information through two sources. First, they will use the drinking water quality report that is published annually by the local water supplier (Hillsboro water at www.hillsborowater.org) to provide background information on nonvisible parameters of water. Second, students will also take notes during a class lecture that illustrates land use types, history and water source connections within the watershed.

2) Using Vernier probes, students will measure turbidity, $\mathrm{pH}$, and nitrates from multiple sources of water that supply drinking water system for the school and surrounding community including tap water and commercially available bottled water.

Three types of probes are used with the Vernier LabQuest:

a) Turbidity Sensor: http://www.vernier.com/products/sensors/trb-bta/

b) $\mathrm{pH}$ Sensor: http://www.vernier.com/products/sensors/ph-sensors/ph-btal

c) Nitrate Ion-Selective Electrode: $\underline{\text { http://www.vernier.com/products/sensors/ion-selective- }}$ electrodes/no3-btal

3) Students will use the information provided on the general land use surrounding the natural water sources, tap water purification process and the bottled water source to develop a research question, hypothesis, and procedure for a water-quality inquiry investigation. The experimental design must include three water sources and a minimum of one water quality parameter

4) Using average values from the class data collected in step 2 students will organize, display, and analyze the data relevant to their inquiry project using graph paper, or Excel if computers are available.

5) Students will write a conclusion to their inquiry project that a) addresses their research question, b) evaluates possible errors in their experimental design, and c) suggests possible future investigations.

6) Students will put together poster presentations of their inquiry project including:

a) Informative and creative title

b) Introduction section:

sets up rational and relevance for inquiry of water quality parameters. Section concludes with statement of hypothesis

c) Methods \& Materials section:

details procedure for conducting experiment and collecting data

d) Results \& Graphs: 
may include summary data, must include clearly labeled graph with verbal explanation of results shown

e) Discussion/Conclusion paragraph:

Addresses the hypothesis, includes discussion of sources of error, and suggests potential future projects based on results.

\section{Activity Plan:}

Data Collection \& Water Quality Analysis

- Depending on logistics, one or more samples may be collected either by students in association with a field trip or some or all of the samples may be previously collected and setup in the classroom.

- In the field or classroom stations were established for measuring each water quality parameter in distinct locations. Each station should include a Vernier probe, data sheet, and clearly labeled water samples.

- As a class students are given an explanation and demonstration of how to use the equipment appropriately.

- Students are divided into groups (size depends on class size and equipment availability; 2-3 students if possible per group). Groups are then rotated through the water quality parameter stations, recording values for each sample on their data sheets.

- After all stations have been tested by each group, the data are added to a class data sheet on an overhead or board and displayed to the class.

- Students are able to discuss class results including topics of accuracy, sources of error and natural variability.

- The average values from class data are then used in subsequent lessons to generate graphs illustrating the individual student research questions Depending on student experimental design, results may lead to discussion of, for example, why turbidity values vary in stream, lake and tap water. Are the values "normal" for the local water sources and what land use activities, treatment choices or weather/seasonal changes might alter these values? Do the values pose any risks to human health? Do the values pose any risk to ecosystem health?

\section{Related Concepts:}

- Geology - watershed boundaries, weathering and erosion process resulting from the water cycle, natural water quality parameter inputs resulting from these processes'

- Weather - water cycle, precipitation patterns

Materials: Vernier probes ( $\mathrm{pH}$, Nitrate, Turbidity), water samples (individual beakers, labeled), student data collection sheet, class data collection sheet

Handouts and worksheets:

Attached (see below)

Pre/Post Assessment, Experimental Design Framework, Data Collection sheet, Data Analysis sheet

Extensions:

Testing of additional water samples, such as streams/water bodies near the student's home or near the school Multiple samples from a single water source

Sampling similar water bodies from across watersheds 


\section{Assessment Questions:}

Name:

Period:

1. Is water $100 \%$ pure - meaning only containing $\mathrm{H}_{2} \mathrm{O}$ molecules?

a. If no what else might you find in water?

2. Where does your drinking water come from?

3. How does water quality affect human health? 
Water Sources \& Water Quality Parameters - Background Information

Define and take notes on the following information as you listen to the presentation

$\underline{\text { Water Sources }}$

\begin{tabular}{|l|}
\hline DI: \\
\hline Bottled: \\
\hline Tap: \\
\hline McKay Creek Tributary: \\
\hline Tualatin River: \\
\hline Haag Lake: \\
\hline
\end{tabular}

Water Quality Parameters

\begin{tabular}{|l|}
\hline Nitrates: \\
\hline Turbidity: \\
\hline $\mathrm{pH}:$ \\
\end{tabular}




\section{Name: \\ Experimental Design \\ Period:}

Water Quality Experiment:

1. Choose at least $\mathbf{3}$ sources of water and $\mathbf{1}$ water quality parameter to analyze for your research question

2. You cannot have the same research question or experiment as anyone else at your table

3. This is an individual assignment - no groups

\section{Research Question:}

How does , affect

Hypothesis (if/then statement - your prediction):

If , then , because

\section{Variables:}

Independent Variable (manipulated variable, what are you changing? x):

Dependent variable (observed variable y): 
Name:

Original Prediction:

If

\section{Data aratsis ${ }^{\text {Period }}$}

Then

Because

\begin{tabular}{|c|c|c|c|c|c|c|}
\hline \multirow{5}{*}{$\begin{array}{c}\text { (Data table } \\
\text { displays } \\
\text { average values } \\
\text { of class data) }\end{array}$} & \multirow{2}{*}{$\begin{array}{l}\text { y: } \\
\text { Parameters }\end{array}$} & \multicolumn{5}{|c|}{$\mathrm{x}$ : Water Sources } \\
\hline & & Bottled & Tap & Creek & Tualatin & Hagg \\
\hline & Nitrate & & & & & \\
\hline & Turbidity & & & & & \\
\hline & pH & & & & & \\
\hline
\end{tabular}

Was your hypothesis/prediction correct?

Why or why not?

Graph the Results of the Parameter You Chose in Your Prediction:

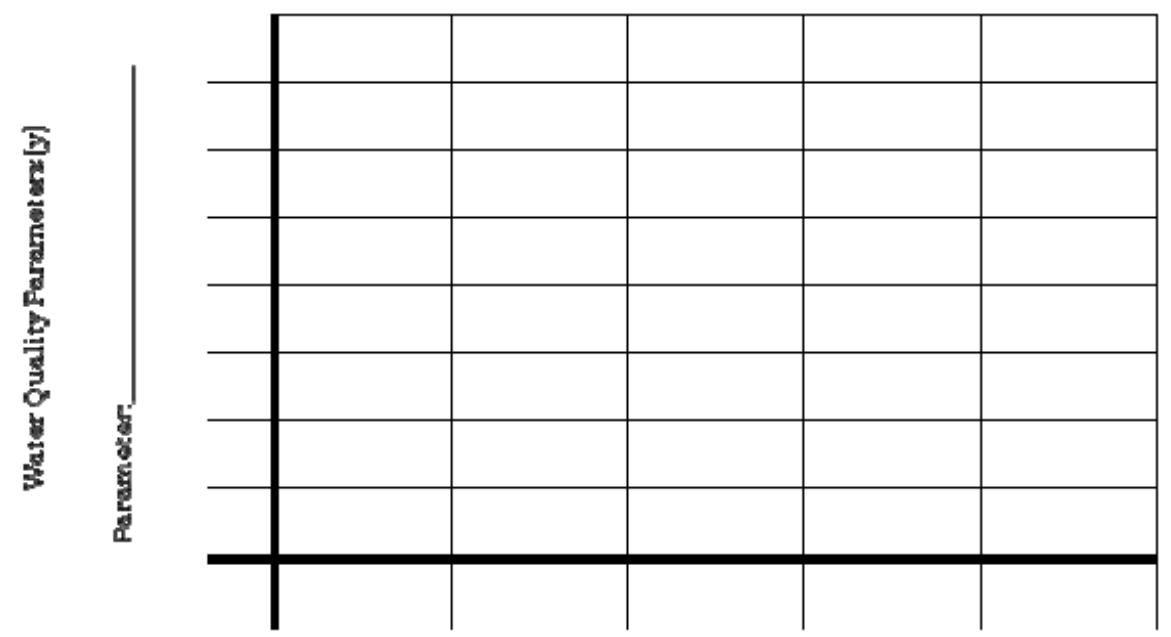

Water Sources (x) 


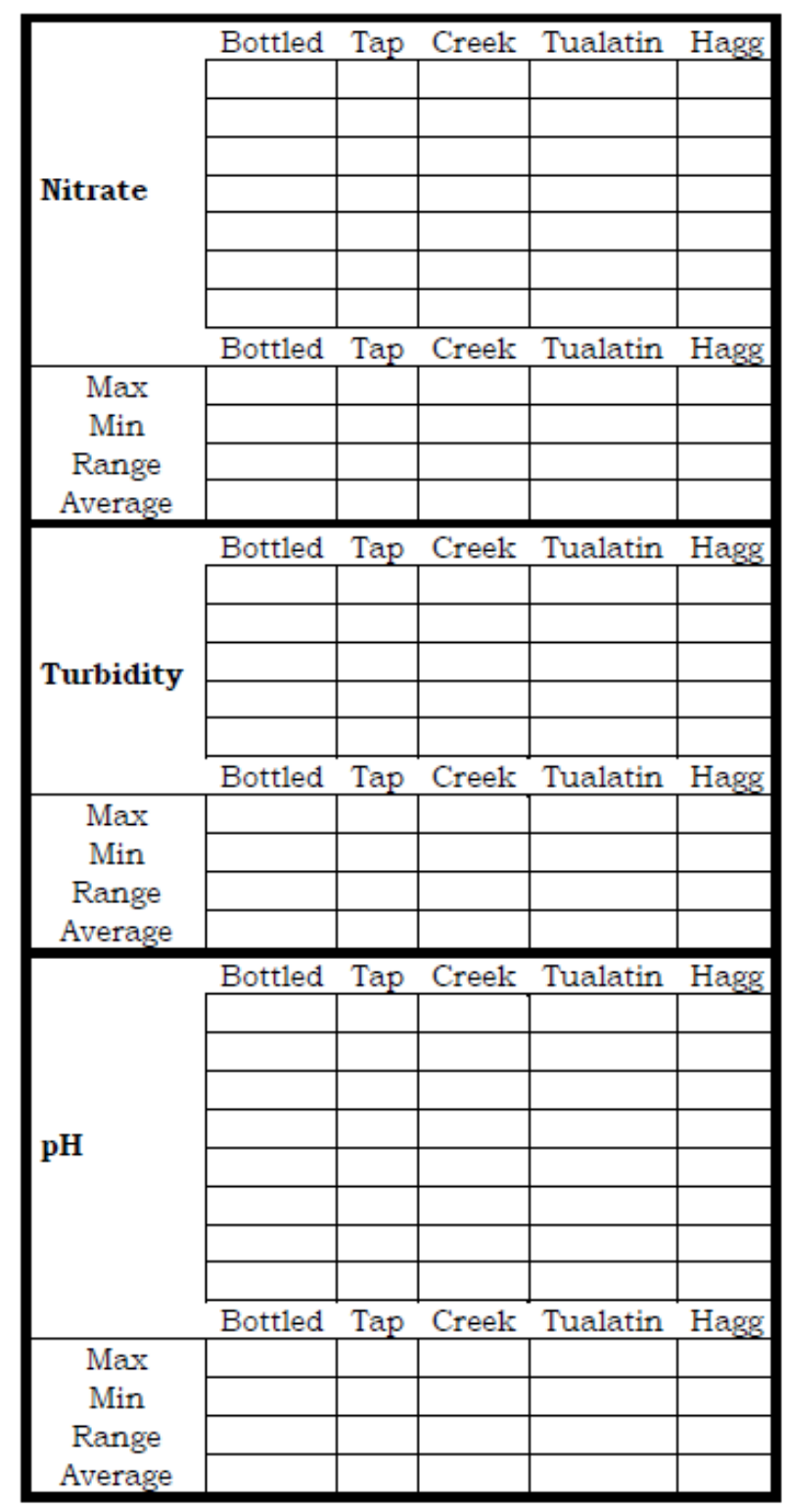

